\title{
ACUTE HYPERCARBIA IN CHRONIC OBSTRUCTIVE PULMONARY DISEASE (COPD): \\ PRESENTATIONS TO A NEW ZEALAND EMERGENCY DEPARTMENT
}

\author{
by
}

Anton Brett Turnwald

A thesis submitted to the Victoria University of Wellington in partial fulfilment of the requirements for the degree of Master of Arts (Applied) in Nursing

Victoria University of Wellington 


\begin{abstract}
Chronic Obstructive Pulmonary Disease (COPD) is the presence of chronic bronchitis or emphysema, which causes a progressive airway obstruction, characterised by airway hyperactivity (Palm \& Decker 2003). In New Zealand there are increasing numbers of people presenting to the Emergency Department (ED) with COPD. COPD exacerbation results in hypoxia and respiratory failure that can be debilitating to the patient because the normal coping mechanisms fail and the patient can end up in a spiralling illness that has a high mortality rate if left un-treated. Hypercarbia is a direct result of hypoventilation either from failed coping mechanisms or respiratory failure from exhaustion. The question lies with, which patients have this hypercarbia during an exacerbation? Treatment patterns within the ED depend largely on the diagnosis of hypercarbia on presentation with an exacerbation of COPD.
\end{abstract}

A retrospective descriptive design was used to examine the records of all presentations to ED of patients with COPD over a 3-month period to determine whether there is a subset group of people who present with hypercarbia. Data from records were extracted using a specially devised data extraction tool. Of the findings there were 114 presentations, amongst those 114 presentations there were 71 individuals, a number of them presenting more than once within the three months. $80 \%$ of the 71 individuals have had a smoking history of which 53\% were female. Of the 114 presentations, 76 had arterial blood gases taken during their ED presentation. Of these 76 presentations 30 had hypercarbia and 46 were non-hypercarbia. These 76 presentations involved 58 individuals, with some individuals presenting five times over the three-month period. Three groups emerged, some who were only hypercarbia $(n=18)$, some in the non-hypercarbia group $(n=35)$ and 5 individuals who had presentations in both the hypercarbia and non-hypercarbia groups.

Data showed that there was no definable subset group of hypercarbia patients within acute exacerbations of COPD presenting to the ED according to the variables. However the sample of presentations (with a blood gas) found within the study suffering hypercarbia was much higher (31.1\%) than anticipated. Further analysis showed that the hypercarbia group had a significant lower forced expiratory volume in one second (FEV1) and a combination diagnosis of emphysema or asthma and congestive heart failure. 
An implication to the clinician is that identification of hypercarbia within COPD exacerbation is problematically difficult until the late signs are shown with the individual. By that time effective treatment patterns may have changed from the initial presenting problem. Future areas of research within this field needs to lie within the community, when are these people starting the exacerbation and what leads them to progression presentation to the emergency department? Also we need to know whether these people are chronic sufferers of hypercarbia or presenting after a period of days exacerbation within their own home? 
Table 1. Key words used in this research

\begin{tabular}{|l|l|}
\hline COPD, COAD & $\begin{array}{l}\text { Group of respiratory diseases characterised by airflow } \\
\text { limitation and therefore gas exchange imperfection. }\end{array}$ \\
\hline Hypercarbia & $\begin{array}{l}\text { Abnormal elevated carbon dioxide levels within the } \\
\text { blood. }\end{array}$ \\
\hline Normocapnic & Normal carbon dioxide levels \\
\hline Respiratory Acidosis & $\begin{array}{l}\text { This high level of carbon dioxide causes a shift in the } \\
\text { blood Ph, causing an acidosis from excess hydrogen ions }\end{array}$ \\
\hline Oxygenation & $\begin{array}{l}\text { Levels of oxygen within the blood adequate for tissue } \\
\text { and organ demands. }\end{array}$ \\
\hline Hyperoxia & $\begin{array}{l}\text { Over delivered supplemental oxygen, greater than bodily } \\
\text { demands }\end{array}$ \\
\hline HRF & $\begin{array}{l}\text { Hypercarbia respiratory failure, related to minute volume } \\
\text { reduction and gas exchange inequities }\end{array}$ \\
\hline NIV & $\begin{array}{l}\text { Non-invasive ventilation provided by a mask to provide } \\
\text { positive pressures at the mouth, so helping the fatigued } \\
\text { patient with gas exchange. }\end{array}$ \\
\hline Intubation & $\begin{array}{l}\text { End result in patient fatigue with COPD, a tube (Endo- } \\
\text { tracheal intubation) placed into the trachea for } \\
\text { ventilation from a ventilator. }\end{array}$ \\
\hline
\end{tabular}




\section{Acknowledgments}

To my wife and family who have supported me emotionally and financially through the whole aspect of my thesis without complaint, and with many encouragements, to my tutor Dr Kathy Nelson for the weekly guidance and thesis supervision, in which she has much expertise in doing so and finally to my clinical work colleagues who have been hugely encouraging towards completion of this thesis, as I find the work environment conducive towards writing and thinking, every one of you have had a hand in getting this done with me. Finally to my editor Inge Jensen, completion and hand-in would have never happened. Thanks goes to Sharp-Tudhope who put forward a grant within the hospital to enable me to complete this research by covering many of the expenses associated with the enormity of a project like this. May I always be indebted to these people who have helped me, in this, my thesis journey. 


\section{Table of Contents}

$\begin{array}{lr}\text { Abstract } & \text { ii. } \\ \text { Key words } & \text { iv. } \\ \text { Acknowledgments } & \text { v. } \\ \text { Table of Contents } & \text { vi. } \\ \text { List of Figures } & \text { viii. } \\ \text { List of Tables } & \text { ix. } \\ \text { Abbreviations List } & \text { x. }\end{array}$

Chapter 1. Introduction 1.

Background 1.

NZ Ministry of Health Census Statistics 2.

Research Question 6.

Chapter 2. Physiology 8.

Normal Lung Functions 8.

Disease Progression 9.

Blood pH Buffering 12.

Normal Lung Function Testing 15.

Chapter 3. Literature 18.

Pivotal articles- Oxygen Administration 19.

Non-Invasive Ventilation 25.

Treatment Guidelines for COPD 27.

Hypoxia versus Hypercarbia 29.

Determination of Disease 30.

Chapter 4. Methodology 32.

Different Methodology 32.

Population 34.

Tool for Data Extraction 35.

Variables 37.

Data Extraction 40.

Analysis 40.

Ethical Consideration 41. 
Chapter 5. Findings

43.

Identifying all Presentations 43.

Sample Population 44.

Clinical Features of all Presentations 48.

Hypercarbia Sub-Group Analysis 55.

Chapter 6. Discussion 61.

The Sample 61.

Individuals 62.

Diagnosis 65.

Supplemental Oxygen 67.

Baseline Observations 68.

Blood Gas Sampling 69.

Pulmonary Function Testing 72.

NIV 73.

Length of Stay 73.

Chapter 7. Conclusion 75.

Sub-Group of Hypercarbia 75.

Exacerbations of COPD 76.

Chapter 8. Appendix

Discharges from Public hospitals 01-02 78.

Nursing Council Code of Conduct 79.

Regional Ethics Committee Approval 80.

Patient Details Consent Form 81.

Cultural Safety Policy-Tauranga 82.

Cultural Consent 85.

Data Extraction Tool 86.

Worldwide Smoking Prevalence 87.

Chapter 9. Reference List 88. 


\section{List of Figures}

Figure 1. Clubbing of the finger 11.

Figure 2. Normal arterial blood gas 14.

Figure 3. Histogram of presentation hour 44.

Figure 4. Histogram of age 45.

Figure 5. Histogram of smoking exposure 47.

Figure 6. Histogram of respiration 49.

Figure 7. Histogram of heart rate 50.

Figure 8. Histogram of SaO2 50.

Figure 9. Histograms of initial ABG 51.

Figure 10. Histograms of secondary ABG 52.

Figure 11. Histogram of lung ratios 53.

Figure 12. Histogram of length of stay 54. 


\section{List of Tables}

Table 1. Key words $\quad$ iv.

Table 2. West's normal values 16.

Table 3. Repeat presentations 44.

Table 4. Demographics of research 45.

Table 5. Individuals smoking and industrial exposure by gender 46.

Table 6. Smoking exposure 46.

$\begin{array}{ll}\text { Table 7. Previous diagnosis analysis } & 47 .\end{array}$

Table 8. Analysis of diagnosis one against two 48.

Table 9. Baseline observations 49.

Table 10. Primary ABG 51.

Table 11. Secondary ABG 52.

Table 12. Pulmonary lung function testing 53.

Table 13. Repeat presentations to the ED 55.

Table 14. Presentations with both hypercarbia and non-hypercarbia 56.

Table 15. Demographics of sub-groups 57.

Table 16. Statistics for sub-groups 58.

Table 17. Sub-group analysis in previous diagnosis one and two 59.

Table 18. Sub-group analysis in lung function testing 59. 


\section{List of Abbreviations}

ABG Arterial blood gas

$\mathbf{C O}_{2} \quad$ Carbon dioxide

$\mathrm{O}_{2} \quad$ Oxygen

COPD Chronic Obstructive Pulmonary Disease

COAD Chronic Obstructive Airways Disease

CPAP Continuous Positive Airway Pressure

DHB District Health Board

ED Emergency Department

GP General Practitioner

Exac Exacerbation

PEPF Peak Expiratory Peak Flow

FEV1 Volume of air expelled from a position of maximum inhalation in one second

FVC Forced Vital Capacity from maximum inhalation to maximum exhalation

V/Q Pulmonary ventilation versus perfusion studies

GCS Glasgow Coma Score - scale of alertness including eye opening, vocalising and movement

MOH Ministry of Health New Zealand

NIV Non invasive ventilation (positive pressure)

$\mathbf{P a C O}_{2} \quad$ Partial arterial pressure of carbon dioxide dissolved in plasma

$\mathbf{P a O}_{2} \quad$ Partial arterial pressure of oxygen dissolved in plasma

pH Power of Hydrogen, measure of acidity or alkalinity of a solution (1-14)

$\mathrm{SpO}_{2} \quad$ Peripheral percentage saturation of haemoglobin by oxygen

$\mathrm{SaO}_{2} \quad$ Arterial percentage saturation of haemoglobin by oxygen

NZ New Zealand

UK United Kingdom

US United States of America 


\section{Chapter 1 - Introduction}

The thesis reports on an investigative study that examined a sample of presentations to the Tauranga Emergency Department (ED) by people with an exacerbation of Chronic Obstructive Pulmonary Disease (COPD). COPD encompasses a group of respiratory diseases that limit the lung function by reducing a person's ability to remove gases of respiration from the lungs because of over inflation, airway constriction and medium airway non-compliance. Exacerbation of COPD is rising steadily in the population and data indicates there is a subsequent increase in admission rates at Tauranga Hospital. Tauranga ED is a medium sized department in a tertiary hospital servicing the Bay of Plenty district from Waihi Beach to the East Cape and inland to Kawerau. According to the 2001 Census, Tauranga district is the seventh biggest urban area in New Zealand (NZ), and the second fastest growing local authority with a rapidly advancing city based around a large working port and harbour and sea frontage. As a Clinical Nurse Coordinator I am required to do shifts on the floor, which is beneficial to any nurse expert. With my past nursing expertise being in trauma intensive care (London), respiratory medicine has an obvious alignment and has contributed to my clinical interest in this subject. In this work I observed the frequency of presentations of the COPD patient, especially over the winter months. I noted that some were acutely unwell on arrival and others did not appear to respond well to oxygen therapy. This led me to wonder why it was that oxygen therapy a standard component of most regimes for treating an exacerbation of COPD did not always work.

This first chapter introduces NZ and global statistics on COPD, with definitions within COPD and the prediction of the potential dominance in the health systems. The importance of this background position is to outline the significance of the problem of COPD and the magnitude nationally and internationally.

\section{Background}

The global prevalence of COPD is expected to increase over the next two decades as a result of people living longer and the exposure to cigarettes and environmental pollutants (Palm \& Decker, 2003). If NZ follows the trends in the United States of America (US) and United Kingdom (UK) then this problem will not diminish and we will see an increase in the frequency of presentations within emergency departments in the near future. New Zealand figures show that in 1996 COPD was the third biggest killer, after 
ischaemic heart disease and cerebral vascular accidents. The COPD mortality rate for 1996 was around 30,000 per annum (Ministry of Health, 2003 (a). The reality is that COPD is the second biggest burden of disease in the population within New Zealand (The Thoracic Society of Australia and New Zealand \& the Australian Lung Foundation, 2002). The Ministry of Health (MOH) website states that in 2003 (a) the prevalence of COPD in NZ for adults over the age of 45 years was $13.4 \%$. The split by gender is $12.1 \%$ in males and $15.3 \%$ in females. A main factor contributing to the COPD is a history of smoking. Chapter 3 will present the linkage between smoking and developing COPD. The MOH further states that the rate of smoking in the population with Maori ethnicity is nearly one in every two people (44\%), compared to European/other smoking rate of $21 \%$ and Pacific Island rate of $26.9 \%$. This high rate presents an increased risk to the welfare and health of the Maori and Pacific Island communities.

Author and nurse researcher Booker (2004) has widely researched and published about COPD within the United Kingdom (UK). She considers that COPD accounts for 30,000 deaths in the UK every year; $5.9 \%$ of all male deaths and $4.3 \%$ of female deaths. Of the 900,000 people diagnosed with COPD, 44\% are under the age of retirement (Britton, 2003). Of these younger COPD patients, $24 \%$ report that they are unable to work and a further $9 \%$ state they have a limited ability to work.

Booker (2004) advises that reversibility testing is an accurate way of differentiating between COPD and asthma. The reversibility is achieved by using inhaled bronchialdilators and re-testing the volumes in the lung function tests.

The Thoracic Society of Australia and New Zealand and the Australian Lung Foundation (2002) worked together to write a COPD handbook for use by health professionals. They state in the introduction that COPD often goes undiagnosed because of other diseases attributed to the aging process. A consequence of this is that many people who have a mild form of COPD, together with a smoking history are not often diagnosed with this problem until they have an exacerbation. Exacerbations of COPD will be at an increasing cost to the health system as the population ages, and the numbers of exacerbations increase. Accurate diagnosis leads to adequate treatment and management.

Cydulka, Rowe, Clark, Emerman and Camargo (2003) published a cohort study within 15 American states and three Canadian states that investigated the ED management of acute exacerbations of COPD. They documented that COPD affects 10\% of older adults 
including $15-35 \%$ of older smokers. The prevalence is expected to increase in the next decade due to the prevalence of smoking and other pollutants. Similar results from the UK as mentioned in the previous paragraph by Booker (2004).

Exacerbation of COPD is defined by Cydulka et al. (2003) as increasing shortness of breath, worsening cough or change in sputum production. A COPD exacerbation can be partially reversed with the aid of inhaled bronchial dilators used at home. However, over time progressive destruction occurs within the alveoli, resulting in a loss of elasticity and permanent enlargement of air spaces distal to the bronchioles. The permanent enlargement of these air spaces in COPD leads to the inability of a person to do one of two things. Firstly people can not properly ventilate as the alveoli that are responsible for gaseous exchange of oxygen and carbon dioxide do not function properly, and secondly, the reduction of the diameter in the medium airway structures from inflammation and mucous production results in people having a lengthened time for inspiration and expiration beyond normal limits.

A common scenario that results in a presentation to the Tauranga ED is initially a person that has an exacerbation at home which they try to manage. If unsuccessful in bringing the exacerbation under control they call the ambulance service for assistance. Ambulance officers then transport the person to hospital, and usually give them high flow oxygen en-route. By the time the person gets to hospital the clinical situation and presentation may have improved, stabilised or deteriorated. Deterioration can occur because hypercarbia and respiratory acidosis has set in. This worsening situation doesn't happen for every COPD patient but predominately for the person who has failed his or her normal compensating mechanisms. Over oxygenation for the person with hypercarbia can lead to a clinically unsafe situation for both the ambulance staff and emergency physicians when the patient arrives at ED.

As Chapter 3 will show there is a growing body of literature on COPD related to hypercarbia. Some of this work is presently informed by animal studies. For example Idris, Wenzel, Becker, Banner and Orban (1995) carried out a controlled study on swine to show that there is an equal probability of death from hypoxia as that of hypercarbia. Evidence from such studies creates a quandary for the ambulance officers and emergency staff related to whether to administer high flow oxygen and treat the hypoxia or give low flow oxygen and preserve the hypoxic drive that is being maintained by the patient, thus limiting the potentially drastic effects of hypercarbia? Uncontrolled oxygen 
administration during transit or within the confines of the Emergency Department can lead to a worsening clinical picture for the patients as normal coping mechanisms fail. Ventilation and the spiralling respiratory depression and worsening hypercarbia now start to encroach on mentation ${ }^{1}$ and alertness of the patient. Not only is hypercarbia problematic for the medical and nursing staff within ED but also can be detrimental to the patient.

The importance of this research is that the COPD population is not only living longer but these people, in the largest population growth in the western world within the last 100 years, are now approaching retirement. This is also a generation who where not fully informed about the dangers of smoking. During the Second World War, army training in New Zealand was mandatory for men over the age of 18. My father who is now nearing retirement was one of those who, as a young man having left the constraints of boarding school, was encouraged to smoke during army training and, he like many men and women started smoking for various reasons including an environment where 'everyone was doing it'. It was culturally, socially and financially easy and normal to smoke. Also the knowledge and availability of safety data for many pollutants in the workplace at the time, was minimal. The normal decline of lung function due to age, is coupled with the damage from years of smoking and abuse from environmental exposure to harmful pollutants gives rise to the COPD generation that are at the mercy of seasonal and situational triggers. Given this scenario, the people presenting with an exacerbation of COPD is becoming commonplace within every Emergency Department in NZ.

Definitive diagnosis of adult asthma and COPD is as acutely problematic as an accurate diagnosis in preschool children when trying to differentiate between bronchiolitis and asthma. The only effective means is by pulmonary lung function testing with reversibility testing with an inhaled bronchodilator. The usual treatment patterns of COPD and the normal function of the lungs and supporting structures around respiration will be examined in Chapter 2, Physiology. As the treatment patterns vary with diagnosis or dual diagnoses the medical providers and hospitals will be challenged to manage the treatment of this increasing population appropriately while still avoiding causing gratuitous harm.

\footnotetext{
${ }^{1}$ Mentation: an altered level of consciousness
} 
The MOH (2003 a) in New Zealand reported a research study of a sampled population including face-to-face interviews with 14,005 people. The research aimed at learning about their health styles and chronic diseases, and their use of health services and their vital bodily statistics over the 2002-2003 period. The findings, which make interesting reading, were reported in a descriptive format and provide important information for the "implementation, evaluation and further evolution of the New Zealand Health Strategy" (Ministry of Health 2003 a, p. iii). The report highlights the extent of the problem needing to be addressed:

One in five adults aged 15-44 had been diagnosed with asthma, that the prevalence of asthma was four times higher in the European / Other and Maori ethnic groups than the Pacific and Asian groups and that one in 18 adults over the age of 45 years had been diagnosed with COPD.

(Ministry of Health 2003 a, p. 37)

These one in 18 adults in the population of New Zealand means approximately 209,000 people have the diagnosis of COPD and / or suffer with the effects of COPD. Tauranga Hospital in the Bay of Plenty serves a population of 112,746, and assuming that the $\mathrm{MOH}$ 1996 census figures are applicable to the Tauranga district, the estimated population with COPD of around 6263 people could increase to 7640 by the year 2006, an increase of $22 \%$. This is potentially a significant problem, particularly if environmental factors like extreme weather patterns or change of virulent strain of influenza causes a large exacerbation problem for this COPD population. The hospital and services would be stretched to full capacity if this were to occur.

Recent admission data obtained from the MOH (email, 18/11/2005) in NZ, about hospital admissions around NZ, has been tabled as Appendix 1. This data shows that the largest group of people with COPD being admitted to a District Health Board is in the category of 'Other' COPD, this equates to $47.2 \%$ of the admissions being 'undiagnosed', or having no diagnosis. The next largest group is asthma with $41.4 \%$ of the admissions, the bronchitis including acute and chronic makes up 6.83\%, bronchiectasis totals $4.42 \%$ and emphysema only makes $0.07 \%$. The diagnosis of COPD has many implications for patients and medical providers within NZ. This represents a population either having no diagnosis or an unclear diagnosis being the largest stakeholder in the COPD admissions to our public hospitals.

Important research has been done on COPD with regard to best treatment patterns and clinical trials for best practice (Chein et al., 2000; Haidl et al., 2004; Idris et al., 1995; 
O'Donnell, D'Arsigny, Fitzpatrick, \& Webb 2002; Plant, Owen, \& Elliott 2000; Robinson, Freiberg, Regnis, \& Young 2000). Traditionally with the management / treatment of COPD with bronchial dilators, steroids and supplemental oxygen, COPD has been a problematic disease with no 'quick fix' medication to reverse the exacerbation. One could say that non-invasive ventilation (NIV) has been the decade's most important improvement in clinical practice to treat respiratory failure and hypercarbia. Now commonplace within many Emergency Departments in NZ, the NIV can provide beneficial support to the ailing patient during an exacerbation and either reduces the chance of progressing into invasive ventilation from fatigue or averting the patient from a pre-arrest situation with acute hypercarbia and provide improvement to the acute respiratory acidosis (Squadrone et al, 2004). This leads directly into my research question concerning COPD, the specific interest being, is there an identifiable population with hypercarbia as a result from exacerbation of COPD?

\section{Research Question}

Within the population of people with COPD presenting to Tauranga Emergency Department, is there a subgroup population with COPD who retain carbon dioxide during an exacerbation of COPD?

This was a descriptive study aimed at investigating the COPD population presenting retrospectively over a period of three winter months. Data were collected from clinical records using a collection tool developed specifically for this study. The potential benefit of this descriptive research was not only to undertake clinical inquiry into this COPD population with regard to the acute presentation but also to build on the knowledge base about COPD as a research platform to further enhance the capabilities to which further studies can be done by the medical fraternity (doctors and nurses). A descriptive methodology was selected as the best design, given that the aim was to describe the people who were presenting and what their presentation patterns were.

The thesis comprises seven chapters, commencing with this Introduction which introduced the question, why this research is important and key terms. Chapter 2 focuses on pathophysiology, it includes a description of the mechanics of breathing and lung functioning, including disease processes that affect the lung function. The research literature available related to COPD and hypercarbia is presented in Chapter 3. Chapter 4 outlines the research design, including all the steps involved in undertaking such as 
designing the data extraction tool, the analysis and gaining ethics approval. Chapter 5 presents the findings of the analysis. Tables and graphs are used to illustrate the findings of the research. Chapter 6 discusses the findings including discussing the research limitations. The final chapter, Chapter 7 presents the Conclusion of the research study including the clinical implications and areas for further research. 


\section{Chapter 2 - Physiology of the lung}

This chapter provides a detailed explanation of the physiology of normal lung function and of disease processes researched within this study. Its purpose is to provide a reader from any background with sufficient information to appreciate the mechanics of lung function, the effort of breathing and the gaseous presentations of inhaled and expired air including the effect of gaseous exchange within the lung. Footnotes are used to define and explain clinical terms that not all readers may be familiar with.

\section{The lungs}

The lungs and respiratory system are important organs providing the essential oxygen used in the release of energy for all activity at cellular level and assists in the removal of waste produced during this activity (cellular respiration). These organs fulfil these functions by the efficient process of gaseous exchange in the lungs, so that oxygen can be delivered to the cells to meet demand, and carbon dioxide removed.

The lungs are divided into two parts; the conducting airways that transport the air and gas exchange region called the lobules. The conducting airways warms, moistens and filters the air as it moves through the structures. They use epithelial cells on the lining that secrete mucous and contain small hairs to facilitate removal of foreign matter contained in the air as it is purified. They are relatively large structures that are selfsupportive and are free from proneness to diseases such as Chronic Obstructive Pulmonary Disease (COPD).

The lobule is the region where gas exchange takes place. Each lobule is structured for gas exchange where inhaled air comes in contact with a vascular supply which then supplies the body with these dissolved gases. The lung is spongy in nature and under close inspection is largely air filled comprising of alveolius which are cup shaped, thin single cell walled structures which hold their shape on both inflation and exhalation. These alveoli provide a greater surface area for gas exchange to take place by providing millions of alveoli in series connected to thousands of bronchioles. The normal human body has about 300 million alveoli to meet the demands of the body during normal function and in times of stress. The vascular structures wrap around the outside of the alveolus to transport the carbon dioxide into the alveolus and take oxygen from the alveolus and transport it around the body for use (Porth, 1994). 
Almost all (99\%) oxygen $\left(\mathrm{O}_{2}\right)$ transportation is accomplished by the oxygen binding onto the outside of haemoglobin which carries it around to the source of use, the remaining $1 \%$ is dissolved in the blood plasma. Carbon dioxide $\left(\mathrm{CO}_{2}\right)$ has a varied transportation process (venous blood), $7 \%$ is carried as gas, $23 \%$ is carried on the haemoglobin and $70 \%$ is dissolved in the plasma and transported as an ion called bicarbonate. The transition of these two substances results in an efficient gas exchange from the alveolus and maintenance of the bodily function as the body depends on a narrow operating $\mathrm{pH}^{2}$ for cellular and organ function. The chemical equation for carbon dioxide transport is shown as:

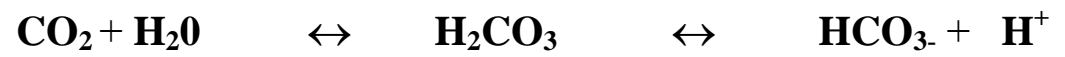

$$
\begin{aligned}
& \text { (Carbonic acid) (Bi-carbonate ion) }
\end{aligned}
$$

(Porth 1994, p.518)

To summarise oxygen is inhaled and absorbed into the bloodstream and taken to the site of use including muscles, organs and bones. The use of the oxygen combined with glucose and water results in energy release and the bi-product, carbon dioxide. This is a complex formula involving many cycles but can be simplified into the following:

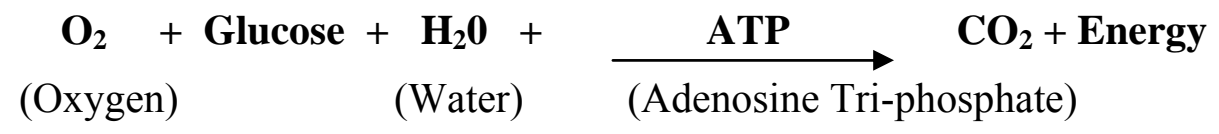

(Porth 1994, p.518)

The $\mathrm{CO}_{2}$ produced is then transported from the site of production back to the lung where it is transformed into a state that can to be exhaled to the atmosphere again. The diseases incorporated in COPD have an effect on the exchange and use of the gases involved in respiration.

\section{Chronic Pulmonary Disease}

COPD is a group of diseases characterised by damage to the structures contained within both the lobule and the smaller regions of the conducting airways. The damage reduces the surface area of the lung primarily due to alveolus breakdown and clumping into larger air cavities. The net result is airflow limitation resulting in a reduced ability to exchange gases to meet demand. The damage to the smaller conducting airways is generally permanent; chronic mucous and inflammation causes a narrowing of the airway, as a

\footnotetext{
${ }^{2} \mathrm{pH}$ is the negative decimal logarithm of hydrogen ion concentration. This gives the acidity or alkalinity of a solution, ranging from 1 to 14 .
} 
consequence lengthening the time to get air to the alveolus. Porth 1994 documents that the walls lose the ability to dilate because of chronic toxin exposure and higher airway pressures, this is compounded during times of higher demand. The diseases incorporated in the COPD grouping are chronic bronchitis, emphysema and chronic long-term asthma. The major differential is that COPD has a limited reversibility with pharmacological intervention where as asthma has a good reversibility from inhaled bronchodilators. This means that the airway constriction is reversible with the use of bronchodilators and steroids. The testing of lung function is a diagnostic tool for the reversibility of the lung disease, this will be examined within the literature chapter 3.

Booker (2004) discusses the fact that smoking has a lot to do with the presentation or progression of the disease. Occupational exposure to organic and non-organic dust, fumes and solvents also contributes to COPD presentation especially with a history of smoking. Another factor is chronic bronchitis; many patients have repeat attacks and require repeated courses of antibiotics to treat lower respiratory tract infections following a cold. This repeat exacerbation of bronchitis puts further stress on damaged lung structures, which is progressive and irreversible for the patient.

The long-term effects of COPD are not restricted to the lung; the effects on the heart are well documented within pathophysiology books (Porth 1994; Tintinalli, Kelen, \& Stapczynski 2000). These authors describe how a breakdown of the alveolar sacs causes destruction in the vascular beds increasing pulmonary arterial resistance pressures, coupled with this increase in pressure is constant hypoxia that causes further vasoconstriction within the pulmonary circulation increasing the circulating pressure. The hypoxic effects that are quantified to push the circulating blood to the areas of lung, which would be better, ventilated and so increase the gas exchange from the atmosphere to the blood stream. Both these effects increase the pressure to the right ventricle and occurring over a long time period, cause dilation and ischemic changes to the heart. This is called cor-pulmonare ${ }^{3}$ as the blood flow from the right side of the heart is reduced and the output from the pulmonary circuit now affects left ventricle output, which means further hypo-perfusion of organs and tissues, adding to the acidosis picture (metabolic acidosis). Long term progression of this hypoxia and hypo-perfusion, is characterised by one of the obvious changes called clubbing of the nail beds within the finger.

\footnotetext{
${ }^{3}$ Cor-Pulmonale results from primary lung disease and longstanding pulmonary hypertension, right sided heart dilation and hypertrophy.
} 
This constant hypoxia causes changes within the vascular beds in the nail, this causes a flattening of the angle ( $160^{\circ}$ is normal finger to nail relationship) as shown in Figure 1.

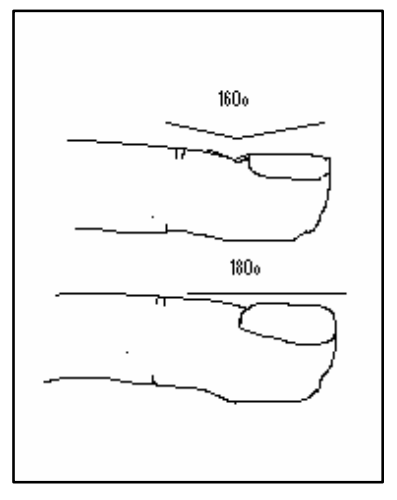

\section{Figure 1. Illustration of the changes to the nail as a result of COPD}

Over growth of the nail and end of the digit are obvious physical changes. Other changes to chronic hypoxia include changes to the haemoglobin levels within the blood, they increase so that more available oxygen can be carried to the site of use by the body, and this is termed polycythemia. "Chronic hypoxia includes symptoms of dyspnoea (SOB), fatigue and polycythemia" (Porth 1994, p.580).

Clinicians treating COPD exacerbations, traditionally manage the patient by oxygen $\left(\mathrm{O}_{2}\right)$ administration, steroid use for the inflammation and inhaled broncho-dilators which act on the smooth muscle contained within the walls of the conducting airways allowing greater flow of gases for exchange (Porth 1994). An exacerbation as defined by Cydulka et al. (2003) is characterised as a worsening shortness of breath, increased sputum production or change in sputum production which puts a demand on the already affected lung, normal coping mechanisms. The affected lungs are unable to cope with the increased demand and fatigue, hypoxia and tachypnoea ${ }^{4}$ follows. Acute presentations according to West (2003) are from exacerbation on an already compromised respiratory system, the pulmonary reserves are very much limited and any increase in work of breathing and/or worsening of ventilation-perfusion ${ }^{5}$ (V/Q) relationships as a result of retained secretions or broncho spasm results in pushing the patient over the brink into respiratory failure ${ }^{6}$ (hypoxia and hypercarbia coexisting). West discusses how the slow regression of respiratory function from disease results in a division in the measured

\footnotetext{
${ }^{4}$ Tachypnoea: Raised frequency of respirations with a shallow respiratory volume within a cycle of breathing.

${ }^{5}$ Ventilation-perfusion relationship is value when total air movement per minute is put against the volume of blood passing through the lungs per minute.

${ }^{6}$ Respiratory failure is when the lungs fail to oxygenate the arterial blood adequately and/or fails to prevent $\mathrm{CO} 2$ retention.
} 
gases: a slow downhill decline in oxygen levels and an increasing in levels of carbon dioxide can occur over a period of months to years. Given this picture West, states that the situation with COPD is not conventionally called respiratory failure, but is in a league of its own. The patient is generally able to carry out limited physical activity even though hypoxia and hypercarbia exist.

Oxygen within the blood is expressed as $\mathrm{pO}_{2}$, translated as the partial pressure of oxygen dissolved in the plasma. Normal $\mathrm{pO}_{2}$ for a healthy adult is $12 \mathrm{kpa}$, every haemoglobin can be $97 \%$ saturated by oxygen ( $\mathrm{SpO} 2-$ Saturation of oxygen of haemoglobin), as it is a highly efficient oxygen carrier. With COPD and the undermining lung disease, the $\mathrm{pO}_{2}$ is lowered and with that a lowered saturation of oxygen availability for cellular and organ use. Carbon-dioxide transport is also measured as a partial pressure, $\mathrm{pCO}_{2}$ for a normal healthy adult is 4.5-6 kpa, sometimes the diseased state of the lungs allows this carbon dioxide to elevate slightly and so altering the equilibrium of the gases transported around the body.

The $\mathrm{pH}$ of the blood depends on a fine balance of the acid and base factors travelling around the body in the bloodstream (buffering systems). A balanced $\mathrm{pH}$ is important for the body because all organ/ cellular and enzyme function can only operate if this blood $\mathrm{pH}$ is normal. Three major buffering systems control and regulate the body's $\mathrm{pH}$ when there is imbalance by either a respiratory or metabolic factor. The bi-carbonate system is the major system for acid-base regulation. This system uses a weak acid (carbonic acid) and weak base (bicarbonate) to balance inequities in the $\mathrm{pH}$ from either respiratory or metabolic causes. The system works by buffering the weak acid to a stronger one called hydrochloric acid and buffering a weak base to a stronger one, called sodium hydrochloride to normalise the $\mathrm{pH}$ of the blood. The equations demonstrating how this occurs are:

$$
\begin{array}{ll}
\mathrm{HCl}+\mathrm{NaHCO}_{3} \leftrightarrow \mathbf{H}_{2} \mathbf{C O}_{3}+\mathrm{NaCl} & \text { Acid buffering } \\
\mathrm{NaOH}+\mathbf{H}_{2} \mathbf{C O}_{3} \leftrightarrow \mathrm{NaHCO}_{3}+\mathrm{H}_{2} \mathrm{O} & \text { Base buffering }
\end{array}
$$

(Porth 1994, p.631)

Another pH buffering system is the phosphate buffer system, which consists of hydrogen phosphate and hydrogen phosphate ions. In the presence of a strong acid such as hydrochloric acid $(\mathrm{HCl})$ the buffering system converts the hydrochloric acid to a weaker 
one, hence reducing the level of acidity and raising the $\mathrm{pH}$. Likewise in the presence of a strong base like sodium hydroxide $(\mathrm{NaOH})$ the buffering system turns it into a weak base, in turn these are eliminated in the kidneys as urine. These processes are represented in the following equations:

$$
\begin{aligned}
& \mathrm{HCl}+\mathrm{Na}_{2} \mathrm{HPO}_{4} \leftrightarrow \mathbf{N a H}_{2} \mathbf{P O}_{4}+\mathrm{NaCl} \text {. Acid buffering } \\
& \mathrm{NaOH}+\mathbf{N a H}_{2} \mathbf{P O}_{4} \leftrightarrow \mathrm{Na}_{2} \mathrm{HPO}_{4}+\mathrm{H}_{2} \mathrm{O} \text { Base buffering }
\end{aligned}
$$

(Porth 1994, p.631).

A third mechanism - a protein system also has a small impact on the $\mathrm{pH}$. Proteins are composed of amino acids, some of which have free acid radicals that can dissociate into a base and hydrogen ions $\left(\mathrm{H}^{+}\right)$. The protein buffers are largely located within cells, $\mathrm{H}^{+}$and $\mathrm{CO}_{2}$ and can easily diffuse across cell membranes for intra cellular protein buffering. The combination of these buffering systems allow moment-by-moment regulation of the $\mathrm{pH}$ and provides the ability to combine with excess acids or alkalis preventing large changes in $\mathrm{pH}$, which has a range from 1 to 14 .

Excess acids or bases occur from two situations, firstly from metabolic incompetence during infection or malfunction in regulation of normal bodily functions and secondly, from respiratory compromise either from disease or atmospheric change in the percentages of inhaled gases affecting the gaseous exchange within the lungs, which is the one I am reporting on in this thesis.

With COPD and hypercarbia, the excess $\mathrm{CO}_{2}$ dissolves in water to readily form bicarbonate ions and hydrogen ions, it is this spare hydrogen ion that easily combines with chloride ions to form hydrochloric acid $(\mathrm{HCl})$. The more hydrogen ions available the worse the $\mathrm{pH}$ becomes from the effects of $\mathrm{HCl}$. This is where the buffering systems come into place, to buffer the $\mathrm{HCl}$ to a weaker acid (carbonic acid) lessoning the acidity of the blood.

A normal respiratory drive is essential to maintaining homeostasis ${ }^{7}$. A detailed cellular function, (Krebs' cycle ${ }^{8}$ ), is a proficient process which works to keep the dissolved gases of oxygen and carbon dioxide within normal limits. Carbon dioxide crosses the blood-

\footnotetext{
${ }^{7}$ Homeostasis is the normality of functions for the bodily processes or as discussed by Porth 1994 as the concept of a normal internal environment.

${ }^{8}$ Krebs' cycle uses oxygen and glucose and water to produce energy with bi-product of carbon dioxide.
} 
brain barrier with ease to combine with water as discussed earlier, forming carbonic acid which then divides up into hydrogen ions and bicarbonate ions. It is the hydrogen ions that stimulate the respiratory centre into lifting the work of breathing (WOB) and hence the respiratory rate (RR) to increase the $\mathrm{CO}_{2}$ removal from the body. This decreases the $\mathrm{CO}_{2}$ remnants in the body and allowing more $\mathrm{O}_{2}$ molecules to fit into the alveolus to be diffused through the alveolus wall and be transported around the body for use. Normal baseline healthy blood gases (ABG) levels used in Tauranga ED are presented in Figure 2 .

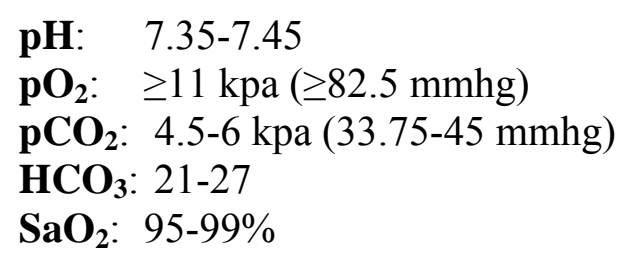

\section{Figure 2. Normal Blood gas levels}

With a normal healthy human, elevated $\mathrm{pCO}_{2}$ results in an increase in the WOB or minute volume ${ }^{9}(\mathrm{MV})$ of the particular patient. Because of the COPD, some patients having chronically elevated $\mathrm{pCO}_{2}$, the respiratory drive fails to work to set the pattern and frequency of the breathing. However, COPD patients fall back on to a hypoxic drive to control their work of breathing. The hypoxic drive works on the fact that during periods of demand they use up more $\mathrm{O}_{2}$ and they then get more hypoxic. This is sensed by the brain and results in driving up their WOB in a vain attempt to get more $\mathrm{O}_{2}$ into the alveolus and therefore into the bloodstream for cellular use within the body. Work of breathing as described earlier, is pivotal to respiration frequency and lung volume, because the tidal volume for people with COPD is often unchanged due to over inflation. This is characterised by a lengthened respiratory cycle from airway constriction and poor lung compliance from fibrosis and/or alveolar breakdown. These chronic changes mean that to increase a person's minute volume it is only possible to increase the frequency to ventilation $(\mathrm{RR})$ to alleviate hypoxia and raise the carbon dioxide levels. This is expressed as:

Minute Volume (Work of Breathing) = Tidal Volume x Frequency

\footnotetext{
${ }^{9}$ Minute volume is the volume inhaled and exhaled per minute through normal respiratory measures set in litres per minute. This is made up of the tidal volume (inhaled and exhaled volume) of each breath and the frequency or number of breathes in that minute.
} 
Measurement of patient's respiratory function within the Emergency Department can be difficult depending on the acuteness of a person's presentation. A person can be too sick to undertake a test or they may also complete it ineffectively because of extreme shortness of breath as oxygen reserves are used up quickly. Snow, Lascher and MotturPilson (2001) argue that respiratory function is a poor measure of the severity of an exacerbation. However as people with COPD may also have a degree of asthma, Peak Forced Expiratory Peak Flow (PEPF) are regularly measured within the ED. This is because in asthma, PEPF has great clinical interpretation, because of the effective reversibility of asthma with bronchial dilators, this is evidenced by the peak flow rate increasing after inhaled bronchodilators. PEPF with non-reversible COPD, PEPF has no benefit in testing with the exacerbation because having no change in the baseline, and more often than not uses up the patients energy reserves, which should be kept for normal breathing or coping mechanisms.

The PEPF is the maximal force to which the patient can expel a maximal breath of air from maximal inhalation to maximal exhalation, tested on a hand held device. This is a direct measurement of the airway pressure or limitation. The PEPF is a good test for monitoring asthma, as an asthma exacerbation is usually greatly reversible with a combination of bronchial dilators and steroids. However it is my experience that PEPF is not helpful in monitoring COPD patients. The COPD patients often have a poor PEPF (100 L/min or less) that does not change after inhaled bronchial dilator use. The best / ideal tests for diagnosing and monitoring the severity of COPD are pulmonary function tests. Respiratory technicians using expensive and large testing equipment undertake these tests during well periods of the patient. These complex tests shows a range of values, functional vital capacity $(\mathrm{FVC})$ is the volume of air, expelled from maximal inhalation to that of maximal exhalation. Another value, the forced expiratory volume of air in one second $\left(\mathrm{FEV}_{1}\right)$, is the volume of air expelled from maximal inhalation over a one second period.

The combination of these two values give an insight into the severity of the pulmonary disease as it measures as a percentage the volume of air expelled in one second compared to full air expelled represented as: 
People who have been troubled by respiratory problems especially for a number of years ideally should have a hospital lung function test performed to investigate and enable tracking of changes in lung function. West (2003, p.189) reference values for lung function based on non-smoking white adults in United States are presented in Table 2.

Table 2. West's Normal values for lung function tests

\begin{tabular}{|l|r|r|}
\hline & Male & \multicolumn{1}{|c|}{ Female } \\
\hline FVC & $7.74 \mathrm{~L}$ & $4.14 \mathrm{~L}$ \\
\hline FEV1 & $5.66 \mathrm{~L}$ & $2.68 \mathrm{~L}$ \\
\hline FEV1/FVC (\%) & $73 \%$ & $65 \%$ \\
\hline
\end{tabular}

Functional residual capacity (FRC) is a value which is shown within lung function testing. This has importance to the clinician because the larger the value, the more 'stale air' remains in the lungs, this has a strong relation to respiratory failure because of less fresh inspired air is mixed with respired gases in the lungs, and so carbon dioxide levels increase and oxygen levels are lowered (alveolar hypoventilation). The problem with this FRC is that the person needs to be well during the lung testing, and they need to reproduce the figures a few times to be of any benefit in recording the value. This often goes unrecorded for the patient during the testing because of un-repeatable results.

To summarise, a normal healthy male can expel $73 \%$ of their lung volume within one second and females $65 \%$ of their lung volume. A decrease in this ratio or percentage indicates the presence of lung disease or an interference in normal lung physiology. A decrease indicates there is trouble getting the air out from the lungs due to alveolar enlargement, medium airway inflammation or secretion plugging. This ratio gives the practitioner a benchmark to position where the patient sits on the cascade of severity of disease, for example a normal ratio would be $75 \%$, and a poor ratio would be $35 \%$. This determination of the ratio has a bearing on problems they could encounter and/or the chance of reversibility in the event of admission to hospital. The advantage of patients having lung function tests is that an understanding is gained related to the level of a patient's disease impairment and assists the clinicians in deciding the treatment plan. Normal lung alveolar numbers decline with age, reducing this ratio furthermore and hence the $65 \%$ to $73 \%$ volume of air expelled within 1 second is a figurative value with which clinicians can predict what effect the disease process has on the investigative subject. 
In conclusion, the lungs are important organs of the body. They are not only the location of exchange of gases but they also provide the essential oxygen for use in all the cellular and organ functions within the body. It is therefore essential that the respiratory system maintains adequate and constant supply of oxygen and is able to remove carbon dioxide to keep the $\mathrm{CO}_{2}$ levels within the normal range, essentially, keeping the body free from $\mathrm{pH}$ fluctuations and further system intervention to control $\mathrm{pH}$. For, without that fine balance of $\mathrm{pH}$ many cellular and organ functions are adversely affected. People with hypercarbia, the interest group in this thesis, retain $\mathrm{CO}_{2}$. The next chapter presents a review of the literature that examined what is known about hypercarbia and COPD exacerbation presentations. 


\section{Chapter 3 - Literature}

Chronic Obstructive Pulmonary Disease (COPD) has been researched and investigated for many decades to the benefit of both the patient and the treatment provider. For example a paper by Rudolf, Banks and Semple published in the Lancet in 1977 raised questions about hypercarbia in over oxygenation of the COPD patient. The literature reviewed indicates some positive investigation in the COPD arena, with a number of research and clinical papers being found which discussed and explored COPD exacerbation and treatment options. The chapter commences with oxygen administration and then literature on non-invasive ventilation, treatment guidelines for COPD and final literature on a study on how hypercarbia and hypoxia are related to resuscitation.

Rudolf et al.'s (1977) hypothesis was unlimited oxygen supply in a diseased lung leads to an elevation of the carbon dioxide levels. This hypercarbia during hyperoxic therapy can lead to an increased lactic acid production in the brain secondary to hypoxia. The central hypoxic drive leads to increased ventilation and so a status quo in oxygenation and carbon dioxide removal results. Traditional hypotheses at that time were that COPD patients have a lower than normal sensitivity to Oxygen $\left(\mathrm{O}_{2}\right)$. The hypoxic drive from peripheral chemo-receptors is removed by supplemental $\mathrm{O}_{2}$ administration resulting in ventilatory hypoventilation. Hypercarbia doesn't stimulate increased ventilation due to de-sensitivity to the $\mathrm{pCO}_{2}$ as a chronic condition, and partial pressure of carbon dioxide $\left(\mathrm{pCO}_{2}\right.$ ) continues to rise with the $\mathrm{O}_{2}$ administration, leading to loss of pulmonary hypoxic vasoconstriction and thus increase in blood flow to poorly ventilated areas of the lung and further deterioration in V/Q ratio leading to further $\mathrm{pCO}_{2}$ rise. The change in hypothesis is that during an exacerbation, cerebral hypoxia and central lactic acidosis stimulate breathing and that when $\mathrm{O}_{2}$ is given, the stimulation is abolished, leading to ventilation reduction and widening V/Q ratio. The current understanding of the hypercarbia picture isn't very different from this earlier proposition; in essence we still do not fully understand what is going on during an exacerbation (exac) of COPD and have much to learn about this condition.

Most of the literature reviewed falls into four categories: firstly, there is a plethora of research investigating oxygen administration to the population of COPD. Questions raised include what happens in uncontrolled administration and what effect that has on dissolved gases in the blood stream? Secondly, the reported research investigating the 
effectiveness of non-invasive ventilation (NIV) compared to traditional treatments on patient outcomes. Since 1999 NIV has been recognised as a treatment for COPD especially for people with hypercarbia and fatigue during exacerbation of COPD. Thirdly, there is a group of studies/articles on treatment guidelines, written by International committees about appropriate treatment and investigations of the COPD patient. Finally there is research on swine undertaken to measure the effect of both hypercarbia and hypoxia on effective resuscitation.

\section{Oxygen Administration}

Pivotal published literature related to hypercarbia comes from an author in Australia. Dr Joseph Ting, who is a clinician within the field of emergency medicine in Brisbane, wrote an article titled "Hypercarbia and Oxygen Therapy in Older Asthmatic Patients" that was published in the European Journal of Emergency Medicine in 2004. This paper is a case report on a patient treated within an emergency department (ED). The patient with a history of COPD progressed into hypercapnic respiratory failure (HRF) with unrestricted oxygen therapy. Ting argues that respiratory acidosis and hypercarbia during acute exacerbation of COPD leads to neurological and cardio-respiratory dysfunction although hypoxia is more rapidly harmful to tissues than acute hypercarbia. When a person presents with hypoxia they require urgent supplemental oxygen even in worsening hypercarbia. Hypercarbia indicates worsening respiratory fatigue and warrants assisted ventilation either in the form of NIV $^{10}$ or invasive ventilation (endo-tracheal intubation). However, inter-mandatory positive pressure ventilation (IPPV) often poses difficulties for the older person when it comes to weaning from the ventilator because they can enter a new realm of positive ventilation diseases that have a higher morbidity risk. This is because invasive ventilation ${ }^{11}$ requires sedation and paralysis medications to assist ventilation. These medications increase the likelihood of respiratory infections and inflammatory conditions where higher pressure ventilation is needed to combat pressure induced bronchial constriction/ mucous plugging. This can lead to over inflation and interstitial changes within the lung adding to the normal age related changes.

Older patients with a disease condition of asthma given unrestricted oxygen (Ting terms hyperoxic) during the treatment continue to deteriorate, presumably because of COPD

\footnotetext{
${ }^{10} \mathrm{NIV}$ : mask type positive level ventilation where inspiratory and expiratory pressures can be varied to suit the patient. The benefit is the assisted pressure ventilation improves minute volumes and gas exchange within the lungs.

${ }^{11}$ Invasive positive ventilation is called IPPV (inter-mandatory positive pressure ventilation).
} 
overtaking the asthma diagnosis. In these situations of respiratory failure, hypoxia and hypercarbia improve with the gentle reduction of inspired oxygen, whilst maintaining adequate tissue oxygenation, i.e. achieving a saturation of oxygen ( $\mathrm{SpO} 2)$ of greater than $90 \%$. It is unclear whether unrestricted oxygen administration predisposes the patient with COPD to acute hypercarbia and worsening respiratory failure in severe acute exacerbation COPD. Ting refers to authors Chien et al. (2000) who discuss that older patients with respiratory acidosis can develop hypercarbia from $100 \%$ inspired $\mathrm{O}_{2}$ after 20 minutes duration, Ting found that several of the patients he had treated became less hypercapnic after lowering inspired oxygen.

To conclude, Ting (2004) argues that unrestricted $\mathrm{O}_{2}$ is beneficial in children and young adults in asthma because of the hugely reversibility factor, but may lead to progressive hypercarbia in older patients. The difficulty is to differentiate between COPD and asthma in elderly patients; both conditions may deteriorate in response to overoxygenation. This risk is reduced by careful administration of oxygen to provide adequate tissue oxygenation. Ting considers that assistance from a person's prior pulmonary investigation studies is essential in treating people in distress, as tissue oxygenation needs to take precedence over hyperoxic hypercarbia.

Ting (2004) refers to the older asthma patient, who has a direct relevance to the COPD population that I studied within this research. Over a long period of time, a person's asthma can move into a transitional disease diagnosis and ultimately to a COPD diagnosis. A diagnosis needs to be confirmed by lung function tests. These tests often prove that a person has developed a non-reversible decrease in lung function, effectively moving them, from the asthma group to a COPD diagnosis. The years of asthma characterised by airway constriction and acute bronchial oedema to unknown irritants or stimulus become unable to cope with the normal lung processes of broncho-dilation. These cause an increase in the work of breathing so people can end up with long expiratory period of ventilation, reduced air movement, hypoventilation and alveolus over inflation, causing irreversible damage to the structure within the lung.

My research sits within the same group of people discussed by Ting. In a personal email communication ( $4^{\text {th }}$ March 2005) with Dr Ting, I established that he has concerns about the pre-hospital treatment of this subgroup of hypercarbic people, often being mistreated even though he was speaking of the asthma presentations of all ages. His case does highlight an older and long-term asthma patient. He found that the Queensland 
Ambulance Service routinely applies a non re-breather $\mathrm{O}_{2}$ and the ED nurses often collude with "more oxygen is better" routine for shortness of breath. He has observed several of these patients getting more respiratory depressed due to iatrogenic oxygen over administration. Ting's view is that the inappropriate use of oxygen is a global practice. Markouu, Myrianthefs and Baltopoulos (2004) concur with this; they state that when oxygen is given to a COPD patient in a greater than $30 \%$ concentration $\mathrm{pCO}_{2}$ normally rises because of worsening Ventilation-Perfusion (V/Q) relationships. They conclude that uncontrolled oxygen administration may precipitate hypercapnic coma. My research was designed to investigate whether there is a subgroup of COPD patients that develop hypercarbia?

Murphy, Mackway-Jones, Sammy and Driscoll et.al (2001) reported on guidelines prepared by North West Oxygen Group, titled "Emergency Oxygen Therapy for the Breathless Patient". They discuss how the breathless patient who lives rural to the hospital and requires an ambulance ride of greater than 15 minutes have a greater risk of hypercarbia and hence previous episodes of hypercarbia should be identified and treated with either low flow $\mathrm{O}_{2}$ and/or controlled $\mathrm{FiO}_{2}{ }^{12}$. These authors even mention the need for medical alert bracelets to highlight those patients that could be a potential problem during transit to the ED. The potential problem seems to exist around the world; no country is free from the hypercapnic exacerbation of COPD.

A study published in the American Journal of Respiratory Critical Care involved a quasi-experimental design to examine the effects of direct hyperoxic hypercarbia in acute COPD (Robinson, Freiberg, Regnis, \& Young, 2000). A sample of COPD patients recruited from COPD exacerbation admissions $(n=22)$, were administered $100 \%$ oxygen for a period of 20 minutes. Robinson et al. found that there were two responses to the $100 \%$ oxygen therapy; those who became carbon dioxide retainers whose $\mathrm{pCO}_{2}$ had increased by more than $3 \mathrm{mmhg}(0.4 \mathrm{kPa})$ to the baseline and a group $(\mathrm{C})$ who only had a zero to up to $3 \mathrm{mmhg}$ rise in their $\mathrm{pCO}_{2}$. The researchers looked at the samples real-time V/Q studies, cardiac output and ventilation studies. Interesting data revealed that the retainers group showed a fall in ventilation from 9 to $7.21 / \mathrm{min}$ (minute volume) compared to a no change in the non-retainer group. This study showed a reduction in ventilation is characterised by oxygen induced hypercarbia. The study concluded that, the significant increase in dead space in the retainer group may cause hypercarbia.

\footnotetext{
${ }^{12} \mathrm{FiO} 2$ : Fraction of inspired oxygen, determines the percentage of oxygen in inspired gases.
} 
Robinson et al. (2000) refer to previous research undertaken in the field of hyperoxic hypercarbia, which identified that the important mechanisms were considered to be that of a reduction in ventilation responses to hypoxia by removing the stimulus. Hypoxia causes vasoconstriction in parts of the lung where low ventilation occurs and thus keeping the absorption or retention of carbon dioxide to a minimum. However, when oxygen is placed in excess to the affected patient, vasodilatation occurs and worsens the $\mathrm{pCO}_{2}$ for that patient. So the question or hypothesis is, does the cerebral centre for ventilation work in conjunction with this localised anomaly within the lungs, or does it play a different role in the control of ventilation?

Research with a similar clinical inquiry to Robinson et al. (2001) was carried out by O'Donnell, D'Arsigny, Fitzpatrick and Webb (2002). These latter authors demonstrated the hypercapnic response to hyperoxia and change in $\mathrm{pCO}_{2}$ from rest, to peak exercise. This response involved just 10 minutes exposure to hyperoxic oxygen, giving two groups, retainers of $\mathrm{pCO}_{2}$ and non-retainers. The group where hypercarbia was present at rest were at a greater risk of developing hypercarbia with exercise testing. The changes noted in COPD exercise were that hypoxic induced vasoconstriction and increased respiratory drive (rate) to maintain V/Q and normality of respiratory function. They note that mild cases of COPD with minimal changes in lung function are less likely to retain carbon dioxide and become hypercapnic as a response to an acute exacerbation of COPD and respiratory failure. This relationship of exercise in COPD has been assumed a worthy testing condition by the researchers where oxygen consumption and increased carbon dioxide production are in response to the exercise.

Baram, Degene, Amin, Bilfinger and Smaldone (1994) published a case presentation about a man with Hypercapnic Respiratory Failure (HRF). The man who had 100 pack years ${ }^{13}$ as a smoking history and an exposure to asbestos (industrial exposure) was found on autopsy to have pleural effusions and fibrosis. The authors concluded that he was suffering from hypercarbia and respiratory failure. The man's blood gas results were: $\mathrm{pH}$ 7.2, $\mathrm{pCO}_{2} 78 \mathrm{mmhg}, \mathrm{pO}_{2} 49 \mathrm{mmhg}, \mathrm{HCO}_{3} 30$ and $\mathrm{SaO}_{2} 73 \%$. His hypercapnic respiratory failure was unable to be improved with invasive ventilation and changing ventilation patterns. The man was ventilated long-term and had problems weaning from the ventilator, pneumonia infection incurring during this episode proved fatal. Although

\footnotetext{
${ }^{13}$ A pack year is the consumption value worked out on a packet per day per year equals one pack year.
} 
a complicated case, worsening respiratory failure to a spiralling cascade of intervention proved fatal for this patient. The benefit of diagnosing a hypercarbic patient differs from the normal treatment, the change averting the damaging effects of hypercarbia and respiratory acidosis. The person's underlying disease on post mortem was that of greater thickening of the lung parenchyma causing increased thoracic resistance to ventilation. The increasing dyspnoea the patient experienced leading up to admission was not only of worsening alveolar structure but that of increased thoracic resistance to ventilations. This has a direct relationship to carbon dioxide retention and a lowered minute volume increases the ability to remove $\mathrm{CO}_{2}$.

Cherniack (2004) notes that previous researchers aimed to establish why some patients retain carbon dioxide and some do not. Carbon dioxide retention is linked to the disease of chronic bronchitis and emphysema (COPD major diseases). However carbon dioxide retention seems to cause shortness of breath (SOB) only as people respire to such an extent that they still manage to move the wastes out of the alveoli. The problem arises out of the excessive dyspnoea ${ }^{14}$ and the rapid breathing required to maintain oxygenation that leads to exhaustion. Bronchitis patients usually have narrowed airways and have trouble getting air in and out. As a result the carbon dioxide remains in the vascular system leading to an acidosis syndrome. Emphysema patients seem to lose alveoli and have great trouble getting oxygen and vital air into the sac. This is managed by rapid ventilation aiming at maintaining oxygenation. They do this by smaller tidal volumes but breathing at a faster rate than one would normally do. Cherniack concludes that the hypercapnic patients have lower alveolar ventilation, than patients who are normocapnic (normal carbon dioxide levels) but this is difficult to test within the presenting patient, the only determinant is the residual volume testing by pulmonary function tests.

Chien et al. (2002) discuss that while oxygen is the greatest treatment in the COPD syndrome, uncontrolled oxygen is problematic in severe COPD as it causes alveoli hypoventilation, respiratory acidosis and obtundation ${ }^{15}$. They found that certain asthma presentations follow similar patterns to COPD presentations; asthma with hypercarbia is secondary to respiratory failure and patient fatigue from exhaustion and prolonged hypoxia. A reduction in the fraction of inspired oxygen $\left(\mathrm{FiO}_{2}{ }^{16}\right)$ drops the $\mathrm{pCO}_{2}$ and

\footnotetext{
${ }^{14}$ Dyspnoea is a patient's feeling of shortness of breath, rated to a level or urgency to breath.

15 Obtundation: A narrative description for the level of arousal and responses evoked by various stimuli also called drowsiness and stupor.

${ }^{16} \mathrm{FiO} 2$ is the inspired percentage of oxygen, in the atmosphere there is close to $21 \%$ oxygen, when administering supplemental oxygen the FiO2 is increased.
} 
avoids invasive endo-tracheal intubation. The researchers set up a study involving asthma/COPD patients presenting as exacerbation to the department. They placed the patients on $\mathrm{FiO}_{2}$ of $100 \%$ for 20 minutes noting the blood gas before administration of $\mathrm{O}_{2}$ and again at the end of the 20 minutes. The study showed that $40 \%$ of the patients retained carbon dioxide whilst on $100 \% \mathrm{O}_{2}$, and of those, half progressed onto hypercarbia respiratory failure, the rest of the group of non-retainers had no hypercarbia. This study has similarities with my research but Chien et al. excluded patients who had a smoking history of greater than 10 years, who were taking central depressants or sedatives and who had a documented history of COPD in their records and symptoms of purulent cough. The age for inclusion started $\geq 18$ years, which is appropriate for gaining the population of asthma patients. My research used the inclusion age of $\geq 55$ years to eliminate people who present with mild asthma. It follows similar variables to those used in this study, but the population sampled were those with COPD.

Haidl, Clement, Wiece, Dellweg and Kohler (2004) introduce their article by talking about a subgroup of patients with COPD who develop hypercarbia during an exacerbation and/or after exercise. The authors set about creating a study to investigate or recreate this condition by exercise testing patients with advanced airway limitation. The sample consisted of 28 people with COPD being admitted with an exacerbation. They found that all patients developed some degree of hypercarbia, but after a recovery period the $\mathrm{pCO}_{2}$ returned to normal and their $\mathrm{pO}_{2}$ stays above the magical 8kpa (60 mmhg). They argued the probability of developing hypercarbia increases with degree of airway obstruction, hyperinflation, obesity and inspiratory muscle weakness. These authors discuss that reversible hypercarbia does not necessarily lead to chronic hypercarbia within the confines of the disease. The study excluded people with malignant disease such as congestive heart failure, renal disease and diabetes. Inclusion criteria were to include a severity factor using the ratio $\mathrm{FEV}_{1} / \mathrm{FVC}<70 \%$ and $\mathrm{pCO}_{2}>6$ (45mmh) at rest on two different days or a baseline chronic increase in $\mathrm{pCO}_{2}$. Follow up was needed to complete the study to observe the difference in placing a patient on long-term oxygen therapy (LTOT). The study was a randomised control trial with COPD exacerbations. It can be concluded from this study that as most people with severe airway limitation have the ability to retain carbon dioxide, there must be some trigger or situation where people are unable to cope with normal functions and progress into the severe hypercapnic acidosis position leading to clinical instability. My research aims to describe the population presenting with a similar clinical picture to Haidl et al. but by 
looking at actual presentations rather than a research environment, it will help create a clinical picture of ED presentations.

Markou, Myrianthefs and Baltopoulos (2004) discuss important features of respiratory failure with the determinant factor of COPD. They report an exacerbation can be the effect of exhaustion or acute worsening of condition. Their study picked up the numbers of COPD patients who had been compensating within the community before they arrived uncompensated to the department. They noted that a person's kidneys stop excreting bicarbonate ions to compensate for the hypercarbia causing an acidosis within the bloodstream. This compensation occurs after 48-72 hours, and so leads us to conclusions of the exhaustion theory. It can be concluded from their work that the patient starts the exacerbation or hypercarbia much earlier than the presentation to the emergency department. Markou et al. rate the severity of the airway limitation is that of forced expiratory volume in 1 second $\left(\mathrm{FEV}_{1}\right)$ against the predicted for the patient's age and gender $\left(\mathrm{FEV}_{1} / \mathrm{FEV}_{1}\right.$ predicted). Their results were that $\mathrm{FEV}_{1}$ predicted was $40.8 \%$ +/$10.2 \%$, for example the combination of the sample showed that patients removed $40 \%$ of air within one second compared to a predicted volume similar to their age and gender. Other researchers use the FEV1/FVC (Ratio) as a measure of the severity of the patient's disease. This measure which will be examined further later in this chapter, measures the ability to remove the forced expiratory volume in one second over the functional vital capacity (FVC).

\section{Non-Invasive Ventilation}

The introduction of NIV treatment for acute hypercarbia exacerbation of COPD in my view has been one of the foremost dramatic improvements in the treatment of COPD within the last decade. In my discussion with nursing colleagues around New Zealand, it would appear that NIV has infiltrated most emergency departments and has over taken the continuous positive airway pressure (CPAP) therapy as the therapy of choice for acute presentations of COPD. CPAP therapy was the usual therapy for pulmonary oedema and late stage lobular pneumonia with gross areas of consolidation, where the continuous positive pressure drives pooled alveolar fluids back into the interstitial layers and/or ventilates the airways distal to the consolidation to keep the alveolar open for gas exchange (MacGeorge \& Nelson, 2003). 
Paus-Jenssen, Reid, Cockcroft, Laframboise and Ward (2004) set up a research project within a North American hospital to identify who received NIV treatment. Over a time period of five months observation, 75 people were given NIV. Of these $18 \%$ were from the COPD group, and $82 \%$ had other aetiologies causing their respiratory failure. In regional New Zealand hospitals (like Tauranga) I suspect the use of NIV would be greater for the COPD population than others as it's my experience that it is regularly used for people presenting with an exacerbation of COPD. My research will report on the number of presentations for COPD over a three-month period to the Tauranga ED.

Squadrone et al. (2004) carried out research to compare the effect of NIV with that of conventional treatment for people with hypercarbic COPD. The group they sampled were divided between a NIV group $(n=64)$, and an intubated group $(n=64)$. They reported that $65 \%$ of the NIV group failed NIV, and had to be intubated. Despite the high failure rate, NIV did provide some advantages. The NIV group had fewer complications and the failed NIV group didn't have any different mortality or length of stay from that of the intubated group. They suggest that the $\mathrm{pO}_{2}$ and $\mathrm{pH}$ may have a determination on the likelihood of failing NIV. But even though the chance of failing NIV was relatively high, it seems that the chance of successful treatment on NIV out weighs intubation because of the long list of damaging problems associated with intubation and weaning from the invasive ventilator.

Prolific researchers and writers, Keenan, Sinuff, Cook and Hill (2003) undertook a systematic review of the literature cited in Medline and Cochrane on the effectiveness of NIV for people with COPD. They found that only people with severe exacerbations of COPD benefit from NIV. Severe exacerbation of COPD was a subgroup population that had a $\mathrm{pH}$ of $\leq 7.30$. The direct benefit of NIV was to limit the mortality rate, and improve the $\mathrm{pH}$ of the studied population. The authors conclude that NIV should be standard therapy for people presenting with severe exacerbations of COPD, and when on NIV people need close monitoring. They advise if further increasing respiratory distress or acidosis is noted NIV should be exchanged for intubation and ventilation. The benefit is to provide NIV before the patient tires, ending up in an extreme acidosis respiratory failure situation. Plant, Owen and Elliott (2000) observed with a similar NIV study that the benefit to starting a COPD patient on NIV outweighed conventional treatment by reducing mortality and the need with intubation. Their sample had equal inclusion criteria including acidosis and disease limitations. Intubation was reduced by $15 \%$ and mortality reduced by $10 \%$ within the two groups. 


\section{Treatment Guidelines for COPD}

The British Thoracic Society (2002) established guidelines for the treatment of respiratory failure using current literature and studies reviewed by a committee of respiratory clinicians (Baudouin et al). These guidelines advise the treatment for all phases of respiratory failure. The guidelines for COPD and hypercarbia advise that:

1. NIV has been shown to be beneficial treatment for acute hypercarbia in COPD (respiratory failure).

2. NIV should not be used as substitute for intubation.

3. The beneficial effects of NIV have been demonstrated in patients with a respiratory acidosis $(\mathrm{ph}<7.35, \mathrm{H}+>45)$. Knowledge of arterial blood gas tensions should therefore be measured to assist in clinical decision making.

4. Arterial blood gas tensions improve in patients with maximal medical treatment and appropriate supplemental oxygen. A repeat sample of blood gas tensions should follow oxygen administration to indicate whether NIV is required.

The conclusion from the committee is that NIV is a simple and effective treatment for acute hypercarbia in COPD that should be used as soon as hypercarbia is shown within the clinical scenario. They do express concern that blood gas sampling is not done earlier enough to show when hypercarbia exists. It is this that can lead to a worsening clinical picture.

Joint writers from the American College of Physicians (Snow, Lascher, \& Mottur-Pilson, 2001) presented guidelines for treating exacerbation of COPD. They define COPD as characterised by airflow obstruction, and an exacerbation is evidenced by dyspnoea, cough and increased sputum production. The guidelines report that triggers for an exacerbation can be tracheal-bronchial infections, environmental exposures and other comorbidities such as heart failure, pulmonary embolus and systemic infections. Problem patients have typically low $\mathrm{FEV}_{1}$, low $\mathrm{pO}_{2}$ and $\mathrm{pH}$ and increased $\mathrm{pCO}_{2}$, they advice that simple spirometery within the emergency department is not useful in judging the severity of exacerbation, and consider that what is more beneficial to the clinical specialist is the degree of dyspnoea and change in sputum production.

Markou, Myrianthefs and Baltopoulos (2004) are authors with an intensive care background with an interest in respiratory failure. They divide respiratory failure into chronic respiratory failure (CRF) and acute respiratory failure (RF). COPD can fall into either chronic or acute failure categories, which is why my research is investigating the 
subset people with acute hypercarbia. Markau et al.'s description of the differences is documented below.

- Acute RF develops within minutes or hours.

- Chronic RF develops over several days or longer.

- In the case of hypercapnic RF, the presence of bicarbonate ions reflects the renal compensation and indicates Chronic RF.

- Presence of markers of chronic hypoxemia (polycythemia and cor-pulmonale) provides clues to a chronic disorder, where as abrupt changes in mental status suggest an acute or acute on chronic event. (p.355)

Furthermore respiratory failure can be put into two types, Type 1 is a gas exchange problem orientating from the lung as an organ where the lung is the primary problem. Type 2 is ventilatory pumping failure, originating with the chest wall, respiratory muscles, respiratory pathways and pathways from the brain to the organ (lung) not connecting properly. Further to add to the picture is the mechanisms of derangement in a person's ABG. Markau et al. (2004) document six reasons for derangement. These are low fraction of inspired oxygen $\left(\mathrm{FiO}_{2}\right)$, hypoventilation, ventilation-perfusion (V/Q) miss-match, shunt, impaired diffusion and de-saturated mixed venous blood. The main focus of COPD is to do with the direct hypoventilation from the disease and the exacerbation they are currently experiencing. The other determinants of changes to the $\mathrm{ABG}$ are reflective in their own aspect, but have little interest with this study. COPD patients often have hypoxia but during periods of exacerbation the patient has a decrease in the ventilation volume due to airway constriction and mucous plugging. The net effect for the person therefore is a rising $\mathrm{pCO}_{2}$. Markou et al. state the effects of hypercarbia caused by the hypoxia and pulmonary constriction can be life threatening to the patient if untreated. Respiratory acidosis from the hypercarbia also plays a part in the continuing deterioration in condition as the oxygen disassociation curve is forcibly moved to the right (i.e. the $\mathrm{pO}_{2}$ has less an effect on the saturation of oxygen on the haemoglobin). Excessive hypercarbia causes a multilevel cascade of problems within the body including depression of cardiac contractility, decreased respiratory muscle contractility, arterial vasodilatation, increased cerebral blood flow and loss of consciousness though encephalopathy.

Guidelines from a Committee from Northern America were tested for their use within 29 EDs in the United States of America (Cydulka, Rowe, Clark, Emerman, \& Camargo, 
2003). The research sampled a population from the age of 55 years and older. Data showed that many practitioners were not adhering to the guidelines, resulting in a high frequency of relapse. In addition they found that $\mathrm{ABG}$ sampling was under-utilised despite being recommended as an effective determinant of hypoxia and hypercarbia. A high percentage of those sampled reported they relied on the ED as their usual care provider $(15 \%)$, and so high re-admission rates $(43 \%)$ were noted because of that. Concluding recommendations by the reviewing panel were that adherence to the guidelines would or could improve the outcome after ED treatment.

Chu et al. (2004) carried out a study in Hong Kong with the intention to establish the incidence of readmission rates following admission with acute hypercapnic respiratory failure (HRF) with the background of COPD and NIV use. They found that after one year, $80 \%$ of people had been re-admitted with a HRF event, $63 \%$ had been re-admitted with similar life threatening events, and a staggering $49 \%$ had died within that year. Survivors of the admission had spent $12 \%$ of the year within hospital. The hospital concerned had a small NIV ward of six beds that they could admit these patients to and apply controlled NIV to a patient with COPD with hypercarbia who did not have CHF, asthma, bronchiectasis, sleep disordered breathing and pneumonias (any non COPD related respiratory failure). They concluded that there needs to be further investigation into why this population are often re-admitted following an acute admission for hypercarbia, and considered urgent further studies are needed to devise strategies to reduce readmission rates amongst this population of COPD.

\section{Hypercarbia versus Hypoxia}

Up to this point I have presented literature on hypercarbia and hypoxia within the COPD patient and illustrated how both conditions are detrimental in certain clinical situations. In an attempt to improve treatment Idris, Wenzel, Becker, Banner and Orban (1995) set up a study using a randomised controlled trial design using swine $(n=24)$ to measure the variables of hypoxia and hypercarbia against the effect of resuscitation. As clinicians we are aware of the damaging causes of hypoxia and hypercarbia independently, what we don't know is which is worse for the patient. The RCT was set up inducing a cardiac arrest using both variable conditions and a control group. The induced cardiac arrest was sustained for 6 minutes where by all the swine were subject to cardio-pulmonary resuscitation and ventilation with $85 \%$ oxygen. Results were that $13 \%$ of both the hypoxic and hypercarbic groups had a spontaneous return of circulation after active 
resuscitation, compared to $75 \%$ of the control group having a return of circulation after resuscitation. This has some clinical relevance to the treatment of COPD assuming humans react similarly to swine. It is useful in helping our understanding about which condition carries a better outcome for organ and cellular function, and highlights why clinician's need to be mindful about treating both hypoxia and hypercarbia during an exacerbation of COPD.

\section{Determination of disease}

Determining the severity of a person's condition is important as it guides the decisions related to how best to treat the person at the time of the presentation. There are two general ways the assessment of a person's lung function can be calculated. These are either plotting a person's FEV1 against the predicted value for their gender and age or alternatively by a percentage of FEV 1 from Functional Vital Capacity (FVC). Results within literature studied show that the majority of authors (Booker, 2003; Chu et al., 2004; Haidl et al., 2004; Snow et al., 2001; Squadrone et al., 2004; Tuggey et al., 2003) use the expected FEV1 over gender and age as a determinant of the severity of disease and lung function. These authors come from USA, Hong Kong and European countries. The FEV1/ FVC is used by two authors (O'Donnell et al., 2002; Ting, 2004) are from Canada and Australia. The pulmonary function-testing department within the DHB in which this research is conducted use the $\mathrm{FEV}_{1} / \mathrm{FVC}$ as an expression of lung function and so this measure was used as a variable in this study.

Other information relevant to this research that was regularly reported on by researchers includes a person's smoking history. There is a general agreement to use a pack year system to gauge both length of exposure and consumption of tobacco has been adopted. Booker (2003) uses this pack year classification; she argues that it is the best way to calculate smoking exposure. Calculations related to consumption are made by using the number of packets per day by the number of years a person has smoked. Other authors using a similar classification are Baram et al. (1994) and Chu et al. (2004). Cydulka et al. (2003) on the other hand only referred to whether a person did or did not smoke. This latter approach has drawbacks to evaluating the exposure to smoking as an independent variable, the more widely appreciated classification is of a pack year value. 


\section{Summary}

This chapter has explored what is currently understood about COPD and what are the best ways to treat this condition at the time of an exacerbation. It highlights how there are many unanswered questions about COPD and how best to treat an exacerbation. Modern day ventilation improvements can aid the management of an exacerbation and help avoid a worsening condition. Clinical trials and studies show quite positively that NIV benefits patient outcomes not only in averting intubation and respiratory failure but also in saving health dollars as a result of fewer admission days in hospital. The literature presented shows details about treatment patterns, how to appropriately treat the hypercarbic patient and the clinical risk that co-exists with hypercarbia in COPD exacerbation. The question remains, what person ends up with acute hypercarbia and are there some characteristics of this group or how people present that may help? To answer this question involves an investigation of who presents to ED with COPD, and how often is hypercarbia present within this group.

The methodology of my research into these factors of exacerbation will be the topic of the next chapter. 


\section{Chapter 4 - Methodology}

This study aimed to describe the population who present to the emergency department (ED) with an exacerbation of their Chronic Obstructive Pulmonary Disease (COPD) and to establish whether there is a subset of people who present with acute hypercarbia. The previous chapter highlights that people with an exacerbation of COPD do present with hypercarbia, but it is unclear from the literature whether there are any characteristics apart from the differences in $\mathrm{pCO} 2$ in those who present with hypercarbia $\left(\mathrm{pCO}_{2} \geq 6 \mathrm{kpa}\right)$ compared with those who are non-hypercarbic $\left(\mathrm{pCO}_{2}<6 \mathrm{kpa}\right)$. This research was designed to address this issue, it aimed to establish whether there is a group of people who present to the emergency department (ED) with hypercarbia and to detail who and how this group is from the normal population of COPD presenters.

The study was therefore designed to initially describe all presentations to ED for people experiencing an acute exacerbation of their COPD over a three-month period. Several options were explored how best to undertake the study, and the decision was made that a descriptive study using retrospective data was the best methodology to use. This decision was made because the aim was to widen the clinical inquiry into the COPD population by examining variables within the acute presentation and gain underlying interpretation of the groups and subgroups.

\section{Description}

Prior to deciding to use a descriptive design, other research options were explored. The range of methods and approaches are endless within the field of health and nursing research. Knapp (1998) considers the purpose of nursing research is to extend the knowledge base in a discipline by contributing to the theory generation or theory testing, which is called basic research. Experimental design, which involves the formation and testing of a hypothesis, is the ultimate in research when the aim is to determine the effectiveness of an intervention. Researchers' LoBionado-Wood and Haber (1998) discuss how research using an experimental design is beneficial in the health sector as it provides "a basis for changing and supporting current nursing practice" (p. 182). While I am interested in changing practice, I did not consider that sufficient knowledge was known about people who present with hypercarbia compared with those who were nonhypercarbic to undertake an experimental study, I also had restrictions related to time and the scope of a project. 
In that this research wanted to establish whether there were differences between the hypercarbic and non-hypercarbic group a quasi-experimental design was also considered. This was rejected for similar reasons to the experimental design, namely that while it was known that people presented with hypercarbia, it was unclear how many there were and whether there was a group of such presentations. Once it was established that there were a group of presentations where people were hypercarbic some analyses similar to those used in quasi-experimental design were used.

Description is the art of describing a certain condition or situation that exists in the clinical setting, or can be a "way to summarising the principle features of the data you happen to have." (Knapp 1998, p. 159). It involves creating a picture of what is happening. Pictures of ED presentations could be taken from a number of angles or perspectives and from a number of sources. The angles or perspectives could be that of the patient's self report, a support person's perspective and/or the clinician's view of what happened. Such a picture however could be limited, as it would only provide people's recall of their experience. Such recall could be compromised for the person because of their clinical position; hypoxia for example causes a confused state. A clinician's view may also not be very clear as often people in the ED setting are involved with a number of different personnel.

Another picture could be taken by systematically following a cohort of people who present to ED with COPD. Quite a few problems arise with this method, as obtaining informed consent to observe people could be a problem especially as some people who present with an exacerbation of COPD are acutely unwell. I also considered it would be unethical to request consent from people to study and observe them, until people's health is relatively stable. Issues could also arise if I observed something causing acute deterioration to the patient. As an experienced nurse and against my code of conduct set out by Principle 2 of the Nursing Council of New Zealand Code of Conduct (Appendix 2 ), it would be unethical if I didn't assist or suggest care more appropriate for the patient, but such actions would impact on the research findings. Also staff normal way of managing a scenario may change as a result of the observation. Another risk is that staff may feel that their clinical performance is being accessed, rather than aiming to understand what is happening. Lastly undertaking a prospective design could be problematic as COPD is often one of a number of provisional diagnoses a person presenting with breathing issues to ED may have. Differential diagnoses for COPD presentations can include asthma, pneumonia, bronchitis, infective COPD, non-infective 
COPD, heart failure, pleural effusion, shortness of breath (SOB) and chest pain. Following an assessment the person may be found to have any of these or an alternative diagnosis, which they may be admitted with, so COPD not being the reason for the presentation.

For these reasons a decision was made to undertake a retrospective design as this would provide the information about everyone who staff had recorded as having an admission for COPD. A descriptive design can use either a randomised or a convenience sample. This study used a convenience sample in that it was all people who presented to ED with COPD over a three-month period. The time-period being chosen to ensure the research remained within the size of a two-paper research thesis. A key to describing is to decide the framework to be used on which to base the description. As I was interested in a standardised approach that could demonstrate difference, a data extraction tool was developed for the purposes of recording data extracted data from the records for this study. The development of the tool will be outlined later in this chapter.

To free the research from bias and ensure the findings are valid, care and attention was taken to developing the details of the research design. Inclusion and exclusion criteria for which presentations would be included in the analysis were well documented and followed. This was important as including presentations which did not fit the inclusion criteria could create bias in the research and so skew the results. Attention was also needed to pre-define all variables including how missing data would be managed. Systems were also needed to ensure the accurate entry of data. The remainder of this chapter discusses how I designed this research to achieve valid and trustworthy results.

\section{Population}

Inclusion criteria were any person presenting aged 55 years and over with the admission complaint of either one of the following "shortness of breath (SOB)", "COPD or COAD (Chronic Obstructive Airways Disease) and Asthma". These terms are frequent presentation complaints entered into the patient management system for the hospital, which is called IBA ${ }^{17}$. In the pre-testing phase of this study, only the words COPD and SOB were used. These were extended to include asthma and COAD when it was found

\footnotetext{
${ }^{17}$ IBA (international business administration) is the patient management system used by Tauranga Hospital for patient admission and follows through to discharge. This database can be used to selected patient presentations from a local database and national database attributing diagnosis, dates and times for treatment. Every admission entered on IBA becomes a permanent record on the computer system for future reference.
} 
that the triage nurse had entered some other potential presentations to the ED as COAD. COAD is a term given as an equivalent to COPD depending where your training originated. Many of the European countries and New Zealand and Australia use the COPD expression where as in the United States clinician's commonly use the term COAD.

Exclusion criteria were also developed to ensure that I could be confident of obtaining only COPD presentations. People under 55 years were excluded to avoid people with very definite asthma presentations from being included in the study. As Chapter 2 reported, overtime asthma can develop into COPD, however it is generally accepted that this does not happen until people are older. When a patient had a problem with the lungs such as thoracic surgery and known lung carcinoma, they were omitted from the sample. These conditions could skew the findings because they can change the thoracic pressures and may affect the total vital capacity of the lung. This would result in a change in the "normal" values of the gases contained within the bloodstream as a result of the exacerbation. Also initially excluded were people presenting with congestive heart failure (CHF) and pneumonia as the management plan for people presenting with these illnesses are very different to that of people with COPD. However, at the pre-test data collation it was evident that many people present with a combination of CHF or pneumonia and an exacerbation of COPD so a decision was made that people with either of these diagnoses and COPD could be included. Given that the focus of the study is on describing the sample on presentation and not on the treatment people received, I do not believe including this group compromised the findings.

\section{The development of the tool for easy data extraction}

A draft tool was developed and pre-tested to ensure that the necessary data could be obtained from the files, and that extracting this could be done efficiently. A number of issues arose at this point that needed clarification. These related to how to record smoking information and how to manage missing data. These issues are discussed here as a result of the pre-test some variables changed. The records pre-tested highlighted that practitioners' recorded smoking in different ways. Some wrote about how long people smoked and how many cigarettes people smoked, others just recorded how many? And, in some cases the how many was recorded as the number of cigarettes smoked per day and in other cases the number smoked per week. To align the study with international 
research a decision was made to use the term pack years. The term pack years involves averaging the number of years a person has smoked by the number of packets of cigarettes smoked per day. For example if a person smoked two packets per day for 10 years this would equate to 20 pack years.

The pre-test found that often arterial blood gases (ABG) were not done on presenting patients, and very few people had an ABG within 2 hours, and few had a repeat blood test within five hours. The ABG results are necessary for the diagnosis of hypercarbia. Following the pre-test stage of the research it was decided to extend the $1^{\text {st }} \mathrm{ABG}$ time frame to tests within five hours and to extend the $2^{\text {nd }} A B G$ time limit from 5 to 24 hours post presentation These decisions were taken to ensure more presentations could be captured to establish whether people had hypercarbia at the time of presentation. This changed time frame was considered unlikely to impact on the actual numbers of presentations found to have hypercarbia, because as Chapter 2 shows, the development of hypercarbia usually takes from 24 to 72 hours. The pre-test also raised problems with the planned recording of a person's neurological state. A person's neurological function is usually assessed within the emergency department using the Glasgow Coma Score $\left(\right.$ GCS $^{18}$ Teasdale \& Jennet 1974). This is an elaborate assessment score that takes into account major alteration in a neurological function. However, what was found was that staff rarely recorded this on the COPD presentations. This lack of recording probably reflects that people were arriving alert and orientated and clinician's did not see a need to record the GCS. A decision was made given the low recording rate that the GCS would not be gathered. Consideration was given to assuming that the non-recording would mean that a person's score was 15 , reflecting that the person was alert and orientated, but this was considered unacceptable as it might have led to an underestimation of consciousness levels. Discussion with fellow research students explored whether there were other tools or scores that could be used such as the alert, vocalising, pain and unconsciousness $\left(\mathrm{AVPU}^{19}\right)$ score that is used within the New Zealand Resus Council ${ }^{20}$ and the Training Nursing Core Courses ${ }^{21}$ as a quick measure of alertness or wakefulness. While this is a very good assessment tool it would not be very useful, as it isn't always documented in a standard format. Consideration was also given to measuring exercise

\footnotetext{
${ }^{18}$ CGS: Score of level of consciousness.

${ }^{19}$ AVPU: A patient sits in either one of 4 categories: alert and orientated, only vocalising, responsive to pain or completely unresponsive.

${ }^{20}$ NZRC: New Zealand Resus Council is a body of administrative colleagues who discuss and advise on how to organise a resuscitation attempt to a cardio-respiratory arrest.

${ }^{21}$ TNCC: Trauma Nursing Core Course is an international body teaching on trauma skills to the emergency nurse.
} 
tolerance, but again this was rarely recorded in the records, and when it was different terminology was used. These were then omitted from the data extraction tool.

\section{Variables}

The data extraction tool can be found in Appendix 7. The final variables to be examined were decided based on the literature, and from my experience as a nurse within the field whom I often manage acute presentations of COPD. The variables were grouped around five areas. They were:
i) general socio-demographic data needed with any project;
ii) clinical history;
iii) clinical manifestations of COPD assessment within the emergency department;
iv) emergency department management; and
v) post emergency department admission.

In recording data, either people's clinical test results were recorded or in the case of a nominal variable such as industrial exposure the presence or absence of the variable were recorded. Decisions about coding are presented alongside the description of the variable.

Socio-Demographic Features: Age, Gender and Ethnicity. Age and gender are relatively straightforward variables to collect, but decisions are required with respect to recording ethnicity. Ethnicity within New Zealand (NZ) has traditionally focused on New Zealand being a bi-cultural society, however, it is becoming more multi-cultural. The Tauranga DHB currently uses six ethnicities categories: Maori, Pakeha (New Zealander), Polynesian, Asian, Indian, and European. People self-report their ethnicity on admission to ED. At the time of extracting data the following decisions were made to be clear who was a Pakeha and who was a European. If a person was born in New Zealand and was a Caucasian they were coded as Pakeha. If a person was born in any European country but now reside in NZ, then they were coded as European.

Clinical History: Previous last admission, previous diagnosis, smoking exposure and industrial exposure pulmonary lung function tests $\left(\mathrm{FEV}_{1} / \mathrm{FVC}=\right.$ ratio $)$.

Previous last admission - was a date when the person last presented to the emergency department within the previous 3 months, and then when in the previous year. This data was obtained from IBA, as a last presentation to the DHB. 
Previous diagnosis - Documented previous diagnosis were obtained from the history taken either from the general practitioner (GP) referral note or by admission details recorded at the time of admission. Although the primary diagnosis was often listed with a time of diagnosis within the GP letter, written as a coded diagnosis, details of these dates were not gathered. Provision was made to record all previous diagnoses as often people with COPD have more than one other diagnosis. By capturing all previous diagnosis it was hoped the research would accommodate the fact that respiratory diseases progress often on from one to another, and also manage the nature of co-morbidity on presentation such as the mixed system involvement of COPD and cardiac failure. It was decided to only document the first two of these diagnoses. Clinically, a secondary diagnosis is recorded to support the primary diagnosis, to provide a basis for understanding why an exacerbation has occurred, and to inform the treatment plan.

Smoking history - Consumption values of tobacco have been troublesome to place a value on. Internationally, the best method for placing a numerical value on consumption of tobacco is the formation of pack years. One pack year is given to a person who smokes one packet of cigarettes per day for a whole year. The assumption in the formula is that one packet has 20 cigarettes in a pack, however as manufacturers now sometimes packages 25 and 30 cigarettes in one pack, this could be equivalent to 1.25 and 1.5 packs. This clearly is not part of the history taking procedure of the medical professional, so hence the assumption is if they state the number of packs per day for a number of years then it is a 20-cigarette pack. The similar could be applied to "Roll your own cigarettes" a 30 gram pack was assumed to be equivalent to 50 cigarettes and so the pack years could be worked out. No-one within the population capture was documented as smoking cigars. If a person had reported smoking cigars they would have been reported as a nonsmoker, as many people do not inhale the smoke from cigars as they only swill the smoke within their mouth, hence doing less damage to the structures within the lungs.

Industrial exposure - Captured any reporting of an exposure to fungicides, herbicides, inhaled toxins gases and fibres including asbestosis, as there is documented discussion that these can be the causative agents in COPD progression (Booker 2005).

Pulmonary lung function tests - Investigation of the most recent lung function tests done within the hospital or if the patient had moved from another area to the Tauranga DHB, test results from their GP. Three values were captured, FEV1, FVC and ratio. 
Presenting Clinical Features: Initial ambulance $\mathrm{SpO} 2$, presentation time and date, respiratory rate, heart rate, and presentation source.

Initial ambulance SpO2 - The initial saturation of oxygen ( $\mathrm{SpO} 2)$ was also that recorded either by the ambulance staff or the ED staff depending on how people were transported to hospital. From a research point of view it was not always possible to establish whether a person had been given supplemental oxygen; a person's SpO2 can be either without oxygen or whilst oxygen treatment had been started.

Presentation source is something particular to the Emergency Department, with the department considerably central to most of the town and surrounding areas within the region. A coding of self-referral was termed as a person presenting by themselves or with a family member in their own car. These people could have been referred by their local GP. Those coded as presenting by ambulance transport, either called the ambulance of their own accord or were picked up from their GP because they were unwell and the GP considered they needed a hospital assessment and treatment.

Presentation time and date was coded into the study to give the spread of presentations over both the 24-hour period and the 3 months, collated off IBA system.

Respiratory rate and heart rate were the first recorded recordings taken by either the ambulance officers or the ED staff, for people who did not present by ambulance. The data was extracted from either ambulance records or ED records. In the situations where people came by ambulance and no baseline ambulance data was located in the records, the first hospital recordings were completed.

Within ED Stay: ABG, NIV use during presentation Arterial blood gas measurement is invasive but a good measure of investigation of the respiratory status for hypoxia, hypercarbia and acidosis. The initial ABG included any blood gas taken within the first 5 hours of presentation. The secondary blood gas if recorded is anything after 5 hours and up to a 24-hour period after admission. This data was usually collated from the IBA laboratory system. 
NIV variable was obtained from the notes to find out the actual numbers that were given NIV as an initial treatment within the emergency department. No attempt was made to establish whether people received NIV treatment post ED.

\section{Post Ed Admission: Length of admission}

Length of admission related to people's hospital stay. Data related to this was gathered from IBA admission data. This data was used to establish how long people with COPD stayed in hospital.

\section{Data Extraction}

Once ethical approval was gained from the regional ethics committee (Appendix 3), the files needed were identified and access was sought from the medical records department to obtain these. I usually obtained 10 files at a time. The files were taken from the medical records room to an office in the ED where they were examined to ensure they met the inclusion criteria for the study. Once presentations were identified using the inclusion and exclusion criteria the data collection tool (Appendix 7) was used as a template to extract data from the records. Data were entered directly into Statistical Package for Social Sciences version 11.5 (SPSS) for analysis purposes. Patient names were not recorded, hospital numbers were initially used to capture who had more than one presentation and these were later substituted with research numbers.

Each presentation by an individual was treated as if a first presentation, the hospital numbers being used to establish who had repeat presentations. All data was gathered on every presentation, the analysis later determining if those with repeat presentations, presented differently on admission.

\section{Analysis}

Analysis of data within research plays an integral part for every researcher during the timescale for research application. Taking raw data and turning it into something worthy of reading and clinical relevant is the aim for any researcher. The analysis plan for this study was to create a picture of ED presentations for an exacerbation of COPD. SPSS was a valuable computer programme to create such a description. SPSS has the ability to also list chosen variables and cross tabulate them against other variables looking for positive trends in the variables or non-accidental tendencies. It is from these tabulations 
that interpretation can be formalised into discussion from the researcher, and made available for open discussion in a public arena when published.

The data analysis needed to accommodate the fact that some people had more than one presentation over the three-month period. To prevent a skewing of results, it was important to think of the data as being in two groups: first being the master collated data file with all the relevant presentations listed and collated from the presentation and notes, and the second including the data where individual patients were only counted once. This second file is important because in some of the variables it is needed to quantify one per patient to prevent a skew in the results and provide a true and valid set of comparisons.

A four-stage analysis process was used. Descriptive statistics such as mean, median, range and frequencies were used depending on variable type.

1. Individuals

2. All presentations

3. Hypercarbic presentations

a. Individuals with hypercarbia

b. Individuals with non-hypercarbia or mixed situations (non-hypercarbia and hypercarbia).

4. Differences between hypercarbia and non-hypercarbia

Given the limited sample size, few inferential statistical tests were able to be used to establish whether there were statistical differences between the hypercarbia and nonhypercarbia group.

\section{Ethical Issues}

This study was approved by the regional ethics committee (Appendix 3). The approval was obtained for a retrospective review of patient/client notes or data. The approval process required the completion of a locality assessment form by the DHB. In Tauranga hospital on admission people can consent to their records being used for research purposes on admission (Appendix 4). If the patient is opposed to being included in research of health training purposes then they can indicate on this form by ticking inside the box on the form. No records identified where the patient had declined their records being used for research purposes. 
Treaty of Waitangi considerations were not expected to impinge on the focus of the project, however through courtesy, local support was invited from the Te Puna Hauora within the DHB (Appendix 5). Expected Maori population sample within the cohort group was around than $10 \%$, so clinical and cultural consideration was sort. The audit was not going to change treatment or approach treatment duration as all study material was from a retrospective presentation. The submission to Te Puna Hauora was accepted in full support to the researcher with a detailed conclusion to be submitted back to the Te Puna Hauora group, they have been interested in the conclusion results of the study that will be gladly given to them (Appendix 6).

Confidentiality of people's whose records were reviewed was achieved by changing the patient number for a research number and by maintaining a secure database. The file can only be accessed by the researcher's login on the DHB (District Health Board) computer system, the researcher only knows the database password. All other research material electronically is carried on a mass storage device, which is carried around my neck the majority of the time during research collation, in the event of me not wearing the portable storage device, it was locked within the department onsite within the DHB.

The following chapter presents the findings from the data collection obtained within the patients' notes using the data extraction tool. The findings are presented in a similar order of the variables in the data extraction tool. 


\section{Chapter 5 - Findings}

This chapter presents the findings of the retrospective review of records of people who presented to the emergency department (ED) with acute exacerbation of chronic obstructive pulmonary disease (COPD) over the 3 -month period of $1^{\text {st }}$ June to $31^{\text {st }}$ August 2005. The findings are presented in four sections. Section 1 is a general introduction to the number of presentations identified and how they were found and recorded. Section 2 describes the individuals using demographic and clinical features to give a picture of the people who presented to ED with COPD. Section 3 focuses on presentations generally, capturing the clinical picture of what was happening when a person presented. The final section presents the findings from the subgroup analyses undertaken to establish whether there is a discernible group of people with COPD who present to ED in a hypercarbic state. This latter section uses the same demographic and clinical features utilised to describe the sample in Section 2. Descriptive statistics, tables and graphs are used to present the data.

\section{Section 1- Identify the presentations with COPD to ED}

The search of the International Business Administration (IBA) system with key words S.O.B, exac COPD, exac COAD and exac Asthma identified 114 presentations of COPD between $1^{\text {st }}$ June 2005 and $31^{\text {st }}$ August 2005. Most records of the presentations were found in the medical records department and data extraction from these took place directly into the SPSS database. Details related to a group of 32 presentations were initially unavailable and had to be obtained from emergency department records; none of these people were admitted to hospital at the time of these exacerbations. When data on variables linked to individuals such as smoking history or industrial exposure was missing for a particular presentation, a person's previous admission records were reviewed to see if they contained the relevant information. Details could be extracted related to all 114 presentations.

There were presentations in 80 of the 92 days in which records were searched. The number of presentations on any one day ranged from 1 to 6 . On average 1.24 persons presented daily. As Figure 3 shows presentation times spanned the 24-hour period. The mean time was 1311 hours with a standard deviation (SD) of 0552 hours. The bulk $(75 \%)$ of the presentations were between $10 \mathrm{am}$ and $8 \mathrm{pm}$, and there were quite a few $(\mathrm{n}=8)$ who presented between midnight and $2 \mathrm{am}$. 


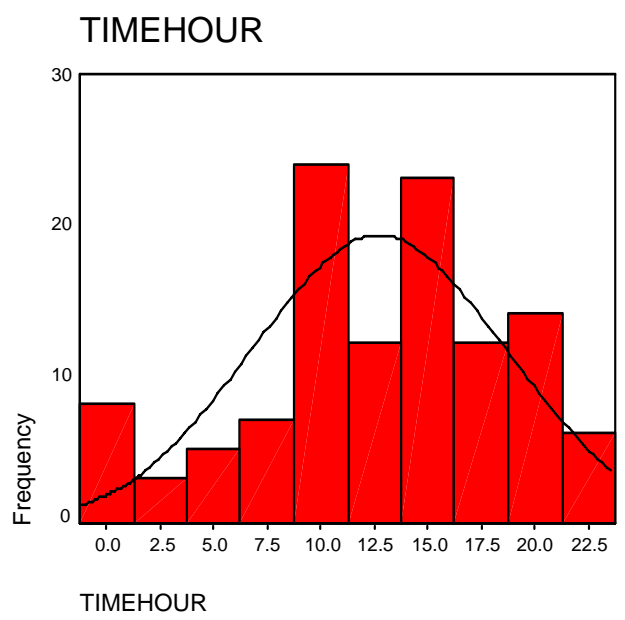

Figure 3. Histogram of all presentations by presentation hour

The 114 presentations involved 71 individuals. Table 3 presents the number of times individual people presented to the ED over the 3-month period. It highlights that the majority $(65 \%)$ of patients only presented once, but that a small group $(n=4,5.5 \%)$ presented five times over this period. However, $42(57.0 \%)$ people had had a previous admission to the ED within the past year outside of the time period for this study. Data about these previous admissions were not collected. Only 12 (10.5\%) people had never had an admission to the Tauranga ED over their lifetime. No information was obtained to establish if people had presented to other hospitals out of the area.

Table 3. Number of times individuals presented

\begin{tabular}{|c|r|}
\hline $\begin{array}{c}\text { No of } \\
\text { Presentations }\end{array}$ & \multicolumn{1}{c|}{ No (\%) } \\
\hline 1 & $46(65.0 \%)$ \\
\hline 2 & $15(21.0 \%)$ \\
\hline 3 & $6(8.5 \%)$ \\
\hline 4 & $0(0.0 \%)$ \\
\hline 5 & $4(5.5 \%)$ \\
\hline Total & $71(100 \%)$ \\
\hline
\end{tabular}

A focus is now given to presenting the demographic and clinical details of the 71 individuals.

\section{Section 2 - The Sample Population}

The 71 individuals who presented included 27 (38\%) males and 44 (62\%) females. Table 4 shows the majority of $68 \%(n=48$,$) were Pakeha and only 8(11 \%)$ were Maori. 
European $(n=13,18 \%)$ in this context refers to people who were born outside of New Zealand, in one of any of the European countries.

Table 4. Summary of demographic details of individuals who presented to ED

\begin{tabular}{|l|l|r|}
\hline Variable & Value & Total (n=71) \\
\hline Gender & Male & $27(38 \%)$ \\
& Female & $44(62 \%)$ \\
\hline Ethnicity & Pakeha & $48(68 \%)$ \\
& European & $13(18 \%)$ \\
& Maori & $8(11 \%)$ \\
& Indian & $2(3 \%)$ \\
\hline Age in years & Mean (SD) & $71.10(9.98)$ \\
& Median & 71.00 \\
& Range & $55-91$ \\
\hline
\end{tabular}

Age was determined from the age at the first presentation each person had over the threemonth period. Figure 4 shows there was no particular age group who dominated presentations, the range of age being 55 years (the minimal inclusion age) through to 91 years.

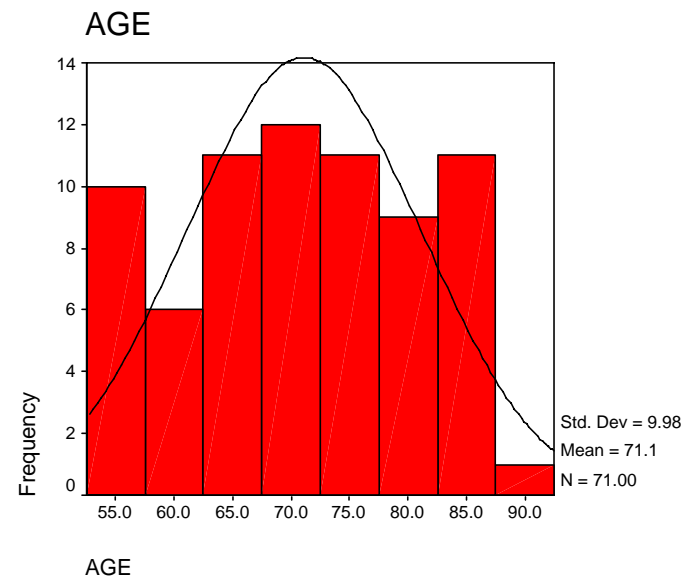

Figure 4. Histogram of sample group by age

The age cut off, of 55 years, was used to minimise the possibility of COPD presentations reflecting asthma presentations.

\section{Brief clinical history of the individuals who presented to the ED}

Table 5 only presents the smoking history of 68 individuals, as the details related to smoking were not documented in three $(4.2 \%)$ of the records sampled. 
Table 5. Individual's history of smoking and industrial exposure by gender and ethnicity

\begin{tabular}{|ll|r|r|r|r|}
\hline Gender & \multicolumn{1}{c|}{$\begin{array}{c}\text { Smoking } \\
\text { exposure* } \\
\mathbf{n}=\mathbf{5 7}\end{array}$} & $\begin{array}{c}\text { No smoking } \\
\text { exposure } \\
\mathbf{n = 1 1}\end{array}$ & $\begin{array}{c}\text { Industrial } \\
\text { exposure } \\
\mathbf{n = 8}\end{array}$ & $\begin{array}{c}\text { No industrial } \\
\text { exposure } \\
\mathbf{n}=\mathbf{5 3}\end{array}$ \\
\cline { 2 - 6 } & Female & $26(45.6 \%)$ & $1(9.1 \%)$ & $5(62.5 \%)$ & $22(35.0 \%)$ \\
\hline Ethnicity & $31(53.4 \%)$ & $10(90.9 \%)$ & $3(37.5 \%)$ & $41(65.0 \%)$ \\
& Maori & $7(12.3 \%)$ & $1(9.1 \%)$ & 0 & $8(12.7 \%)$ \\
& Pakeha & $37(65.0 \%)$ & $8(72.7 \%)$ & $8(100 \%)$ & $40(63.5 \%)$ \\
& Indian & $1(1.8 \%)$ & $1(9.1 \%)$ & 0 & $2(3.2 \%)$ \\
\hline European & $12(21.1 \%)$ & $1(9.1 \%)$ & 0 & $13(20.6 \%)$ \\
\hline
\end{tabular}

*Data related to smoking was not recorded for 3 individuals.

Of the $57(80 \%)$ of the sample who smoked, $26(45.6 \%)$ were male and $31(53.4 \%)$ female. Reported another way these figures indicate that $26(96 \%)$ of the males who presented to the ED with a COPD exacerbation were documented as having a history of smoking compared to $31(76 \%)$ of the female group. Smoking exposure by ethnicity shows that European have the highest percentage, with $92 \%(n=12)$ being a smoker, compared with only one Indian person (50\%).

Five males (19\%) and three females (7\%) were reported to have had industrial exposure. Industrial exposure by ethnicity indicates all of eight people (100\%) come from the Pakeha group. Table 6 shows how individuals were related to the exposures of both variables.

Table 6. Smoking, Industrial Exposure Subgroup Analysis

\begin{tabular}{|l|r|}
\hline & \multicolumn{1}{|c|}{$\mathbf{n}=\mathbf{7 1}$} \\
\hline Smoking history only & $49(69.0 \%)$ \\
\hline Industrial exposure only & $2(2.8 \%)$ \\
\hline $\begin{array}{l}\text { Smoking history and } \\
\text { industrial exposure }\end{array}$ & $6(8.5 \%)$ \\
\hline Missing & $2(2.8 \%)$ \\
\hline
\end{tabular}

The industrial only group may be smaller and the combined exposure figures larger given that there are missing data related to smoking on three people. Analysis shows the purely smoking subset group made up the largest of the population with $69 \%(n=49)$, the larger percentage of the industrial exposure had a mixed exposure to both variables totalling 
$8.5 \%(n=6)$, with the smallest group being exposed to industrial exposure alone of $2.8 \%$ $(\mathrm{n}=2)$.

Of the 57 people who smoke, details of how much people smoked and for how long were only recorded for 49 people. Figure 5 shows three of the people within the sample had an extreme smoking history that has skewed the results, moving the mean upwards from the median of 26 to a mean of 34.48 (SD 28.98) years. The range was 3-150 years. The rest of the individual's smoking years cluster between 0 and 70 pack years, with the bulk of the smoking consumption being between 19 and 45.5 pack years.

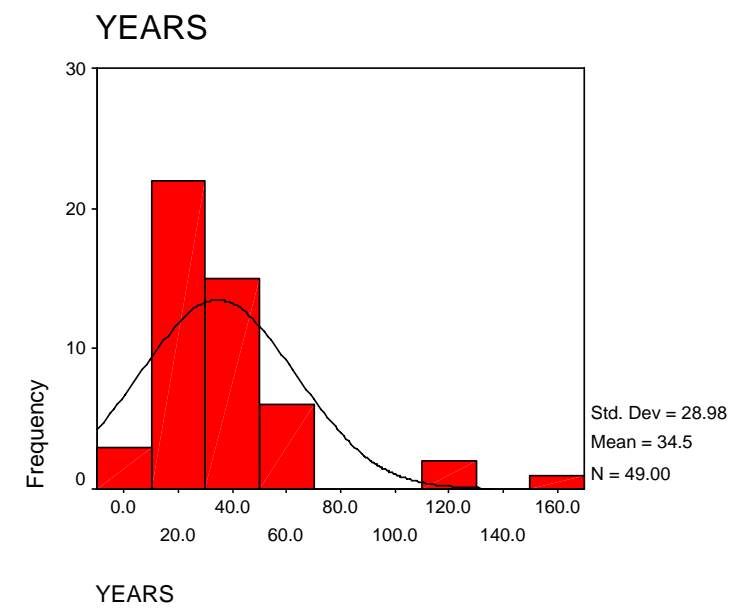

Figure 5. Pack-years of smoking population

Seventy of the 71 people had one or more previous diagnoses. Table 7 presents the findings related to what these diagnoses were. As people could have more than one diagnosis the totals do not add up to $100 \%$.

Table 7. Previous Diagnosis of the individuals who presented to ED

\begin{tabular}{|l|r|}
\hline \multirow{2}{*}{$\begin{array}{l}\text { Emphysema } \\
\text { Asthma }\end{array}$} & \multicolumn{1}{|c|}{$\begin{array}{c}\text { Collective } \\
\text { Previous disease } \\
\text { Total }\end{array}$} \\
\cline { 2 - 2 } CHF & $44(62 \%)$ \\
Bronchitis & $25(35 \%)$ \\
\cline { 2 - 2 } $\begin{array}{l}\text { Cor-pulmonale } \\
\text { Interstitial lung } \\
\text { disease }\end{array}$ & $15(21 \%)$ \\
\cline { 2 - 2 } $\begin{array}{l}\text { Bronchiectasis } \\
\text { Pneumonia }\end{array}$ & $6(8 \%$ \\
\cline { 2 - 2 } $\begin{array}{l}\text { Pulmonary TB } \\
\text { Total }\end{array}$ & $4(6 \%)$ \\
\cline { 2 - 2 } none & $1(4 \%)$ \\
\cline { 2 - 2 } & $1(1 \%)$ \\
\cline { 2 - 2 } & $1(1 \%)$ \\
\hline
\end{tabular}


Table 7 presents the data on collation of previous diagnosis. Diagnoses within the sample shows that the majority $(62 \%, n=44)$ had a diagnosis of emphysema, followed by asthma ( $n=25)$ and CHF $(n=15)$. A small number of people had bronchitis $(n=6)$ and corpulmonale $(\mathrm{n}=4)$.

Table 8 presents the findings of a cross tabulation of the 30 people sample who had two previous diagnoses.

Table 8. Common co-morbidities of individuals with previous diagnoses

\begin{tabular}{|c|c|c|c|c|}
\hline \multirow[b]{2}{*}{ Previous Diagnosis Two } & \multicolumn{4}{|c|}{ Previous Diagnosis One } \\
\hline & Asthma & $\begin{array}{l}\text { Emphys } \\
\text { ema }\end{array}$ & $\begin{array}{l}\text { Bronchi } \\
\text { tis }\end{array}$ & $\begin{array}{l}\text { Interstitial } \\
\text { lung } \\
\text { disease }\end{array}$ \\
\hline \multirow{8}{*}{$\begin{array}{l}\text { CHF } \\
\text { Emphysema } \\
\text { Cor-Pulmonale } \\
\text { Bronchitis } \\
\text { Pneumonia } \\
\text { Bronchiectasis } \\
\text { Pulmonary TB } \\
\text { Interstitial lung disease }\end{array}$} & $3(10.0 \%)$ & $8(26.7 \%)$ & $1(3.3 \%)$ & $1(3.3 \%)$ \\
\hline & $5(16.7 \%)$ & & $1(3.3 \%)$ & \\
\hline & & $4(13.3 \%)$ & & \\
\hline & $2(6.7 \%)$ & $1(3.3 \%)$ & & \\
\hline & & $1(3.3 \%)$ & & \\
\hline & $1(3.3 \%)$ & & & \\
\hline & $1(3.3 \%)$ & & & \\
\hline & & $1(3.3 \%)$ & & \\
\hline
\end{tabular}

This table shows that 13 of the 15 people in Table 7 who had congestive heart failure (CHF) had a second diagnosis. Emphysema and asthma were the commonest primary diagnosis these people had.

\section{Section 3 - Clinical features of all presentations}

In presenting the clinical features of all presentations, each presentation is described as if 114 individuals were involved. The description commences with details of baseline observations such as respiration and heart rate and proceeds to describe results from blood test analyses where available and applicable. As not all people had the same clinical details recorded, the denominator changes at times to indicate how many presentations were included in particular analyses, and information is given about the numbers missing.

The baseline observations were recorded by ambulance staff prior to coming to hospital or at triage on arrival at the hospital. Eighty (70\%) people presented via the ambulance and $34(30 \%)$ arrived via their own means. As baseline observations are taken in accordance with the initial assessment of the patient, patients may have been receiving 
oxygen at the time of the recordings. Table 9 presents the baseline observations of the total sample.

Table 9. Summary baseline observations of all presentations

\begin{tabular}{|l|r|r|r|}
\hline & \multicolumn{1}{|c|}{$\begin{array}{c}\text { Resp rate } \\
\mathbf{n = 1 1 1}\end{array}$} & $\begin{array}{c}\text { Heart rate } \\
\mathbf{n = 1 1 1}\end{array}$ & \multicolumn{1}{c|}{$\begin{array}{c}\text { Sp02 } \\
\mathbf{n}=\mathbf{1 0 8}\end{array}$} \\
\hline Mean (SD) & $26.74(7.8)$ & $102.88(18.55)$ & $93.24(4.57)$ \\
\cline { 2 - 4 } Median & 24.00 & 100.00 & 94.00 \\
\cline { 2 - 4 } Range & $20-46$ & $70-160$ & $73-100$ \\
\hline
\end{tabular}

Surprising, there was no respiratory rate or heart rate recorded on some individuals. The mean respiratory rate within the group is 26.7 with the median being 24 respirations per minute. The inter-quartile range for respiration was 20 - 32 respirations per minute. Figure 6 graphs the spread of the respiration rates on presentation.

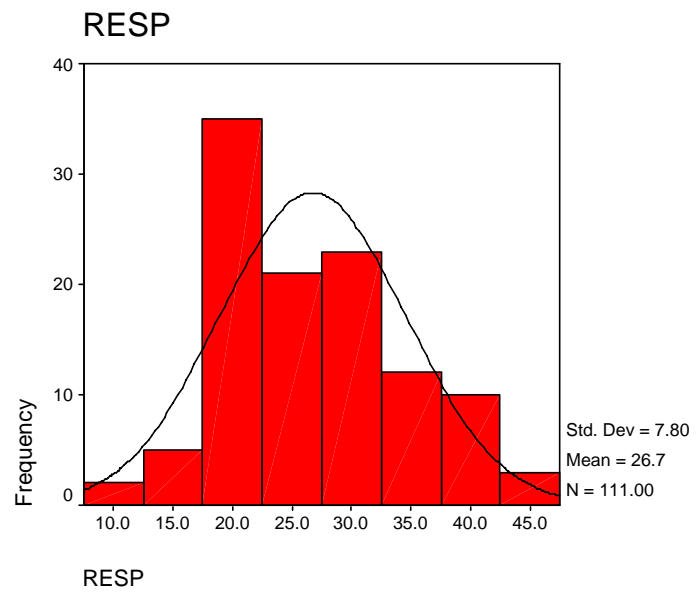

Figure 6. Histogram of respiration baseline observations

The mean heart rate was 103 beats per minute with a median rate of 100 . Twenty five percent of the people had a heart rate less than 88 per minute and a further $25 \%$ had a heart rate of greater than 115 per minute. Figure 7 shows the majority of people's heart rates on presentation were between 70 and 130 beats a minute, but there were four people with a heart rate faster than this, the fastest being 160 beats per minute. 


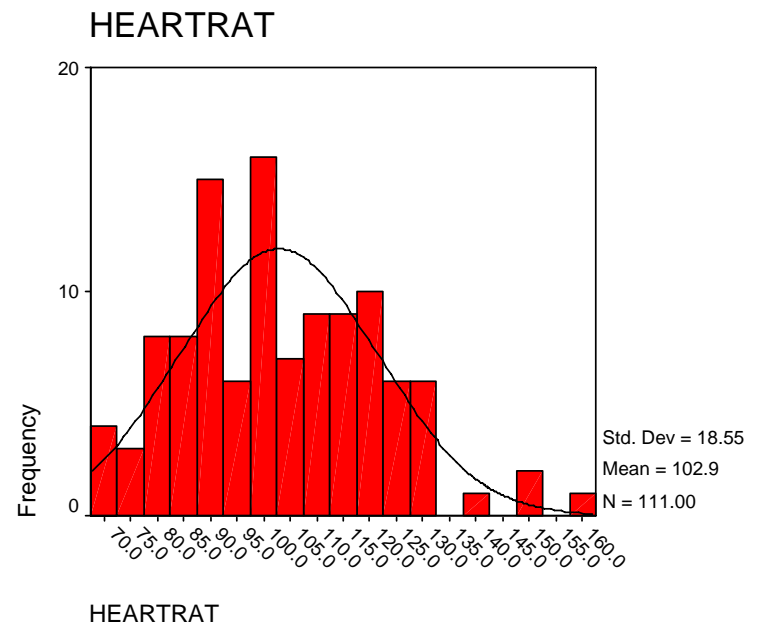

Figure 7. Histogram of heart rate baseline observations

Oxygen saturation was only available for 108 presentations. The mean $\mathrm{SpO} 2$ within the group is $93.2 \%$, the majority having been tested on atmospheric oxygen of $21 \%$. Twenty five percent of the people had a SpO2 percentage of less than $91 \%$ and in $25 \%$ of the presentations, the $\mathrm{SpO} 2$ was greater than $97 \%$. Caution must be read into these $\mathrm{SpO} 2$ results due to some of the results being read whilst on supplemental oxygen. Figure 8 presents quite a different pattern to that of the previous figure, with the results being skewed to the right. It also highlights that there was one person who had a very low saturation $(73 \%)$ recording.

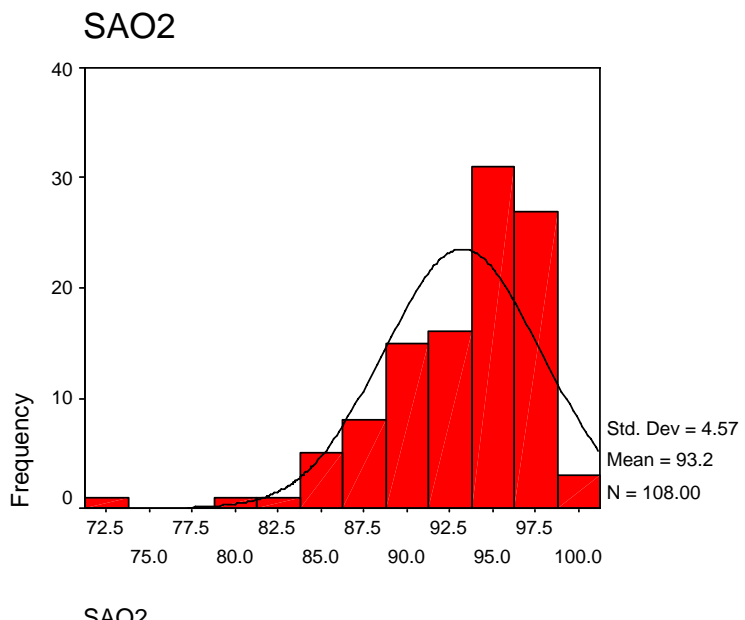

Figure 8. Histogram of SpO2 baseline observations

\section{Arterial Blood Gas}

Arterial blood gas measurement is invasive but a good measure of investigation of the respiratory status for hypoxia, hypercarbia and acidosis. The initial ABG has been 
determined as a blood gas within the first 5 hours of presentation. Table 10 presents data on arterial blood gas sampling of the $76(67 \%)$ presentations where this was undertaken.

Table 10. Summary of initial arterial blood gas results

\begin{tabular}{|l|r|r|r|r|}
\hline & \multicolumn{1}{|c|}{$\begin{array}{c}\text { PH } \\
\mathbf{n = 7 6}\end{array}$} & $\begin{array}{c}\text { PCO2 } \\
\mathbf{n}=\mathbf{7 6}\end{array}$ & \multicolumn{1}{c|}{$\begin{array}{c}\text { PO2 } \\
\mathbf{n}=\mathbf{7 6}\end{array}$} & \multicolumn{1}{c|}{$\begin{array}{c}\text { HCO3 } \\
\mathbf{n}=\mathbf{7 6}\end{array}$} \\
\hline Mean (SD) & $7.39(.07)$ & $6.18(2.26)$ & $11.00(5.4)$ & $26.81(5.25)$ \\
Median & 7.41 & 5.59 & 9.54 & 26.30 \\
Range & $7.16-7.58$ & $3.93-20.32$ & $5.66-37.73$ & $18.0-52.5$ \\
\hline
\end{tabular}

The mean for $\mathrm{pH}$ is 7.39 , being of normal value for the average adult (7.35-7.45), however slightly on the acidic side. Twenty five percent of the cases had a $\mathrm{pH}$ less than 7.35 and $50 \%$ of the presentations had a $\mathrm{pH}$ of between $7.35-7.43$. The median $\mathrm{pH}$ of 7.41 reflecting more dispersement of values greater than the mean value (7.39).

The $\mathrm{pCO}_{2}$ mean at 6.18 was slightly elevated above the normal limit. This reflects there was a level of hypercarbia across the sample, as the normal range is 4.5-6 kpa. Despite this elevation the mean $\mathrm{pH}$ has not been lowered indicating that the sample has some degree of compensation and this is expressed in the bicarbonate level being slightly elevated at 26.81. Twenty five percent of the cases have a $\mathrm{pCO}_{2}$ greater than 6.80 and $50 \%$ of the cases have a $\mathrm{pCO}_{2}$ between 5.07 and 6.80 . The $\mathrm{pO}_{2}$ mean value is 11.00 , being just on the normal value for any given adult (11-13). Again caution must be read into this value as some of the sample had supplemental oxygen while other recordings were off oxygen i.e. atmospheric levels of oxygen. Figure 9 presents the graphs for initial $\mathrm{ABG}$ for the variables of $\mathrm{pH}$ and $\mathrm{pCO}_{2}$.
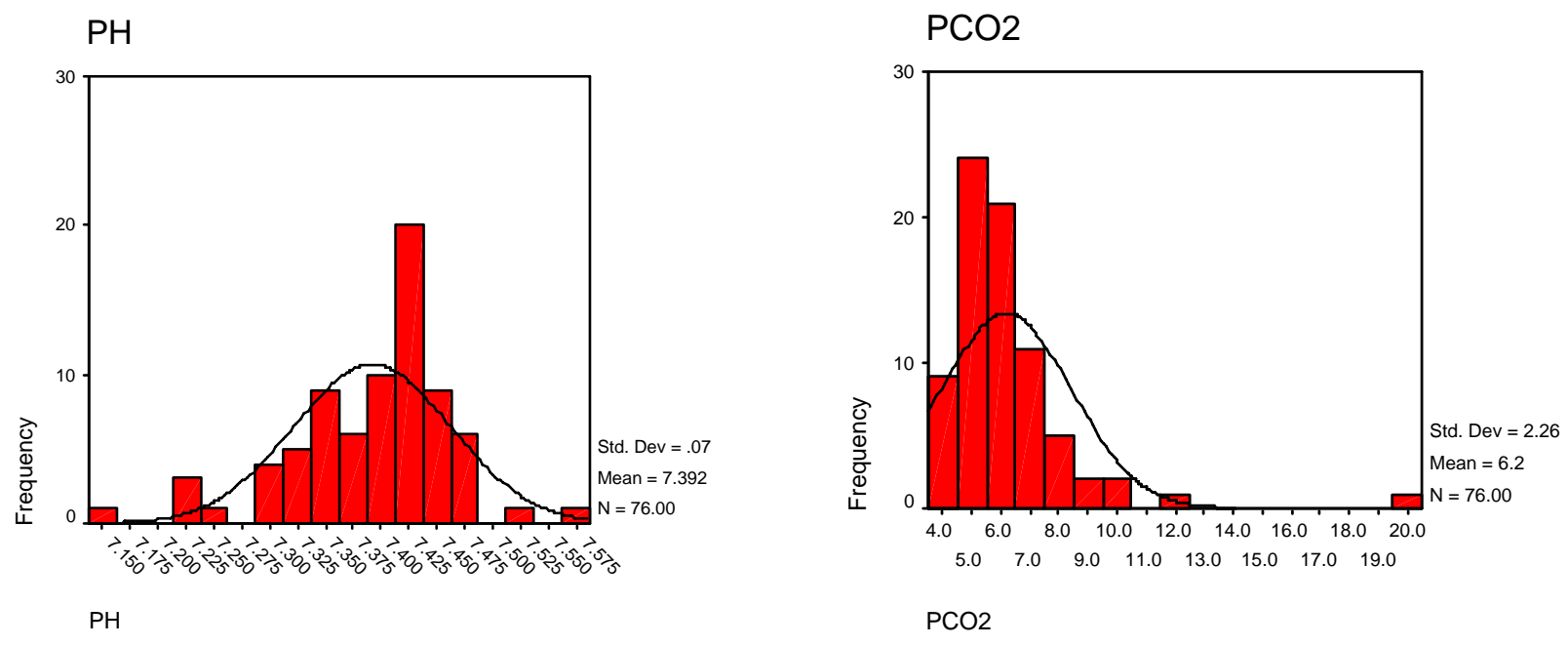

Figure 9. Histograms for initial ABG, $\mathrm{pH}$ and $\mathrm{PCO}_{2}$ levels 
Figure 9 shows even distribution of $\mathrm{pH}$ within the samples of $\mathrm{ABG}$, there is however large numbers within the data for the $\mathrm{pH}$ of 7.40. The $\mathrm{pCO}_{2}$ histogram shows large numbers of data within the normal and upper end of normal, observed above the curve within the histogram. There is one value greatly outside the range of data with a $\mathrm{pCO}_{2}$ of 20.32 .

Table 11 presents the analysis of the arterial blood gas for the $17(15 \%)$ presentations where a second ABG was taken.

Table 11. Summary of secondary arterial blood gas results

\begin{tabular}{|l|r|r|r|r|}
\hline & \multicolumn{1}{|c|}{$\begin{array}{c}\mathbf{p H} \\
\mathbf{n = 1 7}\end{array}$} & $\begin{array}{c}\mathbf{p C O} \\
\mathbf{n = 1 7}\end{array}$ & \multicolumn{1}{c|}{$\begin{array}{c}\mathbf{p ~ \mathbf { O } _ { 2 }} \\
\mathbf{n = 1 7}\end{array}$} & \multicolumn{1}{c|}{$\begin{array}{c}\mathbf{H C O}_{\mathbf{3}} \\
\mathbf{n = 1 6}\end{array}$} \\
\hline Mean (SD) & $7.35(.06)$ & $7.22(2.34)$ & $10.20(1.82)$ & $28.29(6.62)$ \\
\cline { 2 - 5 } Median & 7.34 & 7.15 & 10.71 & 27.55 \\
\cline { 2 - 5 } Range & $7.26-7.49$ & $3.77-13.62$ & $7.11-13.85$ & $18.10-44.90$ \\
\hline
\end{tabular}

From this small sample it can be seen that the mean $\mathrm{pH}$ has dropped to 7.35 from 7.39 in the $1^{\text {st }} \mathrm{ABG}$ sample. The mean $\mathrm{pCO}_{2}$ has increased to 7.22 from the $1^{\text {st }}$ sample of 6.18 and the mean $\mathrm{HCO}_{3}$ has increased from 26.81 in the $1^{\text {st }}$ sample to 28.29 and the mean $\mathrm{pO}_{2}$ has dropped to 10.21 from the $1^{\text {st }}$ sample value of 10.99 . Figure 10 shows a graphical presentation of the range of data for the second $\mathrm{ABG}$ results for $\mathrm{pH}$ and $\mathrm{pCO}$.

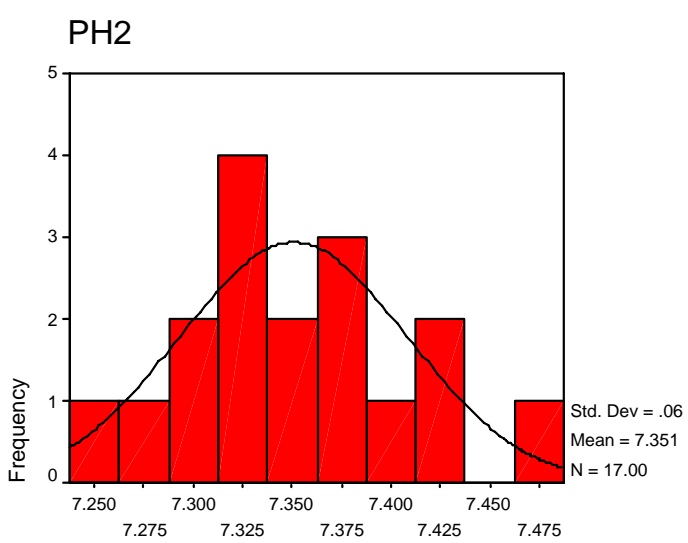

$\mathrm{PH} 2$

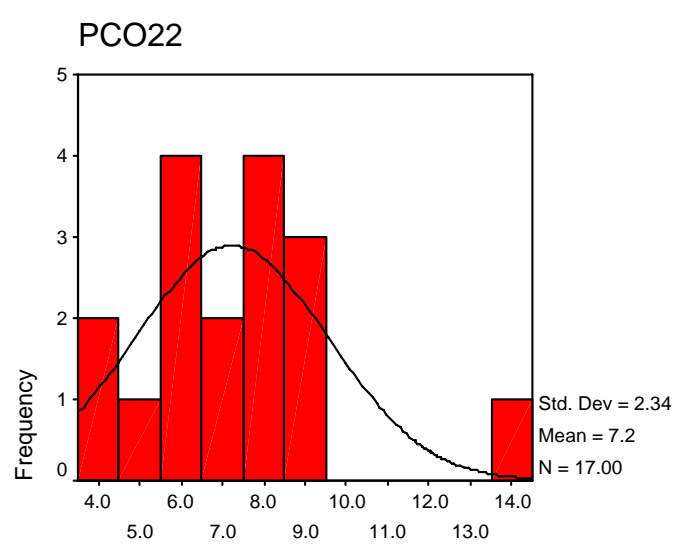

$\mathrm{PCO} 22$

\section{Figure 10. Histograms for secondary $\mathrm{pH}$ and $\mathrm{pCO}_{2}$}

The first of these two figures indicates that the $\mathrm{pH}$ results show an even distribution with slightly larger numbers in the 7.325 range, and a few outside the range distribution in both higher (7.48) and lower range (7.25). The $\mathrm{pCO}_{2}$ range shows uneven distribution of 
data, larger numbers presenting in 6.0 and 8.0 values, the obvious outside the range of data is that of 14.0. This pushes the mean (7.22) higher than the median figure (7.15).

Table 12 presents the summary results from the pulmonary lung function tests.

Table 12. Pulmonary Lung function testing statistics

\begin{tabular}{|l|r|r|r|}
\hline & \multicolumn{1}{|c|}{$\begin{array}{c}\text { FEV1 } \\
\mathbf{n = 9 2}\end{array}$} & $\begin{array}{c}\text { FVC } \\
\mathbf{1 = 9 1}\end{array}$ & \multicolumn{1}{c|}{$\begin{array}{c}\text { Ratio } \\
\mathbf{n = 9 2}\end{array}$} \\
\hline Mean (SD) & $1.07(.55)$ & $2.24(.88)$ & $47.23(13.38)$ \\
\cline { 2 - 4 } Median & 0.91 & 2.07 & 46.00 \\
\cline { 2 - 4 } Range & $0.30-2.63$ & $0.72-4.61$ & $23-87$ \\
\hline
\end{tabular}

This gives the interpretation of the lung function and degree of limitation with the patients of the 92 tested within the sample. The mean ratio for the group is $47.23 \%$. The mean volume ratio as a group has decreased by $26 \%$, from the expected $73 \%$ ratio mentioned in the physiology chapter. Twenty five percent of the cases had a ratio of less than $37 \%$, and $25 \%$ had a ratio of greater than $56 \%$. In every case within Table 12 the mean is higher than the median number, reflecting that the majority of people had lower lung function scores. Figure 11 shows graphical range of data in the ratio.

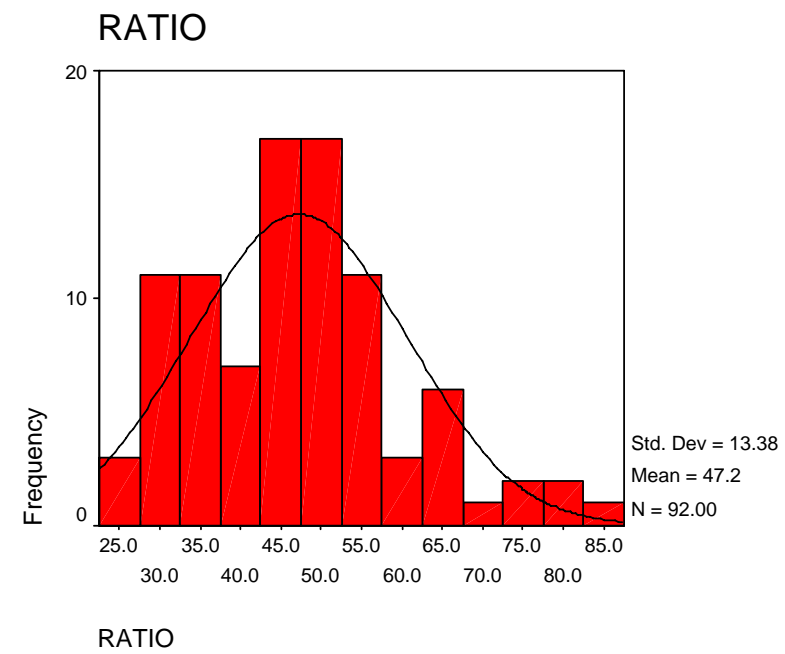

Figure 11. Histogram for ratio statistics

\section{Lung Function Testing}

The results of an analysis of the lung function results by gender variables found that mean FEV 1 was lower in males $(1.201)$ than female $(0.951)$ population. The differences in ratio values (FEV $/ \mathrm{FVC}$ ) were $45.8 \%$ for male and $48.4 \%$ for female. 


\section{NIV Initiation}

The analysis found that $9(8 \%)$ presentations were given Non Invasive Ventilation (NIV), 104 had no NIV use during the presentation stay (missing data $n=2$ ). To note none of the sample were intubated during the 3 month study.

Elevation in $\mathrm{pCO}_{2}$ and a $\mathrm{pH}$ lower than 7.35 were tested against the use of NIV within the sample. This was to find those who have respiratory acidosis (by $\mathrm{pH}$ indication) and had NIV implemented. Of the 30 presentations with hypercarbia, eight (28\%) had noninvasive ventilation used during assessment or the following treatment in hospital. Of the 16 presentations with respiratory acidosis, six (37.5\%) had the treatment of NIV and 10 $(62.5 \%)$ of them did not.

\section{Length of Stay}

The mean length of stay for the 114 presentations was 5.09 (SD 5.03) days. Figure 12 presents the graphical histogram for length of stay. The graph shows one person stayed 35 days, which is hugely outside the range of data, the majority of people stayed only 10 days.

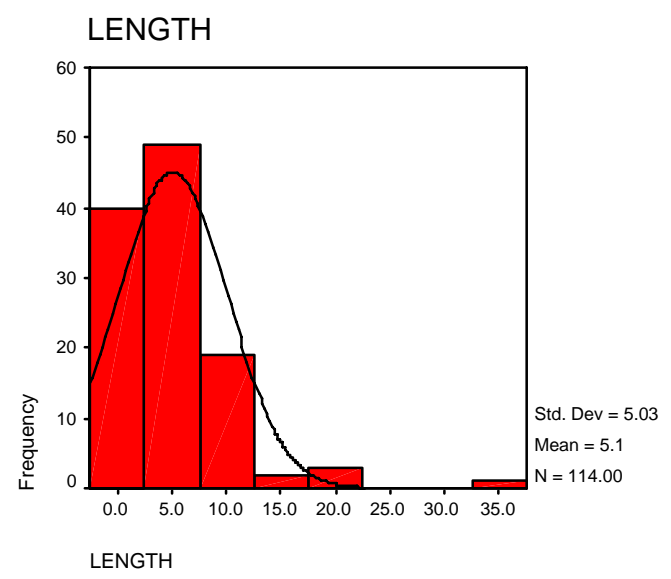

Figure 12. Histogram for length of stay

Thirty three percent of the sample only stayed one day. A one day-stay does not necessarily mean they stayed 24 hours but stayed anything from 30 minutes to a maximum of 24 hours, regardless of whether the stay was only in the ED or the person was admitted to a medical ward. Fifty percent of the population stayed up to 4 days and $75 \%$ of the population stayed up to 7 days with the large majority $(95.5 \%)$ of patients staying less than two weeks. 


\section{Section 4 - Hypercarbic Sub Group Investigation}

Following the initial analysis the sample of the 76 presentations that had had an ABG recorded were divided into two groups based on their ABG results. These groups were a hypercarbic group $(n=30)$, and a non-hypercarbic group $(n=46)$. The hypercarbia group included all presentations where the $\mathrm{ABG}$ results included a $\mathrm{pCO}_{2}$ greater than the normal upper limit of $6 \mathrm{kpa}$. The non-hypercarbic group includes all presentations where the $\mathrm{pCO}_{2}$ was less than $6 \mathrm{kpa}$. The term non-hypercarbic is used in preference to the word normal, although in some presentations, people's $\mathrm{pO}_{2}$ were abnormal, indicating hypoxia as opposed to hypercarbia. Despite this, for this hypercarbia analysis they were still termed non-hypercarbia (normal). Of note there were 38 presentations that did not have an $A B G$ result recorded. The focus in this section is only on the hypercarbia and non-hypercarbia group as the interest was to establish whether there is a definable group with hypercarbia who present to ED. The analyses reported in the previous sections were repeated on these two subgroups. Although it was intended that inferential statistics would be carried out, as the descriptive findings emerged, cell size numbers meant that such analyses would not generate meaningful results.

The 76 presentations with an ABG result involved 58 individuals. Table 13 presents the repeat presentations by group.

Table 13. Number of times individuals presented by hypercarbia status

\begin{tabular}{|c|r|r|r|}
\hline No of admissions & $\begin{array}{c}\text { Hypercarbia } \\
\text { only } \\
\mathbf{n = 1 8}\end{array}$ & $\begin{array}{c}\text { Non- } \\
\text { Hypercarbia } \\
\text { only } \\
\mathbf{n = 3 5}\end{array}$ & $\begin{array}{c}\text { Hypercarbia } \\
\text { and non- } \\
\text { hypercarbia } \\
\mathbf{n}=\mathbf{5}\end{array}$ \\
\hline $\mathbf{1}$ & $13(72.2 \%)$ & $29(82.9 \%)$ & 0 \\
\hline $\mathbf{2}$ & $5(27.8 \%)$ & $6(17.1 \%)$ & $3(60.0 \%)$ \\
\hline $\mathbf{3}$ & 0 & 0 & $2(40.0 \%)$ \\
\hline
\end{tabular}

Eighteen (31\%) of these individuals presented only with hypercarbia, $35(60 \%)$ only presented in the non-hypercarbia group and five (9\%) presented with either hypercarbia and non-hypercarbia. Of these five, two people presented three times and two of the three presentations were hypercarbic. It would appear then that there is no clear group of people who presented to ED over this time who only fall into the hypercarbia group. Of the hypercarbia group, just under three quarters (72.2\%) of the people presented once in the 3 months and just over a quarter (27.8\%) presented twice. In comparison, of the non- 
hypercarbia group over $80 \%$ presented once and fewer than a fifth $(17.1 \%)$ present twice. Prior to undertaking further analysis a brief review of the five people who presented at different times with hypercarbia and non-hypercarbia (mixed presentations) is provided in Table 14. The presentations are in order of admission.

Table 14. Repeat presentations with both hypercarbia and non-hypercarbia conditions

\begin{tabular}{|l|r|r|r|r|}
\hline patient & \multicolumn{1}{|l|}{$\mathbf{P C O}_{2}$} & \multicolumn{1}{|l|}{$\mathbf{P O}_{2}$} & \multicolumn{1}{l|}{$\mathbf{H C O}_{3}$} \\
\hline $\mathbf{1}$ & 7.466 & 4.19 & 12.49 & 22.1 \\
\hline & 7.241 & 6.22 & 6.57 & 19.6 \\
\hline & 7.232 & 6.42 & 7.88 & 19.8 \\
\hline $\mathbf{2}$ & 7.458 & 4.67 & 9.21 & 24.3 \\
\hline & 7.222 & 9.66 & 15.16 & 29.1 \\
\hline $\mathbf{3}$ & 7.352 & 7.01 & 6.06 & 28.5 \\
\hline & 7.35 & 5.93 & 9.70 & 24.0 \\
\hline $\mathbf{4}$ & 7.398 & 5.07 & 7.68 & 22.9 \\
\hline & 7.391 & 6.03 & 9.00 & 26.8 \\
\hline $\mathbf{5}$ & 7.428 & 5.23 & 9.50 & 25.3 \\
\hline & 7.356 & 6.17 & 7.18 & 25.9 \\
\hline Average & 7.354 & $\mathbf{6 . 0 5}$ & $\mathbf{9 . 1 3}$ & $\mathbf{2 4 . 3 9}$ \\
\hline
\end{tabular}

Table 14 shows that the individuals who have a mixed presentation of hypercarbia and non-hypercarbia had a $\mathrm{pCO}_{2}$ ranging from $4.19 \mathrm{kpa} 9.66 \mathrm{kpa}$. This potential $3^{\text {rd }}$ subgroup has a mean $\mathrm{pCO}_{2}$ after averaging all $\mathrm{pCO}_{2}$ levels of $6.05 \mathrm{kpa}$. Of note, individuals numbered 1, 4 and 5 did not have a blood gas done during other presentations they had during the 3 months.

Despite the lack of a clear hypercarbic group, further analysis was undertaken to determine whether there were any apparent differences between those who were in the hypercarbia group only compared with those in the non-hypercarbia only. The tables that describe the data also include the five people who were in the combined group (that is presented at different times with hypercarbia and non-hypercarbia) but these people are not discussed in the texts as the percentages when only five people are involved are naturally very high. The people who presented in both groups are discussed as appropriate. The analysis of this data focused on describing the individuals in these groups to see whether there were any general patterns in how people presented. This analysis by its very nature was exploratory but was considered important to start and 
create a picture of people with COPD presenting to ED. Table 15 presents the demographic and clinical data of the three groups.

Table 15. Demographic, smoking history and industrial exposure by hypercarbic status

\begin{tabular}{|c|c|c|c|}
\hline & $\begin{array}{l}\text { Hypercarbia } \\
\qquad \begin{array}{c}n=18\end{array}\end{array}$ & $\begin{array}{c}\text { Non- } \\
\text { hypercarbia } \\
n=35\end{array}$ & $\begin{array}{c}\text { Combined } \\
\text { presentations } \\
\mathbf{n}=5\end{array}$ \\
\hline \multirow{2}{*}{ Gender $\begin{array}{r}\text { Male } \\
\text { Female }\end{array}$} & $4(22.2 \%)$ & $15(42.9 \%)$ & $3(60.0 \%)$ \\
\hline & $14(81.8 \%)$ & $20(57.1 \%)$ & $2(40.0 \%)$ \\
\hline \multirow{4}{*}{$\begin{array}{rr}\text { Ethnicity } & \text { Maori } \\
\text { Pakeha } \\
\text { Indian } \\
\text { European } \\
\end{array}$} & $3(16.7 \%)$ & $3(8.6 \%)$ & 0 \\
\hline & $12(66.7 \%)$ & $23(65.7 \%)$ & $3(60.0 \%)$ \\
\hline & $1(5.6 \%)$ & $1(2.9 \%)$ & 0 \\
\hline & $2(11.1 \%)$ & $8(22.9 \%)$ & $2(40.0 \%)$ \\
\hline \multirow{3}{*}{$\begin{array}{r}\text { mean }(\mathrm{SD}) \\
\text { median } \\
\text { range }\end{array}$} & $72.9(7.91)$ & $70.5(10.15)$ & $77.3(6.77)$ \\
\hline & 71 & 70 & 78 \\
\hline & 57-91 & $55-87$ & $67-86$ \\
\hline \multirow[t]{2}{*}{ Smoking yes } & $15(83.3 \%)$ & $30(88.2 \%)$ & $5(100 \%)$ \\
\hline & $3(16.7 \%)$ & $4(11.8 \%)$ & 0 \\
\hline \multirow[t]{2}{*}{ Industrial } & $1(5.6 \%)$ & $5(14.3 \%)$ & 0 \\
\hline & $17(94.4 \%)$ & $30(85.7 \%)$ & $5(100 \%)$ \\
\hline
\end{tabular}

This table shows that the gender distribution in the groups is very different, with just over $80 \%$ being female in the hypercarbia group and less than $60 \%$ being female in the nonhypercarbia group. The pattern for ethnicity was also different in respect of Maori and European. Although the numbers are small there was a higher percentage of Maori $(16.7 \%)$ in the hypercarbia group compared with the non-hypercarbia group $(8.6 \%)$. The opposite trend was for the Europeans, where there was a higher percentage $(22.9 \%)$ in the non-hypercarbic group. The mean age (72.9 years) for hypercarbia group indicates that this group was slightly older than the non-hypercarbia group (70.5 years). The figures for smoking indicate a small difference between groups, and that those in the nonhypercarbic group were more likely to have had an industrial exposure.

Table 16 presents the findings of the clinical baseline data for the hypercarbia presentations and the non-hypercarbia group. 
Table 16. Summary baseline observations by hypercarbia group

\begin{tabular}{|l|r|r|r|}
\hline & \multicolumn{1}{|c|}{ Resp rate } & \multicolumn{1}{c|}{ Heart rate } & \multicolumn{1}{c|}{ SpO2 } \\
\hline Hypercarbia group $\mathrm{n}=18$ & & & \\
\cline { 2 - 4 } $\begin{array}{l}\text { Mean (SD) } \\
\text { Median }\end{array}$ Range & $26.55(8.08)$ & $105.82(15.97)$ & $91.68(6.07)$ \\
\cline { 2 - 4 } $\begin{array}{l}\text { Non-Hypercarbia group } \mathrm{n}=35 \\
\text { Mean (SD) }\end{array}$ & 24 & 103.5 & 92 \\
\cline { 2 - 4 } $\begin{array}{l}\text { Median } \\
\text { Range }\end{array}$ & $12-46$ & $84-140$ & $73-98$ \\
\cline { 2 - 4 } & $27.35(7.10)$ & $104.78(17.94)$ & $92.72(4.47)$ \\
\cline { 2 - 4 } & 28 & 104 & 93 \\
\hline
\end{tabular}

This table indicates that the groups heart rates and $\mathrm{SpO}_{2}$ were similar, but that there may have been a difference between the groups related to respiratory rate, as the median in the non-hypercarbia group at 28 was four breaths larger than the hypercarbia group.

Of the 23 presentations where an individual had hypercarbia (the hypercarbic group and the combined group); 12 (52\%) presentations had a ph below 7.35, indicating that the person had acute hypercarbia (acute respiratory failure), the other 11 (48\%) presentations had a normal $\mathrm{pH}$ indicating that they were compensating either chronically or had been in an exacerbation for more than 72 hours. In comparison of the 41 presentations where an individual was non-hypercarbic, one person had a $\mathrm{pH}$ lower than 7.35, 9 had presentations above 7.45 , and the remainder had a normal $\mathrm{pH}$.

To conclude over $30 \%$ of the exacerbations make it into the hypercarbia group, with the dominance of female gender. Maori were over represented in the hypercarbia group (almost double that of other) along with a slight rise in percentage of the Pakeha.

Table 17 presents the data of subgroups tested against previous diagnosis one and two to look for trending within the diagnosis variation within the sub groups. 
Table 17. Statistics for previous diagnosis one and two by group

\begin{tabular}{|l|r|r|}
\hline & \multicolumn{2}{|c|}{ Combined Diagnosis } \\
\hline & Hypercarbia & Non-hypercarbia \\
\hline Emphysema & $15(48.4 \%)$ & $25(50.0 \%)$ \\
\hline Asthma & $8(25.8 \%)$ & $11(22.0 \%)$ \\
\hline CHF & $5(16.1 \%)$ & $8(16.0 \%)$ \\
\hline Bronchitis & & $2(4.0 \%)$ \\
\hline Cor-pulmonale & $1(3.2 \%)$ & $2(4.0 \%)$ \\
\hline $\begin{array}{l}\text { Interstitial lung } \\
\text { disease }\end{array}$ & & $1(2.0 \%)$ \\
\hline Bronchiectasis & $1(3.2 \%)$ & \\
\hline Pneumonia & & $1(2.0 \%)$ \\
\hline Pulmonary TB & $1(3.2 \%)$ & \\
\hline
\end{tabular}

Table 17 presents the data on the combined diagnosis one and two within the subgroups of hypercarbia and non-hypercarbia. With both of the subgroups emphysema was present in approximately half of the subgroup. Following emphysema, was asthma with around a quarter of the subgroups makeup, and CHF had approximately $16 \%$.

Table 18 presents the data from Lung function testing within the subgroups.

Table 18. Statistics for lung function testing

\begin{tabular}{|l|r|r|r|}
\hline & \multicolumn{1}{|c|}{ FEV1 } & \multicolumn{1}{|c|}{ FVC } & \multicolumn{1}{c|}{ RATIO } \\
\hline Hypercarbia & & & \\
\cline { 2 - 4 } $\begin{array}{l}\text { Mean (SD) } \\
\text { Median }\end{array}$ Range & $0.55(.16)$ & $1.45(.36)$ & $39.16(9.75)$ \\
\cline { 2 - 4 } $\begin{array}{l}\text { Non-hypercarbia } \\
\text { Mean (SD) }\end{array}$ & 0.59 & 1.50 & 40.00 \\
\cline { 2 - 4 } $\begin{array}{l}\text { Median } \\
\text { Range }\end{array}$ & $0.30-0.75$ & $0.72-2.11$ & 23.55 \\
\cline { 2 - 4 } & $1.39(.57)$ & $2.63(.80)$ & $50.29(13.21)$ \\
\cline { 2 - 4 } & 1.33 & 2.62 & 51.00 \\
\cline { 2 - 4 } & $0.44-2.63$ & $1.17-3.73$ & $27-82$ \\
\hline
\end{tabular}

The subgroup analysis of FEV 1 and ratio shows notable differences in the results, the hypercarbia group has both lower values for $\mathrm{FEV}_{1}$ and ratio percentage. The FEV 1 value increases by $60 \%$ comparing the hypercarbia group $(0.55 \mathrm{~L}, \mathrm{n}=17)$ to the non-hypercarbia group $(1.39 \mathrm{~L}, \mathrm{n}=30)$. The ratio increases by $11 \%$ from the hypercarbia group $(39 \%$, $\mathrm{n}=17)$ to the other group $(50 \%, \mathrm{n}=30)$.

Length of stay was repeated for the subgroups of hypercarbia and non-hypercarbia. Results show that mean length of stay for hypercarbia was 6.8 days and 6.9 days for nonhypercarbia groups. Those who did not have an ABG taken had a length of stay of 2.8 days. 


\section{Summary}

This chapter has presented the findings related to 114 presentations to ED over a 3-month period. Analysis of these findings found that there was no clear group of people who only presented to ED with hypercarbia. The next chapter discusses these findings from the perspective of what these may indicate clinically, how these findings relate to what is already understood about COPD and where appropriate raises implications for improving ED practice for people who present with an exacerbation of COPD. 


\section{Chapter 6: Discussion}

The discussion chapter takes the findings presented in the previous chapter and interprets what these mean from a nurse researcher's point of view, incorporating the aims of the study. The layout of this chapter follows the alignment of the findings, starting with demographic features followed by clinical presentations of all presentations using the variables contained within the data extraction tool. The chapter concludes with a discussion related to the subgroup analysis for hypercarbia.

Although a small study, the results of this study provide important information about who presents to emergency department (ED) with an exacerbation of chronic obstructive pulmonary disease (COPD). The research also answered the question, within those who present with an exacerbation of COPD, is there a subgroup of people who present with hypercarbia, and if there is, what are the demographical make up of this group and how do they differ from those who present who are non-hypercarbic?

\section{The Sample}

Over the 92 days in which records were examined, 114 presentations were identified for an exacerbation of COPD. This number equates to 1.24 people per day or 38 people presenting to ED each month with COPD, indicating that people with COPD are a group that ED nurses have regular contact with. The mean time of presentation is $1.31 \mathrm{pm}$, may be reflective of people having been to their GP in the morning who then referred them into the hospital. Arrival mode to the ED shows that $70 \%$ of the sample presented by ambulance and the other $30 \%$ in private cars. This $70 \%$ reflects that the majority of the sample is in either respiratory distress or need treatment prior to hospital in the form of oxygen and broncho-dilators nebulised on-route. The pre-hospital experience of people was not examined within the study. However, one could presume the proceeding events with the nature of an exacerbation of COPD. Environmental triggers an exacerbation, the usual methods of coping are utilised, these are difficult during sleeping especially lying flat, exhaustion results as all their energy is used to maintain the work of breathing and presentation to the ED for treatment is the last result for the individual.

Re-presentation figures for the department findings show that $35 \%(n=25)$ of the sample of individuals attended the ED more than once over the 3-month period indicating how 
serious this condition can be at the time of an exacerbation. It is noted that no one attended 4 times within that period, however $8.5 \%(n=6)$ present 3 times and $5.5 \%(n=4)$ present 5 times. The high re-presentation figures are similar to Cydulka et al.'s (2003) findings. Cydulka et al. found that $15 \%$ of people within their study reported they relied on the ED as their usual care provider, and considered the high re-admission rates (43\%) were because of that. It is not known whether people in this study considered the ED as part of their usual care services. However, the high re-presentation rates indicates that additional work must be done to minimise the severity of the exacerbations and maintain wellness of the COPD population within the community, this in turn should reduce the demand on the hospital presentations at the emergency department. This work could be undertaken by the general practitioner (GP), practice nurse or nurse specialist working within the community setting. Such community-based work aligns to the Ministry of Health's (MOHs) aim as discussed later within this chapter about implementing the primary health strategy $(\mathrm{MOH}, 2003 \mathrm{~b})$. Further research should be done to better understand what happens in the community prior to people presenting to ED to guide the community management of exacerbations.

\section{Individuals}

The demographics of the study start with gender, the female population making up $62 \%$ of the sampled population and $38 \%$ being male. As a clinical nurse coordinator it is astounding that the division is so big, from general observation during working on the floor I would have thought that the male presentation figures to the Tauranga emergency department (ED) would have been closer to the 50\%. It must be noted that these gender percentages are of a convenience sampling over a 3-month winter period on presentation to the Tauranga ED. The MOH (2003 a) census states that COPD prevalence in NZ for adults over the age of 45 years is $13.4 \%$, with $44 \%$ in males and $56 \%$ in females. Unfortunately these are the only figures available, it would have been more beneficial to my research if I could get figures for 55 years and above. The Ministry's figures were from those who self-reported that they suffer the disease of COPD in a census in 2003. So one should not read too much into the difference in percentages from the Ministry to the sample of population within this study, as one is ED presentation figures and the other being a self reported illness.

Ethnicity within the study has been surprising, but once again this could just be situational due to the convenience sampling done over the winter months to the ED. 
Although the $\mathrm{MOH}$ portrait of health states that Maori have the highest incidence of asthma within New Zealand (NZ), figures from this research show the percentage of Maori who presented to the ED (11\%) was lower than the $14.7 \%$ of Maori in the general population. I have been unable to locate any research studies with regards to COPD from my literature search to compare the ethnicity in NZ population and presentation figures.

Age presentation was captured from 55 years and above, an even spread of age values were obtained within the sample, a mean of 71 years, with a median of 71 reflects an normally distributed sample. It is not unexpected that smaller numbers were noted above the age of 90, one could presume that people with COPD do not often survive to very old age as the combination of age and smoking related disease processes and years of COPD probably result in people dying younger. In the future increased numbers of this elderly age-group are expected, as the COPD population gets older and more of the stable asthma population succumb to limitation in respiratory function and the non-reversible element is incorporated by COPD diagnosis.

The documentation of tobacco exposure identified as a problem in the pre-testing phase continued to be present through out the study. Many of the patients' clinical notes would only say a person was a non-smoker or a smoker and provide no details about the number of years that they smoked or they would document the levels of consumption of tobacco, but not the number of years a person smoked. Often from looking at other presentations of the same patient I could find a numerical pack year value, this value sometimes changed from history taker to history taker, but still remained within plus or minus four years. Some people had a consumption value and a year they gave up documented, I had to take an average age of starting smoking of 21 years (conservative), this does have some limitations to the study by trying to second guess the age of induction of smoking, however the statistic was important to include rather than note that they were a smoker and omit the value. The last group of smoking population that had no documentation of length and consumption had the pack year value omitted from the data sheet.

Tobacco exposure shows that $80 \%(\mathrm{n}=57)$ of the individuals had exposure to smoking, 26 $(45.6 \%)$ were male and $31(53.4 \%)$ were female. The number of the males with a recorded exposure was $96 \%(\mathrm{n}=26)$. Ethnicity showed a surprise, 92\% of the European group had a history of smoking compared to $88 \%$ of the Maori population and $82 \%$ of the Pakeha population. The higher European rate may reflect that many European countries have a larger smoking population within the European countries, in my experience 
cigarettes traditionally have been less taxed and promoted to a higher level than in New Zealand (NZ). Smoking figures in NZ are lower than some of the bigger European countries like the United Kingdom (UK) and France where many people choose to smoke for social and cultural reasons. Booker (2003), a nurse researcher who has written extensively about smoking and its effects argued that 15-20\% of smokers develop COPD. This can be related to smoking figures from the Ministry of Health (2005) which show that $24.4 \%$ of people aged 16 years and above smoke in NZ. This represents as a big problem within the future in NZ as this smoking population gets older, and continued exposure leads to non reversible lung damage, which brings them into the lung disease arena of COPD over time. The risk factor of smoking in COPD has been documented and discussed within the physiology chapter, long exposure reduces the pulmonary function and progression into sporadic exacerbations of a chronic respiratory illnesses triggered by various seasonal and unknown factors. The extent of the damage done to lungs by smoking is highlighted by the finding that almost all (97\%) of those who had emphysema had a history of smoking. Another notable result was that over half of those who had asthma (58\%) also a smoking exposure. Of those who did not smoke, the commonest diagnosis was asthma.

The results of consumption of tobacco classed as pack years of 34.5 years were considerably lower than Cydulka et al.'s (2003). Findings of 57 pack years for exsmokers and 65 pack years for current smokers. Booker (2005) discusses that COPD can happen in ex-smokers but a significant smoking history of 15-20 pack years can to lead to COPD. The possible explanation of the differences is that Booker's studies were from an out of hospital population, where my study concerned those who were experiencing an exacerbation requiring a presentation to ED. Cydulka's study on the other hand was similar to this research as they were concerned about exacerbation of COPD Presenting to ED.

The pulmonary lung function test findings of a mean $\mathrm{FEV}_{1}$ of 1.07 litres (L) with a median of $0.91 \mathrm{~L}$ reflects that many people had a poor volume expelled in one second. The FVC mean value of $2.24 \mathrm{~L}$ and the median of $2.07 \mathrm{~L}$ indicate many people had a large reduction in the amount of air that could be expelled. The normal figures relating to lung function come from a prolific writer on ventilation and pulmonary pathology, West (2003). West describes that a normal healthy adult can expel $73 \%$ of their total lung volume within one second $\left(\mathrm{FEV}_{1} / \mathrm{FVC}\right)$. The mean ratio within this research is $47.2 \%$, 
showing that the mean percentage is $32.8 \%$ lower than the average normal according to West (73\% - 47.2\%), through the lung being diseased and having restricted air flow.

Although industrial exposure to irritants and pollutants is known to contribute to COPD only $11.2 \%(n=8)$ of the sample in this research had a documented exposure. All those with an exposure were of Pakeha ethnicity and the majority (62.5\%) were male. The finding that $8.5 \%$ had exposure to both variables (smoking and industrial) compared to only $2.8 \%$ having a single exposure to industrial causes was an interesting finding, as many writers have put a major emphasis on industrial exposure rather than smoking exposure.

\section{Diagnosis}

The findings that the most common previous diagnosis people had was emphysema is understandable given the prevalence of smoking history from the studied sample. The reality of this diagnosis is that years of repetitive airway constriction, mucous production and inflammation lead to a slow progression of lower airway dilation and structural breakdown with or without periods hypoxia causing damage leading into a non-reversible pattern of disease noted by diaphragmatic enlargement and distal airway destruction, so called emphysema. Cor-pulmonale, characterised by right sided heart enlargement from pulmonary hypertension and chronic hypoxia, is linked with emphysema as corpulmonale always follows this primary diagnosis over years of multiple exacerbations.

Authors McCrory, Brown, Gelfand, \& Bach (2001) discuss in a paper written about how to manage acute exacerbations of COPD people in USA, that $85 \%$ of the underlying primary diagnosis of COPD is chronic bronchitis, and emphysema accounts for the other $15 \%$. According to Murphy et al. (2001 (b)) many exacerbations of COPD can be hard to diagnose and treat from the emergency presentation as $84 \%$ of the diagnoses are made up of three primary illnesses (asthma, emphysema and CHF). Treatment patterns may follow alternative pathways until clinical improvement is shown within the patient.

However, only $8 \%$ of people in this study were diagnosed with bronchitis. There are several possibilities for the differences in these results. From my research it is possible that the primary diagnoses recorded are not accurate. The notes of many of the people within the sample sometimes indicated an un-clear diagnostic history. Clarifying and coding diagnosis often involved the notes from several admissions. Many people's 
histories indicated that they had had a mid-life diagnosis of asthma, which became their primary diagnosis. The individual, possibly never having had asthma before, accepted the diagnosis and understood they were being treated by the GP for asthma. The authors (McCory et al. 2001) suggest that this asthma could be chronic bronchitis with regular inflammation and mucous plugging with infective elements during susceptible periods. There may be a gap in the system between what is considered a diagnoses in the community with that of the hospital. This could mean that all of the asthma group within this study could actually have bronchitis. Less than half (40\%) of those with primary asthma did not smoke having suffered asthma in their childhood, the others however had smoking exposure over a period of time. It could also be noted that asthma has affected the sample for greater than 40 years, giving many exacerbations of asthma over a long time period. This can affect the normal structures within the lung, through periodic hypoxia, mucous production and airway inflammation leading to alveolar breakdown and enlargement. The general falling into the COPD disease bracket and a chronic condition now results. The other part of the population noted as asthma had induced asthma later in life, presumably from the effects of tobacco abuse over time affecting the lower airway structures.

The finding of congestive heart failure (CHF) as the third biggest diagnosis could reflect that many of the reasons for an admission were not clear-cut. These are a fine balance between COPD and CHF, deterioration in one can lead to a deterioration in another. The clinical picture is often masked and complicated due to the complexity of these patients.

It is interesting to note that only one case of pneumonia was found as potentially people with COPD develop a general chest infection precipitating or triggering an exacerbation causing an admission for the patient. It is my experience that many people with exacerbations of COPD are placed on intravenous antibiotics as a treatment, with or without neutrophilia (rise in the white cell count in the blood). Other cases of interstitial lung disease, bronchiectasis and pulmonary tuberculosis (one case only for each) are isolated cases not usual to the COPD grouping but are either idiopathic or congenital conditions affecting lung function either by affecting normal lung tissue from functioning normally or causing fibrosis which therefore causes the normal lung tissue to destruct and change its function.

The picture of previous diagnoses found in this research would appear to be as complex as that found by Murphy et al (2001 (b)). According to these authors many exacerbations 
of COPD can be hard to diagnose and treat from the emergency presentation as $84 \%$ of the diagnoses are made up of three primary illnesses (asthma, emphysema and CHF). An individual's treatment pattern may therefore need to follow alternative pathways until clinical improvement is shown within the patient.

Despite this complexity, alternative ways to manage people with an exacerbation of COPD need to be explored. The management including monitoring, intravenous antibiotics, steroids and air driven nebulisers, could be done within the home and/or GP rooms thus freeing up hospital beds. Community management would also provide a better service for the COPD patient, particularly if the exacerbation is picked up early enough, avoiding admission to hospital and transmission of infection to other people. The Ministry of Health (NZ) backs this up with guidelines from a primary healthcare strategy paper, stating that they aim to integrate primary care focussed health education and management with preventative care (MOH, $2003 \mathrm{~b})$.

\section{Supplemental Oxygen}

The finding that the majority of people who presented with an exacerbation of COPD arrived at ED via the ambulance service (70\%) may be reflective of people living alone, having no transport or being extremely unwell. The application of supplemental oxygen given in an ambulance would appear to have relieved the symptoms of shortness of breath (SOB) and reduced the levels of anxiety or stress with several of those who presented as their conditions was such that they did not require arterial blood gases. However, this is where potential over-oxygenation can present and change the clinical situation with the patient, if they have a respiratory acidosis due to the ineffective gas exchange due to lung disease and breakdown of normal tissue. As noted in the literature review, Ting (2004) argues that hyperoxic therapy can be detrimental to the older asthma patient, although certainly some oxygen is needed for the exacerbation but an uncontrolled excess may and can be detrimental to the patient. Murphy et al (2001 (a)) advise within their guidelines that anyone who lives greater than 15 minutes duration away from the hospital has a greater risk of hypercarbia and the potential clinical risk dramatisation from this. Considering the diversity of Tauranga districts and city, many of the people who presented over this 3-month period may well have travelled greater than 15 minutes, bringing them into the at-risk category of having hypercarbia by the time they arrived at the ED. The problem of susceptible hypercarbia individuals could be minimised if the bronchial dilators could be driven by a different means such as 
compressed air within the ambulance. Compressed air is often used in the patients' homes and in ED. With oxygen nebulisers, six to eight litres per minute is needed to atomise the liquid bronchial dilator, in effect providing an excess of oxygen to the patient during the 10 to 15 minutes the nebuliser is working. Compressed air could drive the nebuliser within the ambulance, to treat the hypoxia, nasal oxygen can be delivered at 2-3 litres per minute, Murphy et al (2001 (a)) discuss that with hypercapnic COPD, nasal oxygen is only recommended in the instance of air driven nebulisers, all other oxygen should be delivered by a variable concentration mask at a low constant percentage.

\section{Baseline Observations}

The baseline respiratory rate $(\mathrm{RR})$, heart rate $(\mathrm{HR})$ and saturation of oxygen $(\mathrm{SpO} 2)$ (Table 9) indicates that there was a wide range in presentation figures with the results normally distributed, evidenced by the mean close to the median value. Through a clinical lens, many of the data values contained within the baseline observations are from the high end of RR and HR, this was expected and generally show that people were quite unwell when they presented. A mean RR of 26.7 respirations per minute indicates that dyspnoea is very real for these patients (as a normal RR is from 10-16 per minute) as they either maintained their work of breathing to relieve hypoxia, or compensated for the hypercarbia coexisting during the exacerbation. The HR was also elevated to a mean of 103 , this does however include the patients with tachyarrhythmia's like atrial fibrillation $(\mathrm{A} / \mathrm{F})$ as well as those with a tachycardia as from the exacerbation. Atrial fibrillation coexisting with COPD can increase the HR. The mean would have also been raised because one individual had a tachycardia of 160 beat per minute. Putting that aside, during an exacerbation of COPD the HR does increase as a result of work of breathing and a raised metabolic rate is driving all systems to compensating for the acute exacerbation. Saturation of oxygen is a notable point in this research. The mean SpO2 within the research of $93.2 \%$, would have been influenced by a few people being on oxygen at the time the recordings were taken. Putting this aside, it would be un-ethical to take people who need the oxygen for the dyspnoea off the oxygen supply. Achieving a $\mathrm{SpO} 2$ of $93 \%$ either on or off oxygen is sufficient to provide enough oxygen for demands, as this some of these patients are using a hypoxic drive for work of breathing and respiratory rate regulation, keeping them free from the damaging effects (like acidosis, organ and cellular dysfunction) of an elevated $\mathrm{pCO}_{2}$ level (hypercarbia) from over administration of supplemental oxygen. 


\section{Blood Gas Sampling}

Data within Table 10 showed the summary data related to $\mathrm{pH}$, partial pressure of carbon dioxide $\left(\mathrm{pCO}_{2}\right)$, partial pressure of oxygen $\left(\mathrm{pO}_{2}\right)$ and hydrogen bicarbonate ions $\left(\mathrm{HCO}_{3}\right)$ of the 76 presentations where ABG results were reported. The subgroup investigation of hypercarbia and non-hypercarbia the main focus of the research were presented in Table 15. Initial blood gas sampling was any arterial blood gas (ABG) test up to 5 hours after presentation. Analysis was problematic, a number of people did not have a blood gas during assessment and treatment. One could presume some of the people presenting didn't require an $\mathrm{ABG}$ due to having no history of hypercarbia or having improved sufficiently en-route to hospital, or a clinician may have relied on previous clinical records.

The mean $\mathrm{pH}$ for the group was 7.39 with a median of 7.41 , indicating that the majority of the presentations had a $\mathrm{pH}$ below that of a normal $\mathrm{pH}$, however slightly on the acidotic side of the normal limits. The mean $\mathrm{pCO}_{2}$ of $6.18 \mathrm{kpa}$ is elevated above normal limits, indicating that a number of the group had either acute or pre-existing hypercarbia within the period of observation. The bicarbonate $\left(\mathrm{HCO}_{3}\right)$ level again shows notable results, the mean of 26.8 is at the top end of normal, so despite having a mean raised $\mathrm{pCO}_{2}$ the bicarbonate is relatively normal. There may be some of this sample who are compensating and showing a raised bicarbonate, however this hasn't effected the mean $\mathrm{HCO}_{3}$.

Compensation was examined by looking at the ABGs with hypercarbia within the sample $(\mathrm{n}=76)$. Of the 30 presentations with hypercarbia, 15 (50\%) showed respiratory acidosis. However, a very notable result based on the $\mathrm{pH}$ levels was that $80.0 \%(\mathrm{n}=24)$ of those with hypercarbia were compensating for the hypercarbia, meaning that they had been in some form of exacerbation for more than 72 hours or had a chronic hypercarbia condition. As indicated in Chapter 2 we know this because it takes the kidneys this long to retain bicarbonate ions. A further $13.3 \%(n=4)$ had hypercarbia with no compensation, these are represented as the acute hypercarbia group and a further $6.7 \%(n=2)$ make up the last group which is patients that had both respiratory and metabolic causes co-existing exhibited by a low bicarbonate level. This is reflected in the $\mathrm{HCO}_{3}$ as lower than 21 , this would add to pull the mean $\mathrm{HCO}_{3}$ down. The parallel of having a metabolic and respiratory cause for acidosis within the COPD exacerbation has not been investigated during this study, because it was not within the purpose of the study. 
The mean oxygen level of $11.00 \mathrm{kpa}$ was not unexpected because we do know that people with COPD have an existing hypoxia. Some of the blood gases were recorded on oxygen so caution should be read into these results, the actual pO2 may well be lower than the recorded mean of $11.00 \mathrm{kpa}$.

The secondary blood gas reflects a secondary ABG taken greater than 5 hours or secondary to a primary gas were only taken on a small $(n=17)$ group. Blood gases are generally only taken if needed, as the ABGs are invasive and come with risks they are only warranted if clinical condition changes. The mean $\mathrm{pH}$ is 7.35 reflecting that the $\mathrm{pH}$ is severely affected now, even though the $\mathrm{pH}$ is on the lower end of normal the mean $\mathrm{pCO}_{2}$ has risen to 7.22 , this is pushing the $\mathrm{pH}$ down. This hypercarbia is compensated by the body reflected by the $\mathrm{HCO}_{3}$, rising in response to the elevated $\mathrm{pCO} 2$, the $\mathrm{HCO} 3$ is now 28.29 showing that the kidneys compensate for the respiratory acidosis by keeping more bicarbonate ions from excretion in the urine. When the sample is reduced to show hypercarbia $(n=12)$, again a similar percentage to that of initial ABG of $75 \%(n=9)$ show compensation within the sample and remainder $25 \%$ have no compensation on the second ABG. So once again compensation is occurring either as a long-term condition or because of an exacerbation that started more than 72 hours ago.

A testing of two subgroups within the study is listed as the hypercarbic group and nonhypercarbia group, and a further subgroup of presentations where the person had some presentations of both hypercarbia and non-hypercarbia presentations during the time period. The mixed presentation group (Table 14) had varied blood gas samples, in which the majority ( 3 out of 5) of them appear to sit either just under or just over the threshold for hypercarbia. This leaves the remaining two people who had presentations further away from the threshold level of $6.0 \mathrm{kpa}$ for $\mathrm{pCO}_{2}$. This may give insight into an unknown population with COPD that during times of exacerbation people can easily sit above or below the threshold for hypercarbia, the question is what makes them shift into another domain for hypercarbia? This again leads us to focus on appropriate treatment and preservation of the hypoxic drive during the exacerbation of COPD presentation. We could argue that these people should be always classed as hypercarbia group members, but I am inclined to keep them as a separate subgroup within hypercarbia and nonhypercarbia. 
Findings (Table 13) showed that more of the hypercarbia people re-presented more than once in the 3 -month time period, $28 \%$ of the people present twice compared to $17 \%$ of the non-hypercarbia people. To note a further 5 people presented twice and three times with mixed presentations, these could be hypercarbia admissions also if you combine them with the hypercarbia group. This adds to the re-presentation figures, $44 \%(n=23)$ of the hypercarbia group present more than one time over the 3 months. This is a reflection on the severity of the hypercarbia person during the winter months. Simple environmental triggers can and does make them represent for intervention.

The finding (Table 15$)$ that $31 \%(n=18)$ of the sample were in the hypercarbia group is clinically significant, when I started this research the target group of hypercarbia expected was around the $10 \%$. The group suffering from hypercarbia was infact mucgh bigger than I expected, meaning that as a clinician assessment and treatment Gender findings showed that females $(82 \%)$ were much more likely to be this group than males $(22 \%)$. This dominance is a change in the expected gender data, female value in the whole sample was only $62.0 \%$ (Table 4 ). The gender within the non-hypercarbia group had relatively even representation with the males making up $42.9 \%$ and females making up the other $57.1 \%$. It would appear then that being female and having the disease of COPD gives you a greater chance of having hypercarbia during an exacerbation.

Ethnicity demographics differ a little, with $16.7 \%$ Maori in the hypercarbia group compared to $11 \%$ of the Maori people within the study. Within European people $11.1 \%$ are in the hypercarbia group compared to $18 \%$ within the sample and the Pakeha numbers are relatively the same within the hypercarbia group. Age, within hypercarbia shows the mean age is two years older than the non-hypercarbia group. Exposure to smoking and industrial gases with the subgroups showed that with hypercarbia fewer people had exposure to smoking and industrial elements than the non-hypercarbia group.

The baseline observation comparison shows little changes to the sample groups, the RR change in the hypercarbia group is 1 breath per minute bigger than the other and the same can be said about the HR change with 1 beats per minute larger in the hypercarbia group (Table 16). One could conclude that there is no identifiable observation in trying to differentiate someone with hypercarbia on presenting baseline observations.

In determining the groups of hypercarbia and non-hypercarbia, it was noted that 12 out of 23 individuals with hypercarbia had a respiratory acidosis (52\%), indicating that many of 
this group presented with an acute exacerbation of COPD. The remaining individuals within the hypercarbia group (43\%) were compensating as a chronic condition within the community or had been in an exacerbation for more than 72 hours.

Diagnosis within the subgroup of hypercarbia and non-hypercarbia as shown in Table 17, show high percentages of emphysema (48\%) and asthma (26\%) which dominate the hypercarbia group, giving the understanding that $74.2 \%$ of the hypercarbia group with a diagnosis is made up of emphysema and asthma. CHF follows at $16.1 \%$ of the sample with hypercarbia. To comment on diagnosis and hypercarbia grouping, the greatest chance of having hypercarbia (respiratory failure) on admission is to have emphysema or asthma as a primary diagnosis with then a secondary diagnosis of CHF. All but one of the hypercarbic CHF individuals identified has links to either asthma or emphysema. The presentation of a patient with a dual diagnosis of these may "red flag" the possibility of becoming hypercarbic during an exacerbation of COPD.

\section{Lung Function}

Lung function testing by subgroups identified a significant lower value within the hypercarbia group. When the two groups are compared, the FEV 1 value increased by $60 \%$ from the hypercarbia group to non-hypercarbia group, showing that hypercarbia has a significantly lower $\mathrm{FEV}_{1}$ than the non-hypercarbia group (more than half), the ratio (percentage of FEV1 over FVC) percentage increases by $11 \%$ from the hypercarbia group to the non-hypercarbia group. This shows that lung function has a large part to play in the probability in having hypercarbia on an exacerbation of COPD. These are mean figures given, so I am not stating that anything below .55 L in FEV 1 and $39 \%$ in a ratio will have hypercarbia but the probability could exist. The direct relation of hypoventilation and ineffective gas exchange has a reflection in hypercarbia on presentation to the ED. In future residual volume should be collated as a variable to better understand the hypercarbia and non-hypercarbia grouping in relation to lung function testing, this is because the greater the residual volume, results in a lower alveolar exchange in gases. Clinician or nursing implications to receiving an exacerbation of COPD patient clearly shows that a documented history with previously tested lung function studies aids the treatment provider into knowing whether they could be subject to hypercarbia or not. Even if this presentation is a one off, is the patient could carry information about their lung function with them, would aid the provider. 


\section{NIV treatment}

Non Invasive Ventilation (NIV) use within hypercarbia was investigated, using the value of $\mathrm{pCO}_{2}$ in the initial blood gas. NIV was used $27.6 \%$ of the time in the instance of hypercarbia ( $\mathrm{n}=29$ ), data was not captured regarding how and why this was used and this would be too hard to investigate from a retrospective fashion. Irrespective of this it is appropriate for the patient given the clinical situation that existed. We can also look at NIV use within the acidosis, which is because of primary hypercarbia causing the acidosis. Findings show that NIV was used in $37.5 \%$ of the cases where acidosis exists. This is larger than the NIV use in hypercarbia, but the number $(n=16)$ was less in the $\mathrm{pH}$ acidosis situations, this was attributed to the compensation factor that goes with COPD and hypercarbia as a long-term or chronic condition. Of the 16 with acidosis the number of cases in hypercarbia is 29 , this represents as $55 \%$ of the cases of hypercarbia have respiratory acidoisis, and $45 \%$ compensate with the buffering systems to alleviate the blood from being so affected by acidosis. NIV use within the COPD exacerbation population appears to be when the exacerbation is so dramatic and the patient is acutely ill. This is one service the hospital can easily manage with other supportive therapy, to guide the patient back to wellness.

\section{Length of Stay}

The findings related to length of patient stay showed that $32.5 \%$ only stayed 1 day or up to 24 hours, either in hospital or within the ED. The interpretation of this is that even though the presentation was acute and life threatening the person's clinical situation improved quickly, probably with the use of medications and supportive therapy. Most patients' condition could be returned to normal or as normal as possible so that they can return home for rehabilitation with family or community support, which may also include the GP and community respiratory nurse specialist. It is my understanding that many patients with COPD have their own equipment to deal with the dyspnoea, and with the use of medications at home can continue their own rehabilitation. However, many people did require several days in hospital and a small percentage stayed over for 2 weeks $(n=6$, 5.4\%). Of these six, four were female, four were Pakeha and two were from European decent. Surprising there was no notable difference in the length of stay between those with hypercarbia and those in the non-hypercarbia group. However, those who did not have a blood gas taken stayed in hospital for a considerably shorter time indicating they were not so ill. 
To conclude this chapter, hypercarbia within the population capture could not be described, the potential for an exacerbation of COPD to be hypercarbia is very real for the clinician. Smoking related exposure over a period of years, and undiagnosed and managed COPD are the risk to the population with a burden to the health care system within New Zealand.

The next chapter will conclude the major findings, and present an overall summary for the research. 


\section{Chapter 7- Conclusion}

The aim of this research was to describe who presents with an exacerbation of COPD to the Tauranga Emergency Department and to establish whether there was a subgroup who presented with hypercarbia?

The sample population of 114 was made up of 71 individuals. Although no definable subgroup of people with hypercarbia were found within the study, the research did find that of those who had a blood gas within the ED, $31 \%$ of the group ( $n=58$ ) made up the hypercarbia group. This hypercarbia group combined with those who had dual presentations (hypercarbia and non-hypercarbia) made up $40 \%$ of the individuals with a blood gas during their presentation, of which $50 \%$ of the people presented more than once in the 3-month period. Defining whom this group is, female gender makes up the majority of the hypercarbia group of $81.8 \%$ and Maori made up more of the hypercarbia subgroup (16.7\%) than the non-hypercarbia subgroup (8.6\%). Clinical values including mean age, heart rate and respiratory rate were slightly higher than the non-hypercarbia within the subgroup. Previous diagnosis showed no major difference between the subgroups, with emphysema being the commonest diagnosis in both subgroups. The direct lung volume reduction in forced expiration volume in one second (FEV 1 ) had a large gap within the subgroups, the difference between the two groups is, in hypercarbia the $\mathrm{FEV}_{1}$ is half the volume of $\mathrm{FEV}_{1}$ than the non-hypercarbia subgroup. Actual alveolar hypoventilation has a direct relationship to hypercarbia.

The subgroup of hypercarbia is across all ethnic groups and all ages, irrelevant if they have a smoking history or not. The group is larger than one would assume. The implications to the practitioner within the emergency department is that, the risks of being hypercarbic are now obvious with the $26 \%$ of all the COPD exacerbations ( $n=114)$ have some degree of hypercarbia either as a direct or indirect relation to respiratory function and disease and/or the exacerbation that they are experiencing. To monitor and observe for signs of hypercarbia is the main clinical change indicator warranted for the practitioner, although changes are minimal.

Community maintenance of the COPD population needs to be established, the benefit of this is to reduce the demand on the hospital multiple presentations, improve the health of the COPD individual within the community and provide accurate diagnosis and treatment 
for the individual. It has been shown that many of these individuals are metabolically compensating by the time they enter the hospital system, the question still remains, do they have chronic hypercarbia or have they been in a period of exacerbation for a number of days within the community? Only community management and observation will answer that question, and by providing support and intervention earlier, the exacerbation can be minimised.

Guidelines from the United Kingdom and America show that transport times of greater than 15 minutes gives an increased chance to hypercarbia with an exacerbation of COPD, reflective treatment should managed the COPD exacerbation and monitor for signs of hypercarbia and the accurate oxygen saturation percentage aimed at should be $93 \%$, as this indicates a normal level for oxygenation and protects the hypoxic drive for these patients needed for maintenance of the work of breathing. Many of the districts of Tauranga are more than the 15 minutes time travel as expressed by guidelines and Ting (2004). Of the people noted from the research with a combined presentation inclusion (hypercarbia and non-hypercarbia), they seem to fluctuate between the high end of normal for $\mathrm{pCO}_{2}$ and low end of hypercarbia $\left(\mathrm{pCO}_{2} \geq 6 \mathrm{kpa}\right)$

In the future potential discussion could occur with the Emergency Department (ED) physicians in conjunction with medical physicians, nurse consultants/practitioners and ambulance managers locally to the Tauranga hospital campus need to create a steering committee about exacerbation of COPD. Meetings about future approach of these subgroup people, plan and implement changes and treatment guidelines associated with distance transport to the hospital, within clinical alignment with the US and United Kingdom treatment guidelines that are easily accessible to the group steering committee.

\section{Exacerbation of Chronic Obstructive Pulmonary Disease (COPD)}

A peak presentation time for the exacerbation of COPD was between $10 \mathrm{am}$ to $8 \mathrm{pm}(75 \%$ of the cases). Total sample mean age is 71.1 years and the hypercarbia group the mean age is 75.3 years, showing that the increasing age has an increased risk for hypercarbia. The potential for a person with an exacerbation of COPD to show signs of hypercarbia are related to primary diagnosis coupled with a poor lung function, in particular a FEV 1 of below 0.6 litres in one second. Most of the people with hypercarbia within the sample, $80 \%$ of them were compensating to some degree gives and indication that the exacerbation started days before the arrival to the ED. This presents as a huge 
community need, the COPD population needs management within their community to provide earlier care into their exacerbation. The majority of the patients with an exacerbation have a non-focal chest infection as a trigger, this can be managed by a doctor or nurse within the patients home with steroids and intravenous antibiotics with inhaled bronchodilators.

The research highlights the well known effects of smoking. While public awareness is creating a downturn in the number of people smoking within our communities, many people still choose to smoke in their earlier years creating damage to the lung structures over years of exposure. The comparison of industrial exposure and smoking exposure shows that a greater number have a mixed exposure than industrial exposure only, giving some light into the cause of their COPD. The smoking arena is about to get more of the spotlight as many more of these people exposed to smoking are diagnosed with midlife asthma leading into a COPD diagnosis.

Accurate diagnosis is the beneficial advantage to the practitioner, as seen in the table of discharges from public hospitals (Appendix 1), of the admissions 47.20\% are listed as admitted as other COPD admission, whether this is because of administration negligence or an actual diagnosis problem, it is not known. This lack of diagnosis needs investigating either from a community and hospital initiative. With an accurate diagnosis can come a management plan to improve quality of life for a person.

Care delivery and assessment within any situation needs to be carefully thought out and planned, this real risk for complications in treatment is problematic in the exacerbation of COPD. Adherence to guidelines either local or many of those around the world can avert potential problems in treating this group of people. The unknown future for the COPD person is the fear, and in the future more of this population presenting to the many doors of the health system.

To conclude, this research has been hugely rewarding to me personally and now the journey is over, emotion takes over as I can't believe it's over, I remember hearing at the start of this journey trust the process and set yourself to achieve by organisation and perseverance, this is pertinent information that needs to be adhered to. Enjoy the descriptive research on hypercarbia in exacerbation of COPD knowledge, good luck to other researchers who take on a similar journey and may they also add to the body of knowledge which is continually snow balling. 


\section{Chapter 8- Appendix Appendix One}

Discharges from publicly funded hospitals - chapters, subgroups and individual 3 digit ICD-10 codes by sex Total numbers, mean stay for inpatients, day cases, total population, 2001/2002

\begin{tabular}{|c|c|c|c|c|c|}
\hline & Mean stay & Total & Daycases & \multicolumn{2}{|c|}{ Population of COPD } \\
\hline \multicolumn{6}{|l|}{ J20 Acute bronchitis } \\
\hline Total: & 3.1 & 595 & 111 & 595 & $3.10 \%$ \\
\hline Male: & 3.2 & 242 & 53 & & \\
\hline Female: & 3.1 & 353 & 58 & & \\
\hline \multicolumn{6}{|c|}{ J40 Bronchitis, not specified as acute or chronic } \\
\hline Total: & 4.4 & 588 & 135 & 588 & $3.50 \%$ \\
\hline Male: & 5.2 & 241 & 66 & & \\
\hline Female: & 3.9 & 347 & 69 & & \\
\hline \multicolumn{6}{|c|}{ J41 Simple and mucopurulent chronic bronchitis } \\
\hline Total: & 5.5 & 6 & 4 & 6 & $0.03 \%$ \\
\hline Male: & 0.0 & 2 & 2 & & \\
\hline Female: & 5.5 & 4 & 2 & & \\
\hline \multicolumn{6}{|c|}{ J42 Unspecified chronic bronchitis } \\
\hline Total: & 3.2 & 37 & 24 & 37 & $0.20 \%$ \\
\hline Male: & 3.4 & 16 & 9 & & \\
\hline Female: & 2.8 & 21 & 15 & & \\
\hline \multicolumn{6}{|l|}{ J43 Emphysema } \\
\hline Total: & 23.3 & 135 & 18 & 135 & $0.70 \%$ \\
\hline Male: & 22.4 & 77 & 8 & & \\
\hline Female: & 24.7 & 58 & 10 & & \\
\hline \multicolumn{6}{|c|}{ J44 Other chronic obstructive pulmonary disease } \\
\hline Total: & 10.1 & 9111 & 469 & 9111 & $47.20 \%$ \\
\hline Male: & 9.9 & 4759 & 282 & & \\
\hline Female: & 10.4 & 4352 & 187 & & \\
\hline \multicolumn{6}{|l|}{ J45 Asthma } \\
\hline Total: & 3.6 & 7414 & 1954 & 7414 & $38.40 \%$ \\
\hline Male: & 2.0 & 3380 & 954 & & \\
\hline Female: & 5.0 & 4034 & 1000 & & \\
\hline \multicolumn{6}{|l|}{ J46 Status asthmaticus } \\
\hline Total: & 3.0 & 571 & 72 & 571 & $3 \%$ \\
\hline Male: & 2.5 & 235 & 39 & & \\
\hline Female: & 3.4 & 336 & 33 & & \\
\hline \multicolumn{6}{|l|}{ J47 Bronchiectasis } \\
\hline Total: & 7.0 & 843 & 119 & 843 & $4.40 \%$ \\
\hline Male: & 6.8 & 318 & 43 & & \\
\hline Female: & 7.0 & 525 & 76 & & \\
\hline \multicolumn{6}{|l|}{ Q334 Congenital bronchiectasis } \\
\hline Total: & 4.0 & 3 & 0 & 3 & $0.02 \%$ \\
\hline Male: & 1.0 & 2 & 0 & & \\
\hline Female: & 10.0 & 1 & 0 & & \\
\hline \multicolumn{2}{|l|}{ Sum of COPD admissions } & & & 19303 & $100.00 \%$ \\
\hline \multicolumn{2}{|l|}{ Source MOH New Zealand } & & Sent by email on $18 / 11 / 2005$ & & \\
\hline \multicolumn{6}{|l|}{ Ian Galley } \\
\hline \multicolumn{6}{|l|}{ Information Analyst } \\
\hline Business Intelligence & & & & & \\
\hline
\end{tabular}




\section{Appendix Two}

Exert from: www.moh.co.nz.

Retrieved 1/12/2005

CODE OF CONDUCT FOR NURSES AND MIDWIVES

\section{Principle Three}

The nurse or midwife respects the rights of patients/clients.

\section{Criteria}

The nurse or midwife:

3.1 acknowledges and allows for the individuality of people;

3.2 provides information to enable the patient/client to exercise informed choice and consent to the delivery of professional nursing or midwifery care;

3.3 respects any privileged access, conferred by professional status, to patients'clients' information and their possessions, residences and workplaces;

3.4 safeguards confidentiality and privacy of information obtained within the professional relationship;

3.5 helps patients/clients understand their rights and acknowledge their responsibilities related to the delivery of professional nursing or within the midwifery partnership;

3.6 is aware of and guided by codes of rights and responsibilities for patients/clients and healthcare providers in area of practice;

3.7 practises in a manner which is culturally safe;

3.8 practises within the principles of the Treaty of Waitangi - protection, partnership, participation. 
Appendix Three 
Appendix Four 


\section{Appendix Five}

\section{MAORI CULTURAL SAFETY}

\section{POLICY}

It is Bay of Plenty District Health Board's policy that patients/clients who identify as Maori have their health and disability needs met in a manner that respects and acknowledges their individual values and beliefs. The Bay of Plenty District Health Board recognises and has a commitment to the Treaty of Waitangi and Crown principles of partnership, participation, equity and protection.

\section{PURPOSE}

- To assist staff in understanding the meaning of the Treaty of Waitangi and its significance in relation to Maori Health.

- To develop policies and services consistent with the Treaty of Waitangi principles.

- To provide health services that are culturally appropriate and delivered in a culturally safe manner.

- To improve and advance Maori Health status, and to achieve Maori Health gain in a way that is consistent with national priorities and Maori aspirations (refer 'He Korowai Oranga - The Maori Health Strategy’, Ministry of Health, 2002)

\section{DEFINITIONS}

\begin{tabular}{|l|l|}
\hline Cultural Safety & $\begin{array}{l}\text { Freedom from preventable harm to an individual's cultural } \\
\text { identity, values and beliefs }\end{array}$ \\
\hline
\end{tabular}

\section{EXCLUSIONS}

\section{STANDARDS TO BE MET}

\section{Partnership}

1. The Bay of Plenty District Health Board will acknowledge and provide support for the vision and objectives of the Board to meet their obligations as a Crown agent to iwi and Maori communities.

2. The Bay of Plenty District Health Board will establish and build meaningful relationships with Tangata Whenua, Maori Communities, Iwi Authorities, Iwi and Maori Health Providers and others through its Memorandum of Understanding with the Bay of Plenty Maori Health Runanga.

\section{Participation}

1. The Bay of Plenty District Health Board will ensure Maori participation in decisionmaking and consultation in planning and prioritisation at all levels of the Board. 
2. The organisation's provider operations will ensure the participation of Mai i Nga Kuri a Wharei ki Tihirau, Pacific Health, Maori Health Services in all strategic planning, analysis, service development and monitoring.

3. Services and teams will establish and resource initiatives to build Maori capacity throughout and within Bay of Plenty District Health Board.

4. The organisation will develop and implement policies and protocols that support and facilitate Maori Health development and, where appropriate, have separate Maori policies relevant to the advancement of Maori Health.

\section{Protection}

1. All Bay of Plenty District Health Board services and staff will be responsive to the cultural needs and preferences of Maori patients/clients. The appropriate kawa and/or tikanga surrounding specific practices will be acknowledged, preserved, promoted and safe-guarded as outlined in protocols related to this policy

2. Appropriate support services will be available to both Maori patients/clients and their whanau and Maori staff.

3. The organisation will provide ongoing education and training programmes for all employees (including contractors) on the Treaty of Waitangi and Cultural Safety, and recognise these as core competencies.

4. The organisation will support and promote Maori workforce development by incorporating into its human resource planning, programmes, policies and protocols a strategy that enables recruitment, retention and progression of Maori within the staffing matrix.

5. Maori intellectual, cultural and spiritual property rights will be protected and not used without consent.

6. The Bay of Plenty District Health Board will be guided by the Runanga on significant events, hui, ceremonies or other of significance to iwi, as to how representatives of the Board/organisation will participate.

\section{Equity}

1. All Bay of Plenty District Health Board strategic, annual and service plans must explicitly provide ways and means by which Maori health gain objectives will be achieved.

2. The organisation will establish and implement an evaluation and monitoring process that audits organisational compliance and responsiveness to Maori Health gain. 
3. The organisation will establish mechanisms of obtaining feedback from iwi and Maori communities to measure and improve service delivery.

4. The Bay of Plenty District Health Board is committed to purchasing 'By Maori for Maori' services within the terms of its purchasing prioritisation criteria.

5. The Bay of Plenty District Health Board will actively work to develop improved access and choice of services for Maori through Maori provider development and capability.

6. From the implementation of this policy, all contracts negotiated or re-negotiated for healthcare provision must include Bay of Plenty District Health Board's statement of its position on the Treaty of Waitangi and Maori Health and require the provider to specify how it intends to contribute to 'Maori Health Gain'. 
Appendix Six 
Appendix Seven

Data Collection Tool- Pre Test Research Thesis-COPD

\begin{tabular}{|c|c|c|c|c|}
\hline Research Number & & & & \\
\hline Gender: & Male & Female & Ethnicity: & Age: \\
\hline Presentation: & Date & Time & & \\
\hline $\begin{array}{l}\text { Presentation } \\
\text { source: }\end{array}$ & Self & Ambulance & & \\
\hline History: & Smoking years: & $\begin{array}{l}\text { Many packs/ } \\
\text { week: }\end{array}$ & $\begin{array}{l}\text { Initial } \\
\text { Ambulance } \\
\text { SaO2: }\end{array}$ & $\begin{array}{l}\text { Industrial } \\
\text { exposure? }\end{array}$ \\
\hline Observations & $\begin{array}{l}\text { Respiratory } \\
\text { rate: }\end{array}$ & Heart Rate: & & \\
\hline Time & & & & \\
\hline $\mathrm{PH}$ & & & & \\
\hline PCO2 & & & & \\
\hline PO2 & & & & \\
\hline$\underline{\mathrm{HCO} 3}$ & & & & \\
\hline $\begin{array}{l}\text { Oxygen/ } \\
\text { Treatment }\end{array}$ & & & & \\
\hline $\begin{array}{l}\text { Previous } \\
\text { diagnosis: }\end{array}$ & Asthma & Emphysema & Bronchitis & Bronchiectasis \\
\hline & $\mathrm{CHF}$ & TB & Pnuemonia & other \\
\hline 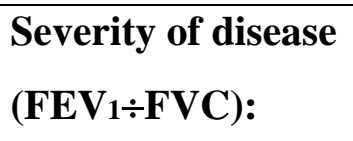 & FeV1 & $\underline{\text { FVC }}$ & $\underline{\text { Ratio }}$ & \\
\hline $\begin{array}{l}\text { NIV use during } \\
\text { presentation: }\end{array}$ & Yes & No & Length of use? & \\
\hline Admission & $\begin{array}{l}\text { Length of } \\
\text { admission: }\end{array}$ & $\begin{array}{l}\text { Previous last } \\
\text { admission: }\end{array}$ & & \\
\hline
\end{tabular}




\section{Appendix Eight}

Worldwide Smoking Prevalence

\begin{tabular}{|c|c|c|c|}
\hline $\begin{array}{l}\text { The Tota } \\
\text { percenta }\end{array}$ & Prevale & of Sm & \\
\hline & 1994-1998 & 1999-2001 & 2002-2005 \\
\hline & $\%$ & $\%$ & $\%$ \\
\hline UK & 28.0 & 27.0 & 25.0 \\
\hline France & 28.0 & 27.0 & 25.4 \\
\hline Austria & 23.9 & 29.0 & 47.0 \\
\hline Germany & 36.7 & 34.8 & 33.9 \\
\hline New Zealand & 27.0 & 25.5 & 24.4 \\
\hline Spain & 33.2 & 31.7 & 28.1 \\
\hline
\end{tabular}

Source World Health Organisation (WHO, http://data.euro.who.int/tobacco/) \& Ministry of Health (MOH), retrieved $12^{\text {th }}$ December 2005. 


\section{References}

Baram., D., Degene., A., Amin., M., Bilfinger., T., \& Smaldone., G. (1994). A case of hypercapnic respiratory failure. Chest, 126, 1994-1999.

Booker, R. (2003). Chronic obstructive pulmonary disease- a primary care problem. Primary Health Care, 13(2), 27-31.

Booker, R. (2003). Testing for reversibility in patients with obstructive airways disease. Nursing Times Net, 99(33), 1-5.

Booker, R. (2004). Chronic obstructive pulmonary disease: Importance of diagnosis. British Medical Journal of Nursing, 13(14), 871-875.

Booker, R. (2005). Chronic obstructive pulmonary disease and the nice guideline. Nursing Standard, 19(22), 43-52, 54.

Bristish Thoracic Society Standards of Care Committee. (2002). Non-invasive ventilation in acute respiratory failure. Thorax, 57, 192-211.

Burns, N., \& Grove., S. K. (1997). The nursing research- conduct, critique and utilization (3rd ed.). Philadelphia: W.B. Saunders Company.

Cherniack, N. S. (2004). Oxygen sensing: Applications in humans. Journal of Applied Physiology, 96, 352-358.

Chien, J. W., Ciufo., R., Novak., R., Skowronski., M., Nelson., J., Coreno., A., et al. (2000). Uncontrolled oxygen administration and respiratory failure in acute asthma. Chest, Mar, 117, 728 - 733.

Chu, C. M., Chan., V. L., Lin., A. W., Wong., I. W., Leung., W. S., \& Lai., C. K. (2004). Readmission rates and life threatening events in COPD survivors treated with noninvasive ventilation for acute hypercapnic respiratory failure. Thorax, 59(12), 1020-1025.

Cydulka, R. K., Rowe, B. H., Clark, S., Emerman, C. L. \& Camargo, C. A. (2003). Emergency department management of acute exacerbations of COPD in the elderly. The Multicentre Airway Research Collaboration. Journal of American Geriatrics Society, 51, 908-916.

Haidl, P., Clement, C., Wiece, C., Dellweg, D., \& Kohler, D. (2004). Long-term oxygen therapy stops the natural decline of endurance in COPD patients with reversable hypercarbia. Respiration; International Review of Thoracic Diseases, 71(4), 342-347.

Idris, A. H., Wenzel, V., Becker, L. B., Banner, M. J., \& Orban, D. J. (1995). Does hypoxia or hypercarbia independently affect resuscitation from cardiac arrest? Chest, 108(2), 552-558.

Keenan, S. P., Sinuff, T., Cook, D. J., \& Hill, N. S. (2003). Which pt's with acute exacerbation of COPD benefit from non-invasive positive-pressure ventilation? American College of Physicians, 138(11), 861-871. 
Knapp, T. R. (1998). Quantitative nursing research. California, United States of America: Sage Publications INC.

LoBiondo-Wood, G., \& Haber, J. (1998). Nursing research-methods, critical appraisal and utilization (4th ed.). St Louis, Missouri: Mosby.

MacGeorge, J. M., \& Nelson, K. M. (2002). The experience of the nurse at triage influences the timing of CPAP intervention. Accident \& Emergency Nursing, 11, 234238.

Markou, N. K., Myrianthefs, P. M., \& Baltopoulos, G. J. (2004). Respiratory failure-an overview (Vol. 27): Lippincott Willims \& Wilkins, Inc.

McCrory, D. C., Brown, C., Gelfand, S. E., \& Bach, P. B. (2001). Management of acute excerbations of COPD. Chest, 119, 1190-1209.

Ministry of Health New Zealand. (2003).a) A portrait of health: Key results of the 2002/03 NZ health survey. Retrieved 18th September, 2004, from http://www.moh.govt.nz/moh.nsf/f872666357c511eb4c25666d000c8888/6ccad0de984cd be6cc256df0001637eb?OpenDocument

Ministry of Health New Zealand. (2003).b) Implementing the New Zealand Health Strategy 2003. Retrieved 12th November, 2005, from http://www.moh.govt.nz/moh.nsf/f872666357c511eb4c25666d000c8888/a620173a2b7f1 79 ecc256df700794563

Ministry of Health New Zealand. (2005). Tobacco facts 2005. Retrieved 12th November, 2005 , from http://www.moh.govt.nz/moh.nsf/0/8BDA21625203A2DDCC25708B00783A1F/\$File/to baccofacts2005.doc.

Ministry of Health New Zealand. (2001). Total population 2001. Retrieved 12th November, 2005, from http://www.moh.govt.nz/moh.nsf/0/2d5ad5b7b3c7817bcc256ee30079d11e?OpenDocume $\underline{\mathrm{nt}}$

Murphy, R., Mackway-Jones, K., Sammy, I., Driscoll, P., Gray, A., O'Driscoll, P., et al. (2001) a). Emergency oxygen therapy for the breathless patient. Guidelines prepared by North West oxygen group. Emergency Medical Journal, 18, 421-423.

Murphy, R., O'Driscoll., P., \& O'Driscoll., R. (2001) b). Emergency oxygen therapy for the COPD pt. Emergency Medicine, 18, 333-339.

Nursing Council of New Zealand. (2005). Code of conduct for nurses. Retrieved 20th October, 2005

O'Donnell, D. E., D'Arsigny, C., Fitzpatrick, M., \& Webb, K. A. (2002). Exercise hypercarbia in advanced chronic obstructive pulmonary disease. American Journal of Respiratory Care Medicine., 166, 663-668.

Palm, K. H., \& Decker, W. W. (2003). Acute exacerbations of COPD. Emergency Medicine Clinics of North America, 21(2), 331-352. 
Paus-Jenssen, E. S., Reid, J. K., Cockcroft, D. W., Laframboise, K. L., \& Ward, H. A. (2004). The use of non-invasive ventilation in acute respiratory failure at a tertiary care centre. Chest, 126, 165 - 172.

Plant, P. K., Owen, J. L., \& Elliott, M. W. (2000). Early use of non-invasive ventilation for acute exacerbations of chronic obstructive pulmonary disease on general respiratory wards: A multicentre randomised controlled trial. Lancet, 355(9219), 1931-1935.

Polit, D. F., \& Beck, C. T. (2004). Nursing research; principles and methods. 7th edition.

Porth, C. M. (1994). Pathophysiology, concepts of altered health states (4th ed.). Philadelphia: J.B.Lippincott Company.

Robinson, T. D., Freiberg, D. B., Regnis, J. A., \& Young, I. H. (2000). The role of hypoventilation and ventilation-perfusion redistribution in oxygen-induced hypercarbia during acute exacerbations of chronic obstructive pulmonary disease. American Journal of Respiratory Care Medicine., 161, 1524-1529.

Rubin, E. 1., \& Farber, J. L. (1994). Pathology (2nd ed.). Philadelphia: Lippincott Company.

Rudolf, M., Banks, R. A., \& Semple, S. J. G. (1977). Hypercarbia during oxygen therapy in acute exacerbations of chronic respiratory failure. Lancet, 2, 483-486.

Snow, V., Lascher, S., \& Mottur-Pilson, C. (2001). The evidence base for management of acute exacerbations of COPD: Clinical practice guideline, part 1. Chest, 119, 1185 1189.

Squadrone, E., Frigeriio, P., Fogliati, C., Gregoretti, C., Conti, G., Antonelli, M., et al. (2004). Non-invasive vs ventilation in COPD patients with severe acute respiratory failure require ventilatory assistance. Intensive Care Medicine, 30, 1303-1310.

Teasdale, G., \& Jennet, B. (1974). Assessment of coma and impaired consciousness: A practical scale. Lancet, 2, 81-84.

The Thoracic Society of Australia and New Zealand \& the Australian Lung Foundation. (2002). Chronic obstructive pulmonary disease, Australian and New Zealand management guidelines and the COPD handbook. Retrieved 17th November, 2005, from http://asthmanzconz.axiion.com/images/page-content/File/PDFfiles/COPDHandbook.pdf.

Ting, J. (2004). Hypercarbia and oxygen therapy in older asthmatic patients. European Journal of Emergency Medicine: Official Journal of the European Society for Emergency Medicine., 11(6), 355-357.

Tintinalli, J. E., Kelen, G. D., \& Stapczynski, J. S. (Eds.). (2000). Emergency medicine; a comprehensive study guide (5th ed.). New York: McGraw-Hill companies, Inc.

Tuggey, J.M., Plant, P.K., Elliott, M.W. (2003). Domiciliary non-invasive ventilation for recurrent acidotic exacerbations of COPD: an economic analysis. Thorax, 58 (10), 86771. 
Turnwald, A. B. (2004). Academic and reflective paper accompanied by a portfolio of research. Unpublished. (p. 1-20): Victoria University, Wellington, New Zealand.

West, J. B. (2003). Pulmonary pathophysiology - the essentials (6th ed.). Maryland, America: Lippincott Williams \& Wilkins.

World Health Organisation. (2005). Tabacco control database. Retrieved 12th November, 2005, from http://data.euro.who.int/tobacco/. 


\section{Bibliography}

Petty, T. L. (2004). How (why) does oxygen work in advanced COPD?

Plant, P. K., Owen, J. L., \& Elliot, M. W. (2001). Non-invasive ventilation in acute exacerbations of chronic obstructive pulmonary disease: Long term survival and predictors of in-hospital outcome. Thorax, 56, 708-712.

Plant, P. K., Owen, J. L., \& Elliot, M. W. (2000). One year period prevalence study of respiratory acidosis in acute exacerbations of COPD: Implications for the provision of non-invasive ventilation and oxygen administration. Thorax, 55, 550-554. 
